Geophysical, Geochemical, and Mineralogical Data from the Pebble Cu-Au-Mo Porphyry Deposit Area, Southwest Alaska: Contributions to Assessment Techniques for Concealed Mineral Resources

Data Series 608 
Cover photo: Aerial view from helicopter above Koktuli Mountain looking northwest over the Pebble deposit in September 2009. Photograph by Robert G. Eppinger. 


\section{Geophysical, Geochemical, and Mineralogical Data from the Pebble Cu-Au-Mo Porphyry Deposit Area, Southwest Alaska: Contributions to Assessment Techniques for Concealed Mineral Resources}

By E.D. Anderson, S.M. Smith, S.A. Giles, Matthew Granitto, R.G. Eppinger, P.A. Bedrosian, A.K. Shah, K.D. Kelley, D.L. Fey, B.J. Minsley, and P.J. Brown

Data Series 608 


\section{U.S. Department of the Interior \\ KEN SALAZAR, Secretary}

\section{U.S. Geological Survey Marcia K. McNutt, Director}

\section{U.S. Geological Survey, Reston, Virginia: 2011}

For more information on the USGS - the Federal source for science about the Earth, its natural and living resources, natural hazards, and the environment, visit http://www.usgs.gov or call 1-888-ASK-USGS.

For an overview of USGS information products, including maps, imagery, and publications, visit http://www.usgs.gov/pubprod

To order this and other USGS information products, visit http://store.usgs.gov

Any use of trade, product, or firm names is for descriptive purposes only and does not imply endorsement by the U.S. Government.

Although this report is in the public domain, permission must be secured from the individual copyright owners to reproduce any copyrighted materials contained within this report.

This database has been approved for release and publication by the Director of the USGS. Although this database has been subjected to rigorous review and is substantially complete, the USGS reserves the right to revise the data pursuant to further analysis and review. Furthermore, it is released on condition that neither the USGS nor the United States Government may be held liable for any damages resulting from its authorized or unauthorized use.

Suggested citation:

Anderson, E.D., Smith, S.M., Giles, S.A., Granitto, Matthew, Eppinger, R.G., Bedrosian, P.A., Shah, A.K., Kelley, K.D., Fey, D.L., Minsley, B.J., and Brown, P.J., 2011, Geophysical, geochemical, and mineralogical data from the Pebble Cu-Au-Mo porphyry deposit area, southwest Alaska: Contributions to assessment techniques for concealed mineral resources: U.S. Geological Survey Data Series 608, 46 p. 


\section{Contents}

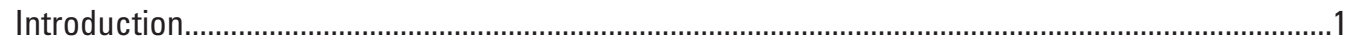

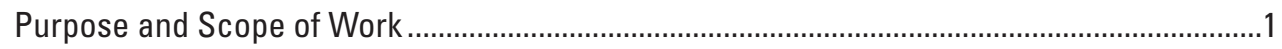

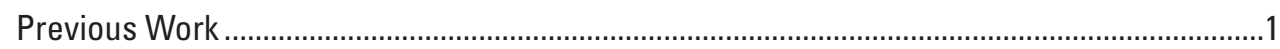

Alaska Radiometric Age Database ............................................................................



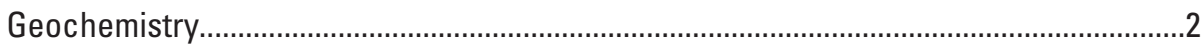



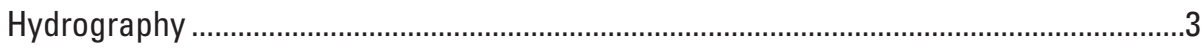

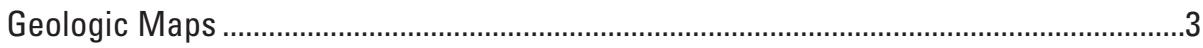



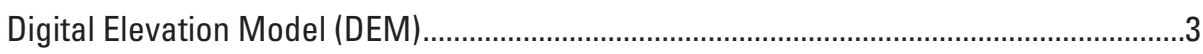

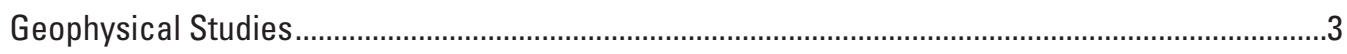

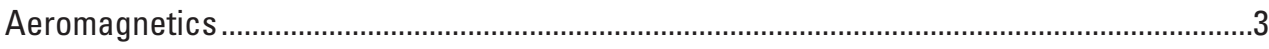

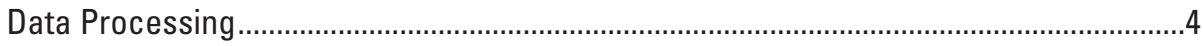

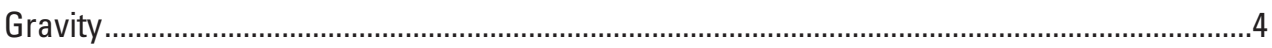



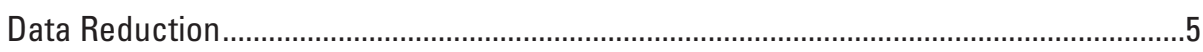

Measured gravity ...............................................................................................

Mean sea level and ellipsoid elevations....................................................................

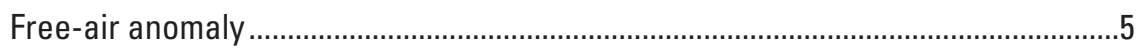



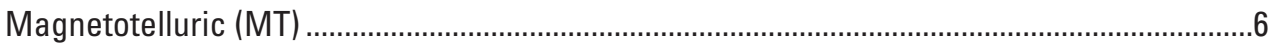

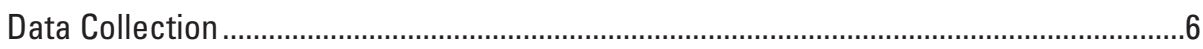

Data Processing......................................................................................................



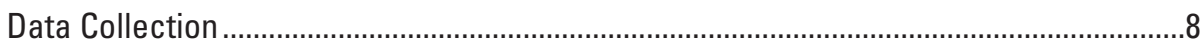

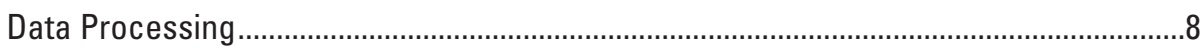

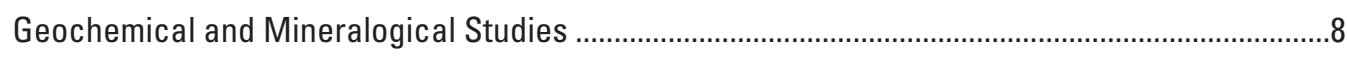

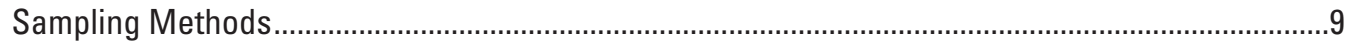

Water

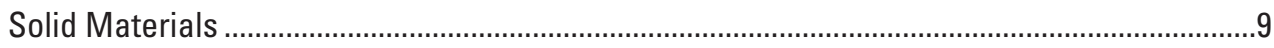



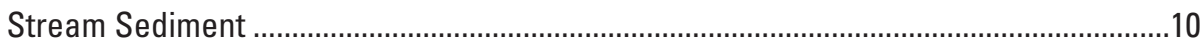

Pond Sediment ……........................................................................................................

Pond-sediment Core .......................................................................................................





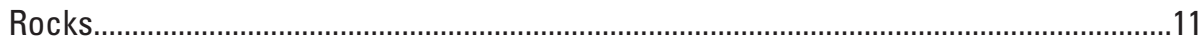



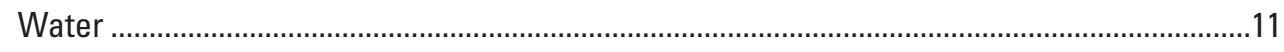










Soil Gas Hydrocarbons (SGH) ..............................................................................12

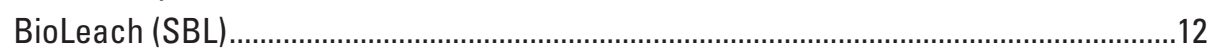

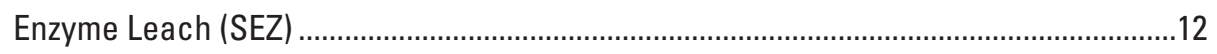

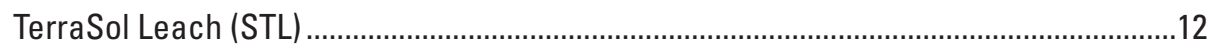

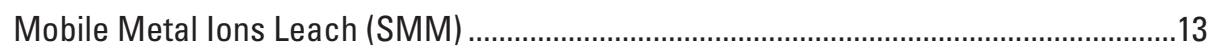

Cold Hydroxylamine Hydrochloride Leach (SCH) .......................................................13



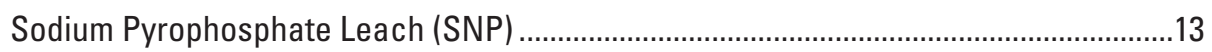

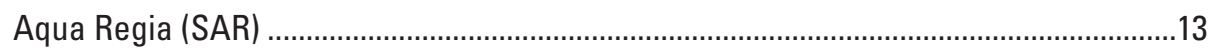

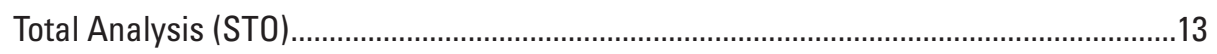

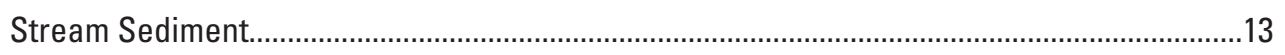

Pond Surface and Core Sediment Analyses ......................................................................14

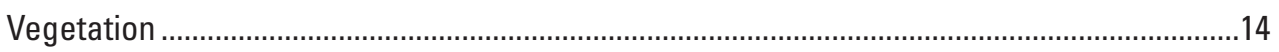

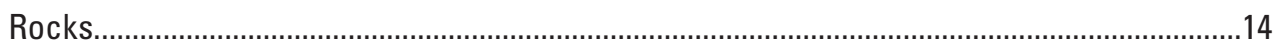



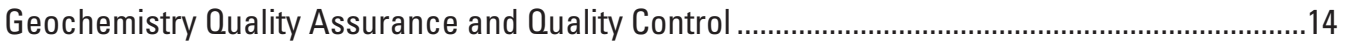

Sources of Geochemical Variation and Methods for Assuring Data Quality ..........................14

Quality Assurance/Quality Control Methods........................................................................15

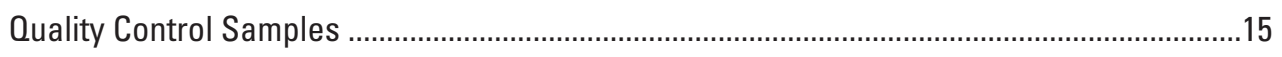

Evaluation of Data Sets by Analytical Laboratory and Year .................................................16

USGS De-lonized Water Leach of 2007 Soils ..............................................................16

Activation Laboratories, Ltd., Soil Gas Hydrocarbons of 2007 Soils ...............................16

Activation Laboratories, Ltd., Bioleach of 2007 Soils.....................................................17

Skyline Assayers and Laboratories Enzyme Leach of 2007 Soils ...................................17

Skyline Assayers and Laboratories Enzyme Leach of 2008 Soils ....................................18

Skyline Assayers and Laboratories Enzyme Leach of 2009 Soils ....................................18

Skyline Assayers and Laboratories TerraSol Leach of 2007 Soils...................................19

Skyline Assayers and Laboratories TerraSol Leach of 2008 Soils..................................19

Skyline Assayers and Laboratories TerraSol Leach of 2009 Soils...................................20

SGS Mineral Services Metal Mobile Ion Leach of 2007 Soils .........................................20

ALS Minerals Cold Hydroxylamine Hydrochloride Leach of 2007 Soils............................21

ALS Minerals Cold Hydroxylamine Hydrochloride Leach of 2008 Soils...........................21

ALS Minerals Cold Hydroxylamine Hydrochloride Leach of 2009 Soils...........................22

ALS Minerals Ionic Leach of 2007 and 2008 Soils ......................................................22

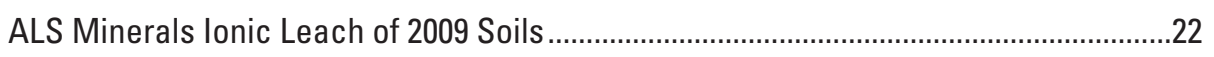

ALS Minerals Sodium Pyrophosphate Leach of 2007 Soils ..........................................23

Acme Analytical Laboratories, Ltd., Aqua Regia Leach of 2007 Soils............................23

Acme Analytical Laboratories, Ltd., Aqua Regia Leach of 2008 and 2009 Soils..............24

SGS Minerals Services (USGS Contract) ICPAES-MS42 Total Analysis

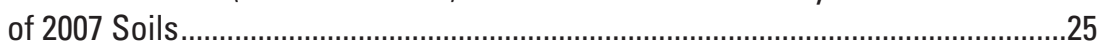

SGS Minerals Services (USGS Contract) ICPAES-MS42 Total Analysis of 2008 Soils, Sediments, and Pond-Sediment Cores.

SGS Minerals Services (USGS Contract) ICPAES-MS42 Total Analysis of 2009 Soils, Sediments, Pond-Sediment Cores, and Rocks 
SGS Minerals Services (USGS Contract) ICPAES-MS55 Total Analysis of 2007 Soils

SGS Minerals Services (USGS Contract) ICPAES-MS55 Total Analysis of 2008 Soils, Sediments, and Pond-Sediment Cores

SGS Minerals Services (USGS Contract) ICPAES-MS55 Total Analysis of 2009 Soils, Sediments, Pond-Sediment Cores, and Rocks

SGS Minerals Services (USGS Contract) Analysis of Various Single Elements in 2007 Soils

SGS Minerals Services (USGS Contract) Analysis of Various Single

Elements in 2008 Soils, Sediments, and Pond-Sediment Cores ...........................29

SGS Minerals Services (USGS Contract) Analysis of Various Single

Elements in 2009 Soils, Sediments, Pond-Sediment Cores, and Rocks ..............29

Activation Laboratories, Ltd., High-Resolution ICP-MS Analysis of 2007 Waters...........30

Activation Laboratories, Ltd., High-Resolution ICP-MS Analysis of 2008 Waters..........30

Activation Laboratories, Ltd., High-Resolution ICP-MS Analysis of 2009 Waters...........30

Activation Laboratories, Ltd., High-Resolution ICP-MS Analysis of 2010 Waters...........31

Acme Analytical Laboratories, Ltd., Analysis of 2007 Vegetation.....................................32

Activation Laboratories, Ltd., Analysis of 2007 Vegetation.............................................32

Summary and Conclusions of the Quality Control Evaluation for the

Various Geochemical Data Sets ....................................................................................3



Soil Gas Hydrocarbons (Activation Laboratories, Ltd.) ...................................................33

Bioleach (Activation Laboratories, Ltd.) .........................................................................33

Enzyme Leach (Skyline Assayers and Laboratories) .......................................................33

TerraSol Leach (Skyline Assayers and Laboratories)...................................................33

Metal Mobile Ion Leach (SGS Mineral Services) ..............................................................34

Cold Hydroxylamine Hydrochloride Leach (ALS Minerals) .............................................34

Ionic Leach (ALS Minerals)...........................................................................................

Sodium Pyrophosphate Leach (ALS Minerals) .............................................................34

Aqua Regia Leach (Acme Analytical Laboratories, Ltd.) ................................................34

ICPAES-MS42 Total Analysis (USGS Contract with SGS Mineral Services)....................34

ICPAES-MS55 Total Analysis (USGS Contract with SGS Mineral Services)...................35

Analysis of Various Single Elements (USGS Contract with SGS Mineral Services)........35

High-Resolution ICP-MS Analysis (Activation Laboratories, Ltd.).................................35

Vegetation Analyses (Acme Analytical Laboratories, Ltd.) ...............................................35

Vegetation Analyses (Activation Laboratories, Ltd.).......................................................35

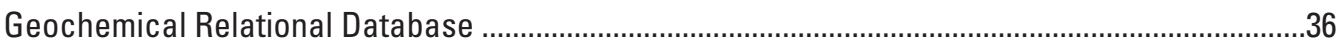

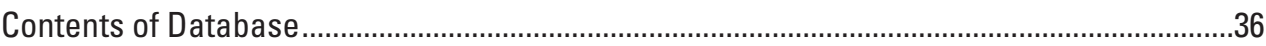

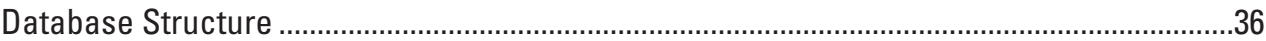

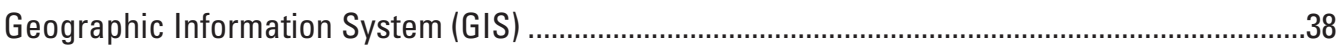

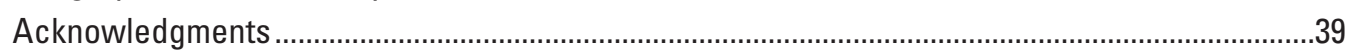






\section{Figures}

1. Map showing location of the Pebble porphyry deposit study area,



2. Tables in the relational database and the relationships between tables

37

\section{Tables}

1. Compilation of specifications for five regional aeromagnetic surveys flown between 1977 and 2005, southwest Alaska.

2. Previous gravity station locations and values used for gravity ties in the Iliamna/Lake Clark area, southwest Alaska......

3. Comparison of new adjusted data to previous gravity station values used for gravity ties in the Iliamna/Lake Clark area, southwest Alaska ..........................43

4. Number of geochemical sample media collected from 2007 to 2010 in the Pebble porphyry deposit study area, southwest Alaska............................................4

5. Samples and subsamples in the Pebble deposit database ............................................45

6. List of Pebble deposit spreadsheets generated from the geochemical relational database. 


\section{Conversion Factors}

Inch/Pound to SI

\begin{tabular}{|c|c|c|}
\hline Multiply & & To obtain \\
\hline \multicolumn{3}{|c|}{ Length } \\
\hline inch (in.) & 2.54 & centimeter $(\mathrm{cm})$ \\
\hline inch (in.) & 25.4 & millimeter $(\mathrm{mm})$ \\
\hline foot $(\mathrm{ft})$ & 0.3048 & meter $(\mathrm{m})$ \\
\hline mile (mi) & 1.609 & kilometer $(\mathrm{km})$ \\
\hline mile, nautical (nmi) & 1.852 & kilometer $(\mathrm{km})$ \\
\hline \multicolumn{3}{|c|}{ Area } \\
\hline square mile $\left(\mathrm{mi}^{2}\right)$ & 2.590 & square kilometer $\left(\mathrm{km}^{2}\right)$ \\
\hline \multicolumn{3}{|c|}{ Volume } \\
\hline ounce, fluid (fl. oz) & 0.02957 & liter (L) \\
\hline cubic inch $\left(\mathrm{in}^{3}\right)$ & 0.01639 & liter $(\mathrm{L})$ \\
\hline \multicolumn{3}{|c|}{ Mass } \\
\hline ounce, avoirdupois (oz) & 28.35 & $\operatorname{gram}(\mathrm{g})$ \\
\hline pound, avoirdupois (lb) & 0.4536 & kilogram $(\mathrm{kg})$ \\
\hline \multicolumn{3}{|c|}{ Density } \\
\hline pound per cubic foot $\left(\mathrm{lb} / \mathrm{ft}^{3}\right)$ & 16.02 & kilogram per cubic meter $\left(\mathrm{kg} / \mathrm{m}^{3}\right)$ \\
\hline pound per cubic foot $\left(\mathrm{lb} / \mathrm{ft}^{3}\right)$ & 0.01602 & gram per cubic centimeter $\left(\mathrm{g} / \mathrm{cm}^{3}\right)$ \\
\hline
\end{tabular}

Temperature in degrees Celsius $\left({ }^{\circ} \mathrm{C}\right)$ may be converted to degrees Fahrenheit $\left({ }^{\circ} \mathrm{F}\right)$ as follows:

$$
{ }^{\circ} \mathrm{F}=\left(1.8 \times^{\circ} \mathrm{C}\right)+32
$$

Temperature in degrees Fahrenheit $\left({ }^{\circ} \mathrm{F}\right)$ may be converted to degrees Celsius $\left({ }^{\circ} \mathrm{C}\right)$ as follows:

$$
{ }^{\circ} \mathrm{C}=\left({ }^{\circ} \mathrm{F}-32\right) / 1.8
$$

Concentrations of chemical constituents in water are given either in milligrams per liter ( $\mathrm{mg} / \mathrm{L}$ ) or micrograms per liter ( $\mu \mathrm{g} / \mathrm{L})$. 
SI to Inch/Pound

\begin{tabular}{|c|c|c|}
\hline Multiply & By & To obtain \\
\hline \multicolumn{3}{|c|}{ Length } \\
\hline centimeter $(\mathrm{cm})$ & 0.3937 & inch (in.) \\
\hline millimeter (mm) & 0.03937 & inch (in.) \\
\hline meter $(\mathrm{m})$ & 3.281 & foot $(\mathrm{ft})$ \\
\hline kilometer (km) & 0.6214 & mile (mi) \\
\hline kilometer $(\mathrm{km})$ & 0.5400 & mile, nautical (nmi) \\
\hline \multicolumn{3}{|c|}{ Area } \\
\hline square meter $\left(\mathrm{m}^{2}\right)$ & 0.0002471 & acre \\
\hline \multicolumn{3}{|c|}{ Volume } \\
\hline$\overline{\text { liter }(\mathrm{L})}$ & 33.82 & ounce, fluid (fl. oz) \\
\hline liter $(\mathrm{L})$ & 61.02 & cubic inch $\left(\right.$ in $\left.^{3}\right)$ \\
\hline \multicolumn{3}{|c|}{ Mass } \\
\hline $\operatorname{gram}(\mathrm{g})$ & 0.03527 & ounce, avoirdupois (oz) \\
\hline kilogram (kg) & 2.205 & pound avoirdupois (lb) \\
\hline \multicolumn{3}{|c|}{ Density } \\
\hline kilogram per cubic meter $\left(\mathrm{kg} / \mathrm{m}^{3}\right)$ & 0.06242 & pound per cubic foot $\left(\mathrm{lb} / \mathrm{ft}^{3}\right)$ \\
\hline gram per cubic centimeter $\left(\mathrm{g} / \mathrm{cm}^{3}\right)$ & 62.4220 & pound per cubic foot $\left(\mathrm{lb} / \mathrm{ft}^{3}\right)$ \\
\hline
\end{tabular}




\title{
Geophysical, Geochemical, and Mineralogical Data from the Pebble Cu-Au-Mo Porphyry Deposit Area, Southwest Alaska: Contributions to Assessment Techniques for Concealed Mineral Resources
}

\author{
By E.D. Anderson, S.M. Smith, S.A. Giles, Matthew Granitto, R.G. Eppinger, P.A. Bedrosian, A.K. Shah, \\ K.D. Kelley, D.L. Fey, B.J. Minsley, and P.J. Brown
}

\section{Introduction}

In 2007, the U.S. Geological Survey (USGS) began a multidisciplinary study in southwest Alaska to investigate the setting and detectability of mineral deposits in concealed volcanic and glacial terranes (fig. 1). The study area hosts the world-class Pebble porphyry Cu-Au-Mo deposit, and through collaboration with the Pebble Limited Partnership (PLP), a range of geophysical and geochemical investigations was carried out in proximity to the deposit. The deposit is almost entirely concealed by tundra, glacial deposits, and post-mineralization volcanic rocks. The discovery of mineral resources beneath cover is becoming more important because most of the mineral resources at the Earth's surface have already been discovered. Research is needed to identify ways in which to assess concealed mineral resources. This report presents the uninterpreted geophysical measurements and geochemical and mineralogical analytical data from samples collected during the summer field seasons from 2007 to 2010, and makes the data available in a single Geographic Information System (GIS) database.

\section{Purpose and Scope of Work}

Southwest Alaska is a vast area covered by tundra and glacial deposits. The occurrence of the largely concealed world-class Pebble porphyry $\mathrm{Cu}-\mathrm{Au}-\mathrm{Mo}$ deposit in southwest Alaska highlights the importance of searching for mineral deposits under cover. This report presents field and analytical data produced from samples collected during the field seasons from 2007 to 2010. The purpose of data collection was to better understand the geophysical and geochemical signatures of the geology near the Pebble deposit. The datasets span the disciplines of geophysics and geochemistry and include: magnetics, gravity, magnetotellurics (MT), self-potential (SP), soil chemistry, stream sediment chemistry, pond sediment chemistry, water chemistry, vegetation chemistry, indicator minerals, and whole-rock geochemistry results. This report incorporates and supersedes releases of previously published geochemical data for samples collected in 2007 and 2008 (Fey and others, 2008, 2009). To facilitate the interpretation process, this report also presents previously released USGS spatial data (see section on Previous Work). The purpose of this report is to make available the newly acquired data and to bring together the large collection of data into a single Geographic Information System (GIS) database. The GIS database is presented within Environmental Systems Research Institute (ESRI) map documents (.mxd and .pmf). ESRI provides freely available software that allows users to view the data content, as it would be represented on a map (ESRI, 2011). Providing the GIS database and map documents greatly reduces the amount of time an end-user will spend building the database and generating maps of the data, thereby allowing more time for data visualization and interpretation. The GIS database may also help the user become more familiar with the extent of publically available USGS spatial data.

\section{Previous Work}

Geochemical data collected in 2007 and 2008 as part of this project were published in 2008 and 2009, respectively, in order to expedite availability (Fey and others, 2008, 2009). This new report incorporates and supersedes the previous two data releases, and incorporates geochemical data collected and produced in 2009 and 2010, in addition to the previously unpublished geophysical data. Also included in the GIS database in this report are preexisting USGS spatial data sets that may facilitate the interpretation of the newly acquired USGS data described in this report. The preexisting data span a broad range of geologic disciplines that includes: hydrology, geophysics, geochemistry, geochronology, and remote sensing. These data are only briefly described in this report, but references to the original work are provided. The purpose of providing these data is to facilitate data interpretation as well 




Figure 1. Map showing location of the Pebble porphyry deposit study area, southwest Alaska. The data presented here are largely from the immediate vicinity of the Pebble deposit, but some extend farther into the Iliamna, Dillingham, Taylor Mountains, and Lake Clark quadrangles outlined in black.

as to make the user aware of existing USGS data sets that may be of use to their work.

\section{Alaska Radiometric Age Database}

The Alaska Radiometric Age Database consists of radiometric ages of rocks or minerals sampled from Alaska (U.S. Geological Survey, 1999). The data were collected from professional publications and (or) received from researchers and populated in the database with permission. A subset covering southwest Alaska is herein provided. The original database is accessible at: http://tin.er.usgs.gov/akages/.

\section{Alaska Resource Data File}

The Alaska Resource Data File (ARDF) is a database that contains descriptions of mines, prospects, and mineral occurrences throughout Alaska (U.S. Geological Survey, 2008). The
ARDF database is a subset of the National Mineral Resource Data System (MRDS) that has been specifically reformatted and redesigned to better meet the needs of the local user community. A subset of the ARDF covering southwest Alaska is herein provided. The original database is accessible at: http://ardf.wr.usgs.gov/.

\section{Geochemistry}

The National Uranium Resource Evaluation (NURE) program collected sediment samples in numerous ponds in southwest Alaska. The samples were analyzed for multielement concentrations. These data were reformatted and described in detail by Smith (1997). A subset of this database from the Iliamna and Lake Clark Quadrangles is herein provided. The original database is accessible at: http://pubs.usgs. gov/of/1997/ofr-97-0492. 


\section{Aeromagnetic Data}

Regional aeromagnetic data are collected to help understand the regional geologic framework. These were collected along parallel flight lines spaced 1 mile $(1.6 \mathrm{~km})$ apart. The nominal flight height is $1,000 \mathrm{ft}(305 \mathrm{~m})$ above the surface. These data measure the intensity of the Earth's magnetic field. Observed measurements are reduced to show magnetic field anomalies that strongly reflects the distribution of magnetic minerals such as magnetite. Such a distribution can provide information pertaining to the subsurface geology. The data presented here are a compilation of 5 regional aeromagnetic data sets. The original data are accessible at: http://crustal. usgs.gov/geophysics/index.html.

\section{Hydrography}

The USGS National Hydrography Dataset (NHD) is a comprehensive set of digital spatial data representing surface water features (Simley and Carswell, 2009). The features include lakes, ponds, rivers, canals, stream gages, and dams. The data set creates a network of features that allows users to trace movement in downstream and upstream directions. The data presented here are a subset of the NHD. The original data are accessible at: http://nhd.usgs.gov/index.html.

Also presented are hydrography features that were digitized from proprietary color orthophotography taken in 2004 near the Pebble deposit. Because of dynamic processes in the glacial landscape around the Pebble deposit, these data provide a more accurate representation of local hydrography features. Such accuracy was necessary for the geochemical studies presented here.

\section{Geologic Maps}

Digital geologic data at a scale of 1:250,000 are included for the Taylor Mountains, Lake Clark, Iliamna, and Dillingham quadrangles (Wilson and others, 2006). The data contain attributes that describe lithology and age of geologic units. The original data are accessible at: http://pubs.usgs.gov/ of/2006/1303/.

\section{Remote Sensing}

Landsat data have been used to map surface features since the 1970's (U.S. Geological Survey, 2010). The Landsat Enhanced Thematic Plus (ETM+) sensor carried aboard the Landsat 7 satellite has been acquiring images since 1999. Each image contains 7 spectral bands that record the intensity of light reflected off the surface of the Earth. A single scene over southwest Alaska, with minimal snow and cloud cover, was obtained from the Earth Resources Observation and Science Center (EROS). The scene was processed to highlight potential areas of surficial iron oxide and hydrous clays. Also provided are the original spectral bands. The Landsat database is accessible at: http://landsat.usgs.gov/.

\section{Digital Elevation Model (DEM)}

Digital elevation models (DEM) are arrays (or cells) of regularly spaced elevation values that represent a model of the Earth's surface (Gesch and others, 2009). DEM data are available at multiple spatial resolutions. High-resolution DEM data that encompass the entire study area are derived from 15-minute quadrangle sheets. The DEM data have an approximate cell size of $60 \mathrm{~m}$ (north-south) and $30 \mathrm{~m}$ (east-west). The DEM presented here is a mosaic of 6 tiles, projected to the UTM zone $5 \mathrm{~N}$, WGS 84 coordinate system. The resultant DEM contains cells of approximately $45 \times 45$ meter resolution. A hillshade is a derivative product of a DEM that models the shadows of the topography that would be produced if the sun were at a particular azimuth and altitude. A hillshade has been generated using an azimuth of 315 degrees (from geographic north) at an altitude of 45 degrees above the horizon. The original DEM data sets are available at: $h t t p: / / n e d . u s g s$. gov/NED/index.asp.

\section{Geophysical Studies}

New geophysical data collected for this study include gravity, magnetotelluric (MT), and self-potential (SP) (pl. 1). In addition, an aeromagnetic compilation from existing surveys has been generated. In general, the geophysical datasets provide information pertaining to the variations in the physical properties of the subsurface. Magnetic surveys map the distribution of magnetic materials in the subsurface, which is largely a function of the amount of magnetite present in rocks. Gravity surveys map changes in density and reflect the configuration of sediments and various types of igneous rocks. MT surveys are sensitive to subsurface changes in electrical resistivity and respond to the presence of aqueous fluids and conductive minerals such as sulfides. SP surveys measure naturally occurring electrical potentials and in a mineralized environment are sensitive to reduction-oxidation (redox) reactions where the oxidation state of atoms is modified.

\section{Aeromagnetics}

Aeromagnetic surveys delineate the distribution of magnetic minerals from which subsurface geology can be inferred. These data help constrain the geological framework and provide useful information for mineral resource assessments, especially in covered areas where few rock outcrops exist. Aeromagnetic data are usually collected along parallel flight lines at a nominal height above the surface. The data are quick to acquire and can cover large areas in a relatively short time. 
The aeromagnetic data presented here are a compilation of five regional surveys that were flown between 1977 and 2005 (pl. 1; table 1; Connard and others, 1999; U.S. Geological Survey, 2006a; U.S. Geological Survey, 2006b). All surveys were flown with northwest-southeast flight lines spaced 1 mile $(1.6 \mathrm{~km})$ apart. The nominal height above the surface was 1,000 feet (305 meters).

\section{Data Processing}

The regional aeromagnetic surveys have been processed and merged to form a continuous magnetic anomaly data set for southwest Alaska. All data sets had standard quality control steps applied by the contractors who flew the surveys (Luyendyk, 1997). These steps include despiking, correcting for lag, and adjusting for heading errors. Because the Earth's magnetic field varies throughout the day, a diurnal correction based upon a fixed base-station magnetometer is applied. The Earth's magnetic field also varies over time scales of years and can require a secular correction to be applied. Because the surveys were conducted over a time period spanning several decades a secular correction was applied. Models of the secular variation referred to as International Geomagnetic Reference Field (IGRF) are removed from the observed data resulting in a residual field.

The data were gridded using a minimum-curvature algorithm with cell dimensions of 400 meters (Webring, 1981). Common to aeromagnetic data are line-to-line leveling errors. These errors are introduced largely from differing observation heights between adjacent flight lines. Leveling errors also result from inadequate compensation of the magnetic field from the aircraft. In either case when flight line data are gridded, the result often shows linear anomalies parallel to the flight lines. Such linear patterns were removed using a decorrugation filter (Urquhart, 1988).

The resultant five data sets were then merged together. This process involves subtracting from one data set the median value for areas of overlap with another data set and then smoothly combining the two. This process was repeated four times resulting in a single continuous residual magnetic anomaly map across southwest Alaska.

The reduction-to-the-pole (RTP) transformation is a common processing step for interpretation of aeromagnetic data (Baranov and Naudy, 1964). The Earth's magnetic field has both inclination and declination that can add complexities such as dipole effects to a magnetic anomaly map. The RTP transformation involves the conversion of the magnetic anomalies to their equivalent as would be seen if their sources were located over the magnetic north pole where the inclination is vertical. This process simplifies the anomalous field by centering the anomalies over their source, assuming the magnetization of the source is dominated by induction. This removes the dipole effect commonly found in the magnetic field, as well as centers the magnetic anomaly over its source. The RTP transformation was applied using an inclination of $72.6^{\circ}$ and declination of $18.5^{\circ}$.
Magnetic data can be mathematically transformed from one observation surface to another (Kellogg, 1953). Transforming the data to a higher observation surface is known as the "upward continuation transformation." Upward continuation can be used to accentuate relatively deep magnetic sources. The transformation highlights the longer spatial wavelength anomalies, commonly due to deeper sources, at the expense of the shorter wavelength anomalies. The data presented here show the RTP field upward continued from the nominal height of $305 \mathrm{~m}$ to $10,000 \mathrm{~m}$.

Aeromagnetic data can be used to locate edges of magnetic sources. The analytic signal transformation is one method used for detecting edges of magnetic sources (Nabighian, 1972). The analytic signal presented here was derived from the RTP data.

\section{Gravity}

Gravity measurements can assist geophysical and geologic characterization by providing constraints on compositional and(or) structural variations within Earth's subsurface. We collected data from 136 new gravity stations within an area of over $6,000 \mathrm{~km}^{2}$ in an effort towards geophysical characterization of an area hosting concealed mineral deposits (pl. 1). A list of data measurements and reduction products provided is given in Appendix 1.

Gravity data delineate variations in subsurface density structure, which often serves as a proxy for variations in rock lithology. Constraints on lithologic structure can be used for studies not only involving resource exploration, but also hazard assessment (for example, volcanoes, earthquakes), geodynamic and geologic evolution, and other topics. This section describes the data collection and reduction process, including approaches to addressing challenges of gravity surveying in remote areas of Alaska. Preliminary interpretive discussions of these data combined with magnetic, magnetotelluric, and drillhole data are given by Shah and others (2010) and Bedrosian and others (2010).

\section{Data Collection}

The remote Arctic tundra environment of southwestern Alaska presents multiple challenges to gravity data collection. The first is a lack of steady ground on which to make measurements. In order to measure vertical acceleration, the instrument must be leveled with respect to the ground and its position held stable long enough for a reading to be taken. However, in summer months many areas of southwestern Alaska are characterized by soft porous ground saturated with water from melting snow and soil frost. Small shifts in the position of the operator or local winds can easily impact the vertical angle of the instrument, even with use of planted legged platform (sometimes referred to as a "tundra pod").

To mitigate these survey conditions, we used a meter that can make automatic repeat measurements over a given 
time period (a Scintrex CG-5). The meter was set to measure acceleration every second over 2-3 minute time intervals and report an average value and variation. At each site we repeated this process 3-5 times, with the final station value determined from the weighted average of these measurements (using the variation over the 2-3 minute time interval to weigh measurements). The precision estimate based on measurement repeatability is $\sim 0.1 \mathrm{mgal}$ or less for this survey.

Corrections for instrument drift over the course of each day were conducted by tying measurements to base station readings recorded at the start and end of each survey day and assuming linear rate of drift. The base station was situated on stable ground outside the Weathered Inn in the town of Iliamna, labeled WINN in the data files. The rate of change between morning and evening readings was nearly constant over the 5-10 day survey periods for both 2008 and 2009. One overnight run, in which continuous gravity readings were acquired in a fixed location, showed linear variations, suggesting the linear drift correction is a reasonable approximation. Tidal corrections were performed using the Scintrex CG-5 internal software (Scintrex, 2009).

A second challenge to gravity surveying in southwestern Alaska is the lack of high-resolution elevation measurements, which are needed to calculate quantities used in geophysical analyses such as the free-air and Bouguer anomalies. Satellitederived elevation grids available from the Shuttle Radar Topography Mission (SRTM) do not provide coverage north of $60^{\circ} \mathrm{N}$ and although the National Elevation Dataset (NED) supplies elevation estimates at a resolution of 2-arc-seconds (Gesch and others, 2009), this is still impractical in rugged terrain. Handheld global positioning system (GPS) units typically have a vertical position estimate with an error of $2 \mathrm{~m}$ or greater, so we deployed a differential GPS (DGPS) system. Each survey site was occupied for a minimum of 8 minutes (usually longer) and a base station maintained throughout the survey day. Vertical positions were calculated as a postprocessing step. In some cases signal loss precluded a DGPS solution, so either an Online Positioning User Service (OPUS) or single-receiver GPS solution was used.

We note that this approach differs from previous compilations that use elevations derived from USGS topographic maps such as the 2006 compilation by Saltus and others (2008) covering the state of Alaska. First order differences arise because GPS methods determine elevation relative to an ellipsoid, while the topographic maps, as well as some other altimetry methods, provide elevation relative to a vertical datum based on mean sea level (MSL).

\section{Data Reduction}

\section{Measured gravity}

The standard method of estimating gravitational acceleration values from drift-corrected instrument measurements involves "tying" these measurements to a site or sites with known gravity values via a uniform shift so that they match (for example, Nettleton, 1971; Blakely, 1996). While there are three locations in the town of Iliamna with calibrated gravity stations (Saltus and others, 2008), these data were collected several decades ago. Two stations are in an area that has since been leveled and serves as an active airstrip, and a third station is currently $\sim 0.5 \mathrm{~m}$ underwater near the edge of Lake Iliamna.

Iliamna Airport staff facilitated gravity measurements at the two runway sites where multiple previous measurements are available (stations ILIA and ZB9/KM72, following the nomenclature of Saltus and others, 2008). We also attempted to occupy two other established stations within the survey area at distances of $\sim 50$ and $\sim 95 \mathrm{~km}$ away from the airport (LJ49 and DM45, respectively). Difficulties in accurately locating remote stations LJ49 and DM45, as well as rugged terrain near those sites (which can cause the gravity field to vary significantly over short distances), are likely to contribute to differences between previous and 2008-2009 gravity values, so the airport stations were favored for estimating the appropriate tie offset. Previous station gravity values compared to 2008-2009 estimates are shown in tables 2 and 3. These ties may be updated at a future time with additional gravity data collection in the region.

\section{Mean sea level and ellipsoid elevations}

Many previous gravity data (for example, Saltus and others, 2008) have been supplied with elevation values determined from topographic maps, which are usually defined by a vertical datum based on mean sea level (MSL). DGPS, on the other hand solves for an elevation relative to a reference ellipsoid. In the survey area, the difference between MSL and the reference ellipsoid ranges $12-15 \mathrm{~m}$, which will have significant effect when merging the new data set with previous ones based on MSL. We thus use the National GeospatialIntelligence Agency's (NGA) GEOID09 model (Smith and Roman, 2001) to calculate an equivalent MSL elevation for the 2008-2009 data. For ease of combination with previous data sets, subsequent gravity reduction values are given relative to MSL elevation. We note that the use of gravity measurements relative to a surface that incorporates Earth's geoid is currently debated. We also note that GEOID09 provides adjustments relative to the vertical datum NAVD88, while some elevation measurements within the preexisting data gravity compilations may be given relative to vertical datum NGVD29. Within the conterminous United States, differences between these datums are at most $\sim 2 \mathrm{~m}$, with highest values within the Rocky Mountains. To date, NAVD88-NGVD29 conversion models for Alaska are not publically available.

\section{Free-air anomaly}

The free-air anomaly is determined by applying standard corrections for latitude (adjustments for Earth flattening) and elevation variations. Details regarding this approach are discussed by Blakely (1996). 
Geophysical, Geochemical, and Mineralogical Data from the Pebble Cu-Au-Mo Porphyry, Southwest Alaska

\section{Terrain correction and Bouguer anomaly}

The Bouguer anomaly is calculated by subtracting the gravitational field due to surrounding topography (the Bouguer correction) from the free-air anomaly. This quantity highlights gravitational variations due to subsurface density variations. The Bouguer calculation includes a correction for elevation (the "simple" Bouguer correction) and a correction for variations in the surrounding terrain (for example, Blakely, 1996). DGPS-MSL elevations were used for the former. To determine the effect of local terrain variations, we used the National Elevation Dataset (NED), which supplies elevation estimates at a grid spacing of $30 \mathrm{~m}$ in the east-west direction and $60 \mathrm{~m}$ in the north-south direction. The gravitational correction was then calculated using a commercial Terrain Correction utility (Oasis montaj, Geosoft, 2010) with a reduction density of $2.67 \mathrm{~g} / \mathrm{cm}^{3}$. We note that there are some differences between measured DGPS-MSL elevations and the NED, which are attributed to a combination of gridding artifacts and likely usage of different vertical datums (NGVD29 vs. NAVD88). However, because NED elevations are consistent within the terrain correction dataset, and the NED grid spacing is much finer than that of the survey, we expect limited errors from these differences.

\section{Magnetotelluric (MT)}

Magnetotellurics (MT) is used to determine subsurface resistivity structure of the crust and lithosphere. MT is a natural-source electromagnetic technique that involves surface measurements of Earth's electric and magnetic field variations (Tikhonov, 1950; Caignard, 1953). The natural electromagnetic signals used in MT originate from a variety of processes in the atmosphere, ionosphere, and magnetosphere. Within the typical MT frequency range $\left(10^{4}-10^{-4} \mathrm{~Hz}\right)$, signal above $1 \mathrm{~Hz}$ is largely due to electrical storms in the atmosphere, while signal below $1 \mathrm{~Hz}$ is dominantly associated with plasma waves within the ionosphere and magnetosphere (Vozoff, 1991). Due to the strong conductivity contrast at the air-earth boundary, the inducing electromagnetic fields, regardless of incidence angle, are strongly refracted, and propagate vertically within the Earth. Relative to the incident magnetic field, the amplitude and phase of the measured electric field depend upon the conductivity of the medium through which it travels, and it is this dependence on conductivity that the MT method exploits.

For a typical MT survey, the depth of investigation is dependent upon subsurface resistivity, sampling rate, recording time, and signal strength. The goal of magnetotelluric analysis is to estimate the Earth's resistivity structure from surface electric and magnetic field measurements. The measured fields are typically transformed into the frequency domain where cross- and auto-power spectra are computed. These are then used to estimate transfer functions relating the fields in the frequency domain. These transfer functions form what is termed the "impedance tensor," a complex, frequencydependent tensor containing the amplitude and phase relations between the horizontal electric and magnetic field vectors. The magnetotelluric response functions, apparent resistivity $\left(\rho_{a}\right)$ and phase $(\varphi)$ are derived from the impedance tensor. In the special case of a homogeneous Earth, the impedance tensor, and therefore the magnetotelluric response functions, is frequency independent. The apparent resistivity, $\rho_{a}$, is then equal to the subsurface resistivity, $\rho$, while the phase, $\varphi$, is equal to $45^{\circ}$. For more complicated structure, the resistivity distribution is folded into the frequency dependence of the impedance tensor, and is extracted via modeling and inversion. It is the inversion process that is used to convert frequency-dependent apparent resistivity and phase into depth-dependent resistivity.

In addition to the MT impedance, derived solely from horizontal-electric and magnetic field measurements, verticalmagnetic field measurements are commonly recorded in concert with an MT sounding. These measurements can be combined with the horizontal-magnetic field measurements to form $T(\omega)$, often termed the vertical-magnetic field transfer function. These data are often inverted in conjunction with MT impedance data to better constrain subsurface conductivity structure.

\section{Data Collection}

From 2007-2009, the USGS collected wideband MT data at 85 stations on a regional scale surrounding the Pebble deposit. These MT stations are organized along 5 profiles (pl. 1) trending NNW-SSE, perpendicular to the structural grain within the area, as based upon topography, geology, and aeromagnetic data. At each station, horizontal-electric field measurements and horizontal-magnetic field measurements were made for a period of roughly 20 hours. Vertical-magnetic field measurements were acquired at many but not all of the stations. In the cases where vertical-magnetic field measurements were not made, permafrost, outcrop, or equipment failures prohibited installation of the vertical-magnetic field sensor. Magnetic field measurements were made using ferritecored induction coils. A list of station names, locations, acquisition dates, and the presence or absence of vertical-magnetic field measurements is provided in table 1 of Appendix 2.

Electric field measurements were recorded using 50-100 m long dipoles with non-polarizing $\mathrm{Pb} / \mathrm{PbCl}_{2}$ electrodes designed after Petiau (2000). Electrodes were surrounded by a ball of bentonite clay and enclosed in a porous cotton sample bag before placement in the ground. This increased the effective surface area of the electrode/ground contact, thus lowering the contact resistance. It also helped to maintain a stable environment with respect to moisture content in the vicinity of the electrode. Typical dipole resistances (the resistance of the circuit including the Earth, electrode/ground contact resistances, and the dipole wire) were on the order of $1-4 \mathrm{k} \Omega$.

Data were recorded using the MT24LF system (Electromagnetic Instruments, Inc., 2010) over a frequency range from $100 \mathrm{~Hz}$ to $0.0002 \mathrm{~Hz}$. Typically, four stations were operating synchronously to permit remote-reference processing of the data (a form of noise cancellation, Gamble and others, 1979). 
All data were synchronously recorded using a timing signal from the Global Positioning System (GPS). Data were collected at three acquisition frequencies on two synchronous data streams. Continuous data acquisition was at $6.25 \mathrm{~Hz}$, while a 'burst' mode acquired 10 minutes of $500 \mathrm{~Hz}$ data and 30 minutes of $50 \mathrm{~Hz}$ data within any one-hour period. This acquisition scheme provides the long time series necessary for adequately sampling low-frequency signal yet limits the high sampling rate acquisition, and hence the data volume, by non-continuous acquisition. Furthermore, as high-frequency MT signal strength often varies with local time, this acquisition layout ensures the capture of high-frequency data over a range of local times within the recording interval. On average, each station collects $150 \mathrm{MB}$ of raw time series data during a 20-hour recording interval.

\section{Data Processing}

Data processing includes manual and automated noise removal, cross- and auto-power calculation, system filter correction, and robust, multi-station remote-reference impedance estimation (Egbert, 1997). The multi-station reference processing is commonly applied to small arrays of synchronously recorded station data. All possible station array combinations were examined (for 4 synchronous stations there are 6 twostation combinations, 3 three-station combinations, and 1 fourstation combination) as well as each individual high-frequency burst run (typically 20 runs at $500 \mathrm{~Hz}$ and $50 \mathrm{~Hz}$ sampling). The resulting response functions for all possible combinations were then visually compared. The best combinations (smoothest continuous response functions) were then selected for each frequency band and combined to arrive at a single response function file for each station spanning the frequency range from $100 \mathrm{~Hz}$ to $0.0002 \mathrm{~Hz}$. The data as presented have not been corrected for telluric distortion, nor have any static shifts been applied to the data. Furthermore, the data are presented without any selection, thus all transfer function elements are provided at all frequencies where calculated.

The MT impedance and vertical-field transfer function data are provided in measurement coordinates in a file format compatible with the remote-reference and multi-station processing code of Egbert and Booker (1986) and Egbert (1997). Presenting the data in measurement coordinates permits a straightforward data assessment, and in particular can identify problems with the measured data, such as a disturbed electric field dipole that will only affect certain transfer functions. With the exception of the 2007 data, which were recorded in geographic north and east coordinates, all data were recorded in geomagnetic north and east coordinates. Station locations are provided in each file as geographic coordinates in WGS84 datum.

The data are also provided in geographic north and east coordinates as impedances in EDI (Electrical Data Interchange) format (Wight, 1987), with one station per file. Spatial information within the EDI files is provided as offsets in meters relative to a survey-wide reference location that is specified in geographic coordinates (WGS84 datum).

The MT response data (apparent resistivity and phase) for the principal (off-diagonal) components of the impedance tensor are also presented in Appendix 2 as individual station plots.

\section{Self-Potential (SP)}

The self-potential (SP) method measures the naturally occurring electrical potential (voltage) on the Earth's surface. Self-potentials are somewhat unique among geophysical methods in that they are sensitive to active processes in the subsurface, in contrast with methods such as resistivity that are sensitive to physical properties. There are several mechanisms that can generate SP signals (Telford and others, 1990). Two mechanisms that are relevant to the Pebble site are groundwater flow and electrochemical reactions; though the latter appears to be the dominant mechanism based on the measured SP data. In cases where there are multiple possible sources to the self-potential signal, it can sometimes be difficult to independently determine the primary source components from the data (Naudet and others, 2003; Minsley and others, 2010).

In the case of groundwater flow, an excess positive charge develops near grain surfaces in saturated porous geologic media, and is transported along with the water creating a streaming electrical current density. This subsurface electrokinetic phenomenon generates a balancing conduction current density, which flows through the Earth's resistivity structure and is manifested as a measurable self-potential on the Earth surface (Ishido and Mizutani, 1981; Sill, 1983; Morgan and others, 1989; Revil and others, 1999). The degree of coupling between fluid and electrical flows varies with fluid and rock chemistry, but is generally such that the electrical potential gradient is in the opposite direction of the hydraulic gradient. That is, increasingly positive self-potentials typically are measured in the direction of fluid flow (or decreasing hydraulic head). In mountainous terrain where flow is topographically driven, this corresponds to increasingly negative self-potentials in the uphill direction.

The electrochemical source of SP signals is frequently associated with the presence of sulfide minerals. The details of this phenomenon were developed by Sato and Mooney (1960), and have since been widely discussed in the literature (Sivenas and Beales, 1982a,b; Hamilton, 2000; Castermant and others, 2008). When an ore zone spans the naturally occurring background reduction-oxidation (redox) gradient in the Earth's subsurface where reduced sulfide minerals are undergoing oxidation, an electrochemical cell is generated that drives the flow of electrical currents in the host rock. This is sometimes referred to as the "geobattery" model, as it is analogous to a galvanic cell naturally discharging within the Earth. The electrical currents traverse the Earth's resistivity structure, and are responsible for the measurable SP signals on the ground surface. 
The background redox potential is the driving force behind this mechanism. Because the redox field typically decreases with depth, often controlled by the diffusion of oxygen, the orientation of the electrochemical cell predominantly is such that the cathode is at the upper extent, resulting in negative self-potentials observed over the ore zones. Electrical currents flow through the host rock in order to balance the currents within the ore zone.

Electrochemical self-potentials of this nature are relatively stable over time, to the extent that the driving background redox field remains unchanged. The magnitude of self-potentials over mineralized zones can reach up to approximately -700 millivolts (mV) (Sato and Mooney, 1960). Factors that increase the magnitude of self-potentials include ore zones which: (1) have low internal electrical resistance; (2) extend vertically across a strong redox boundary such as the water table; and (3) exist close to the ground surface (Sato and Mooney, 1960). In contrast, electrokinetic self-potentials associated with groundwater flow often are on the order of $100 \mathrm{mV}$ or less, though very large anomalies on the order of $1,000 \mathrm{mV}$ have been occasionally measured in volcanic areas with strong topography and hydrothermal circulation (Fournier, 1989; Revil and others, 2004).

\section{Data Collection}

A single SP profile, approximately $2 \mathrm{~km}$ in length, was collected over the Pebble deposit in 2007 (pl. 1). In 2008, multiple interconnected SP profiles covering more than 20 line-km were acquired (pl. 1). A portion of the 2008 data is nearly coincident with the 2007 measurements. The larger 2008 survey was designed to cover a greater portion of the deposit area, and is also coincident with a portion of the geochemical survey data. A detailed description of the field data files is provided in Appendix 3.

$\mathrm{SP}$ data were acquired using $\mathrm{Pb} / \mathrm{PbCl}_{2}$ electrodes based on the design of Petiau (2000), an Agilent digital voltmeter connected to a field laptop for logging data, a long $(\sim 1 \mathrm{~km})$ spool of wire, and a handheld GPS for recording station loca-

tions. One electrode was established as a base station by placing it in a shallow hole to make good electrical contact with the ground, and was connected to the negative input on the voltmeter. A second (roving) electrode was attached to the end of the spool of wire that in turn, was connected to the positive input on the voltmeter.

The roving electrode was spooled out in 25-m increments (nominal spacing) to establish SP stations. At each station, several (4 in. 2007, 3 in. 2008) shallow holes were dug to establish good electrical contact between the roving electrode and the ground. Five measurements of the potential difference between the roving electrode and the base electrode were recorded in each hole, resulting in 20 and $15 \mathrm{SP}$ measurements for each station in 2007 and 2008, respectively. Multiple measurements were made in several different holes at each station to ensure data repeatability and to provide estimates of data errors at each station.
A new base station was established when the entire spool of wire was deployed, or when a new line of data was to be acquired. Because SP measurements are relative to the base electrode, each new base station must be tied into the existing survey. This was accomplished by setting up the new base station at a location that has already been surveyed on a previous line. By doing this, all of the SP measurements along the new line are relative to the SP values on the previous line.

\section{Data Processing}

Final SP values are calculated by averaging the 15-20 measurements at each station, and tying together multiple survey lines of data. Because SP measurements are relative, values are reported with respect to an arbitrarily chosen survey reference point, which is assigned a value of 0 Volts. The absolute SP values do not agree between 2007 and 2008 because these surveys use different reference points; however, the relative trends between the coincident portions of these data sets agree very well. Final SP values at each station, along with station coordinates, are reported in Appendix 3 for each of the survey years.

Data processing for the 2007 survey was straightforward because the data fall along a single profile. The SP values at each station were calculated by averaging the 20 measurements at each station along the profile. Because of the more complicated survey geometry with multiple interconnected loops in 2008, a more sophisticated strategy was required to generate the final SP value at each location. In this case the processed self-potential value is calculated by tying together the multiple lines of raw data according to the methods described in Minsley and others (2008). This approach simultaneously solves for the SP value at each station that (1) accounts for the estimated data errors and (2) minimizes the potential drop around every closed loop in the survey, which is required by Kirchoff's voltage law.

\section{Geochemical and Mineralogical Studies}

The geochemical studies incorporated a variety of analytical techniques and sample media (surface water, soil, stream sediment, vegetation, glacial till, and rocks) to better understand the geology and mineral resources of the study area. Samples were collected from 2007 to 2010. Sample media and analytical techniques were most varied in the first year of the study; sample media and analytical techniques were refined and reduced in subsequent years. Only surface water and glacial till samples for indicator mineral analysis were collected in all four years. Table 4 describes the number of soil samples collected each year and the methods used for analysis.

A cooperative effort among the USGS and several commercial international geochemical laboratories was 
established. Through this effort, a variety of media and analytical methods were used. The media include soil, sediment, rocks, water, and vegetation. For the soil samples, several partial leaching techniques were used. Some laboratories used leaching techniques that are proprietary in nature, whereas others used published techniques. The laboratories, methods, and media include:

- Activation Laboratories, Ltd. (Actlabs) - high-resolution ICP-MS analysis of water samples (all four years of study); soil gas hydrocarbon and BioLeach analyses on soils (2007); and high-resolution ICP-MS analysis of vegetation samples (2007)

- Acme Analytical Laboratories (Acme Labs) - Aqua regia leach of soil samples (2007-2009); total analysis of vegetation samples (2007)

- ALS Minerals - Ionic leach and cold hydroxylamine leach of soil samples (2007-2009); sodium pyrophosphate leach of soil samples (2007)

- SGS Minerals Services - contract analysis of near-total element concentrations of soil (2007-2009), pond and stream sediment (2007-2009), and rock samples (2009); mobile metal ion analysis of soil samples (2007)

- Skyline Assayers and Laboratories (Skyline Labs) Enzyme Leach and TerraSol leach of soil samples (2007-2009)

- Overburden Drilling Management, Ltd.—Porphyry copper indicator mineral identifications on glacial till samples (2007-2010)

- USGS Laboratories - soil pH and soil conductivity (2007-2009); for water samples, ferrous iron, dissolved organic carbon, anions, alkalinity (2007-2010); for soils, de-ionized water leach (2007)

\section{Sampling Methods}

\section{Water}

Water samples and field parameter measurements were collected at 167 sites (pl. 2; table 4). Water samples were collected from lakes, ponds, or groundwater sources from within the deposit boundaries and from distal background locations. Ten sample site duplicates of all water aliquots were collected for quality assurance purposes, resulting in a ratio of about 1 site duplicate for every 17 sites.

Field parameters measured were temperature, specific conductance, and $\mathrm{pH}$, using a Horiba model 24D combination meter. Calibration of the $\mathrm{pH}$ component was performed daily with $\mathrm{pH} 6.86$ and 4.00 standards, and response was checked throughout each day. A specific conductance standard of $251 \mu \mathrm{S} / \mathrm{cm}$ was monitored daily. Field measurements of acidity (generally for samples with $\mathrm{pH}<7$ ), alkalinity (for samples with $\mathrm{pH}>4.2$ ), dissolved oxygen, and turbidity were performed at most water sample sites using standard field kits. When the field alkalinity measurement was $<25$ ppm equivalent $\mathrm{CaCO}_{3}$ or when the sample water was turbid, a separate sample for laboratory alkalinity determination was collected.

Filtered, acidified aliquots (FA) were collected for cation analysis by high-resolution ICP-MS. A composite sample of site water was collected in a clean 1-L polypropylene Nalgene bottle; this water was filtered on site with a disposable $0.45-\mu \mathrm{m}$ syringe-mounted filter into a $60-\mathrm{mL}$ Nalgene bottle. The collection bottle, syringe, and filter were rinsed with site water; the sample bottle was rinsed with filtered site water. After collection, the FA samples were acidified to $\mathrm{pH}<2$ with ultra-pure nitric acid. Unfiltered, acidified aliquots (RA) for cation analysis (as above) were collected by withdrawing water from the 1-L collection bottle with the rinsed syringe into a rinsed $60-\mathrm{mL}$ sample bottle, and then acidified with ultra-pure nitric acid. Disposable gloves were worn during sample collection, clean plastic sheets were used as working surfaces at each site, and care was taken to minimize contamination.

Filtered, unacidified aliquots (FU) were collected for anion analysis by filtering $(0.45-\mu \mathrm{m})$ water from the collection bottle into a $30-\mathrm{mL}$ sample bottle rinsed with filtered site water. Samples for laboratory analysis of alkalinity (ALK) were collected by filling a $125-\mathrm{mL}$ bottle with unfiltered water from the collection bottle. These aliquots were not acidified but were kept cool until analyzed in the USGS laboratories in Denver, Colorado.

A separate filtered, acidified aliquot (FE) was collected for the laboratory determination of ferrous and total iron, and dissolved organic carbon. This aliquot was filtered $(0.45-\mu \mathrm{m})$ into a brown $60-\mathrm{mL}$ plastic collection bottle, and acidified with ultra-pure hydrochloric acid to $\mathrm{pH}<2$. This subsample was collected first at each site and the collection bottle was kept from exposure to sunlight, to minimize photo reduction of iron (the hydrochloric acid fixes the ferrous/ferric ratio). Results from another project have shown that despite these samples being stored in plastic bottles, contamination is low and accurate analyses for dissolved organic carbon (DOC) can be obtained from the acidified iron samples (D. Fey, unpub. data 2006), so the DOC analysis was performed on these aliquots as well.

\section{Solid Materials}

Soil

Soil samples were collected from 210 sites along traverses over the surficial expression in and surrounding the Pebble deposit, as well as from several background areas beyond the deposit (pl. 2; table 4). Various sub-samples of 
soil were collected at each site to be processed, leached by the various leach methods, and then analyzed.

In general, a pit about $0.6 \mathrm{~m}(2 \mathrm{ft})$ wide and $0.7 \mathrm{~m}(2.3 \mathrm{ft})$ deep was dug through the tundra at each site. Several different soil subsamples were collected based on protocols for the given leach method. Details for each leach method follow in the Analytical Methods section. The three-letter codes in the bullets below match the suffixes for field names for sample media in the analytical tables.

- SMM (Soil, Mobile Metal) - a composite sample was taken from a vertical profile in the soil pit between 10 and $25 \mathrm{~cm}$ below the root zone of the surface organic layer (the B horizon in most cases) and was hand sorted to exclude material $>2 \mathrm{~mm}$. Leaching and subsequent analysis was done by SGS Mineral Services (USGS contract lab), using the proprietary mobile metal ion (MMI) method. Samples were collected using gloved hands and plastic utensils. The sample was not sieved.

- SAR (Soil, Aqua Regia)—from the same zone as described above for SMM, bulk material was collected and sieved in the USGS labs to minus- 80 mesh $(<0.18$ $\mathrm{mm}$ ). This fraction was submitted to Acme Labs for leaching using the industry-standard aqua regia method and subsequent analysis.

- FLT (Field Leach Test) - from the same zone as described above for SMM, bulk material was collected and sieved in the USGS labs to minus- 80 mesh. This fraction was leached using de-ionized water and analyzed in the USGS laboratories using ICP-MS.

- STO (Soil, Total)—from the same zone as described above for SMM, bulk material was collected and sieved in the USGS labs to minus- 80 mesh. This fraction was submitted to SGS Mineral Services for industry-standard 4-acid near-total and sinter total analyses.

- SCH (Soil, Cold Hydroxylamine) - from the same zone as described above for SMM, bulk material was collected and sieved in the USGS labs to minus- 80 mesh. This fraction was submitted to ALS Minerals for leaching using a non-proprietary cold hydroxylamine leach method and subsequent analysis.

- SIL (Soil, Ionic Leach) - from the same zone as described above for SMM, bulk material was collected and sieved in the USGS labs to minus- 80 mesh. The sample was submitted to ALS Minerals for leaching using the non-proprietary Ionic Leach method and subsequent analysis. Ionic Leach is a new method introduced by ALS Minerals in 2008. For consistency, archived splits of the 81 samples collected in 2007 were re-submitted for analysis by Ionic Leach. However, four of the 2007 samples had insufficient sample weights; thus, analyses are only reported for 77 of the 81 samples. Similarly, a total of 83 SIL samples were collected in 2008 for analysis, but 14 of these had insufficient sample weights; thus, analyses are only reported for 69 of the 83 samples. There were no insufficient weights for SIL samples collected in 2009.

- SPH (Soil pH)—from the same zone as described above for SMM, bulk material was collected. The unsieved sample was used for analysis of soil $\mathrm{pH}$ and soil specific conductance in the USGS laboratories.

- SEZ (Soil, Enzyme Leach) - The sample was collected from each pit at a zone between 10 to $15 \mathrm{~cm}$ (4 to 6 in.) below the surface and submitted to Skyline Labs for leaching by the proprietary Enzyme Leach method and subsequent analysis. Most commonly the sample collected was within the B horizon and the sample was designated with an SEZ suffix. However, if still within the A horizon at this depth, the sample was collected and labeled SEZA, and a second sample was taken about $10 \mathrm{~cm}$ (4 in.) below the top of the B horizon (labeled SEZB). Occasionally, ice was encountered at depth and collection of the SEZB sample was not possible. For each sample, the material was placed into a $50-\mathrm{mL}$ plastic centrifuge tube, packed tightly with no headspace, capped, and kept cool until analyzed.

- STL (Soil, TerraSol Leach) —The same sample collected for Enzyme Leach analysis was also leached by Skyline Labs, using the proprietary TerraSol leach method, and subsequently analyzed.

- SNP (Soil, Na Pyrophosphate) - The sample was collected from the bottom part of the A horizon. In the field, the uppermost part of the pit was usually an 8- to 12-cm-thick cap of tundra, which could be turned over intact. The bottom of the A horizon was the bottom of this cap. This fraction was submitted to ALS Minerals for leaching by a non-proprietary sodium pyrophosphate leach technique and subsequent analysis.

- SSG (Soil, Soil Gas) - from the pit, the sample was collected from the upper part of the B horizon and submitted to Actlabs for proprietary soil gas hydrocarbon analysis.

- SBL (Soil, BioLeach) - The same sample collected for Soil Gas hydrocarbon analysis was submitted to Actlabs for proprietary BioLeach and subsequent analysis.

\section{Stream Sediment}

Bedload stream-sediment samples were collected at 20 sites, mostly from upper Talarik Creek and South Fork Koktuli River (pl. 2; table 4). An integrated composite streambedsediment sample was collected from 10-20 sites within $15 \mathrm{~m}$ 
(50 ft) of the plotted sample locality; material was collected from active channel alluvium. Each sample composite was sieved on site using a 10-mesh $(2 \mathrm{~mm})$ stainless-steel screen. The minus-10-mesh fraction was retained and the larger size fraction was discarded. Samples were air dried in the laboratory, sieved to minus- 80 mesh $(<0.18 \mathrm{~mm})$, and the minus- 80 mesh fraction was ground to minus-100 mesh $(<0.149 \mathrm{~mm})$ before analysis.

\section{Pond Sediment}

Samples of pond bedload sediment, taken from the top 15 $\mathrm{cm}$ (6 in.), were collected from 76 ponds within and outside of the deposit area (pl. 2; table 4). Samples were obtained using a PVC scoop with a $1.5 \mathrm{~m}$ (60 in.) handle. Twenty subsamples were collected where practical to make a composite. Sample material ranged from nearly total organic debris to sorted and unsorted detrital gravel, sand, and silt. The gravel material is common because many of the sampled ponds are old glacial kettles underlain by till. The material was sieved on site with a 10-mesh (2 mm) stainless steel screen. Samples were air dried in the laboratory, sieved to minus-80 mesh $(<0.18 \mathrm{~mm})$, and the minus-80-mesh fraction was ground to minus-100 mesh $(<0.149 \mathrm{~mm})$ before analysis.

\section{Pond-sediment Core}

Sediment cores were collected from four ponds within the deposit area and from three distal background ponds (pl. 2; table 4). In the deposit area, pond sediment core sites were chosen based on the presence of high metal concentrations determined in pond water samples collected during the 2007 field season. Cores were taken using either (1) a simple 10.1-cm-diameter (4-in.) PVC pipe with cap or (2) a 10.1$\mathrm{cm}$ polycarbonate core barrel with an aluminum head and equipped with an anti-suction valve and were pounded into the sediment with a sledge hammer until refusal. Stratification was not observed in the pond core sediments. The cores were extracted by hand, capped, and kept upright during transport to the Iliamna field facility. They were then frozen and transported to USGS laboratories in Denver, Colorado. In the laboratory, the cores were sectioned into $2-\mathrm{cm}$ or $2.5-\mathrm{cm}$ increments, described, air-dried, sieved to minus- 80 mesh $(<0.18$ $\mathrm{mm}$ ), and the minus-80-mesh fraction was ground to minus100 mesh $(<0.149 \mathrm{~mm})$ before analysis.

\section{Vegetation}

Where available, 46 samples of vegetation were collected at 22 soil sample sites in 2007 only (pl. 2; table 4). Three different plant types were collected; these were identified to the family and genus level. These were: (1) birch family (Betulaceae) Alnus (alder); (2) birch family Betula (bog birch); and (3) willow family (Salicacaea) Salix (willow). Composite samples of twigs cut to about $7 \mathrm{~cm}$ (in length) were taken from a single plant; in sample preparation, leaves were removed from the twigs, and both were analyzed separately by Acme Labs and Actlabs.

\section{Glacial Till}

Indicator mineralogy has been developed as an exploration tool for a variety of base metal sulfide deposits (Averill 2001, 2007). Grain abundance and morphology are among the characteristics that may be diagnostic. Indicator minerals are heavy ( $>2.8$ specific gravity) and thus concentratable, readily identifiable, and chemically stable in weathered surficial sediments. The suite of porphyry $\mathrm{Cu}$ indicator minerals (PCIMs) was initially determined for deposits in arid regions but has more recently been applied to those in humid areas (Averill, 2007). PCIMs typically produce strong anomalies in surficial sediments due to the large size of mineralized porphyry systems (Averill, 2001).

Between 2007 and 2010, a total of 71 till samples were collected up- and down-ice from the deposit, over a total distance of about $20 \mathrm{~km}$. Samples were also collected from locations distal to the deposit (pl. 2; table 4). About 8-10 kg of material was collected at each site, primarily from glacial moraine ridges. The tills consist of poorly sorted to unsorted, nonstratified material ranging from muddy gravel to sandy coarse gravel. At each site, a hand-dug hole, approximately 30-40 cm deep was sampled. Coarse material ( $>20 \mathrm{~mm}$ ) was discarded onsite. The remainder was collected in a cloth bag and sent to Overburden Drilling Management, Ltd., for determination of porphyry copper indicator minerals.

\section{Rocks}

A small number of rocks (11) were collected in 20072009, and analyzed in 2009 (pl. 2; table 4). Rock samples were usually composited by selecting 12-20 small sub-samples from outcrop or rubble crop and bagged for analysis.

\section{Analytical Methods}

\section{Water}

Field parameters were measured and recorded at each water sample site. These included acidity, alkalinity, and dissolved oxygen by field-kit titration; $\mathrm{pH}$, specific conductance, and temperature with a Horiba multimeter; and turbidity with a CHEMetrics meter.

Filtered, nitric-acidified (FA) and raw, nitric-acidified (RA) water samples collected in 2007 were analyzed in the USGS laboratories by ICP-AES [H2O_ICPAES-FA and H2O_ICPAES-RA] (Briggs, 2002) and ICP-MS [H2O_ ICPMS-FA and H2O_ICPMS-RA] (Lamothe and others, 2002). Filtered nitric-acidified (FA) water samples from 2007 were also analyzed by high-resolution ICP-MS by Actlabs 
[H2O_ICPMS-HR-FA] (Actlabs, 2008). Filtered, nitricacidified (FA) and raw, nitric-acidified (RA) water samples collected in 2008 through 2010 were analyzed only by highresolution ICP-MS by Actlabs [H2O_ICPMS-HR-FA and $\mathrm{H} 2 \mathrm{O}$ ICPMS-HR-RA].

A list of elements and their reporting limits for the HRICP-MS water analyses are in Appendix 4 tables 1-1a-1-1b. Filtered, unacidified (FU) water samples for all years were analyzed for the anions $\mathrm{F}^{-}, \mathrm{Cl}^{-}, \mathrm{SO}_{4}^{-2}$, and $\mathrm{NO}_{3}^{-}$by ion chromatography in USGS labs [H2O_Anions] (Theodorakos and others, 2002). Unfiltered, unacidified samples were analyzed for total alkalinity in USGS labs by titration [H2O_Alk] (Theodorakos, 2002). Filtered, hydrochloric-acidified samples were analyzed for ferrous/ ferric iron content by a ferrozine method in USGS labs [H2O_ $\mathrm{Fe}]$ (To and others, 1999). These same samples were also analyzed for dissolved organic carbon in USGS laboratories by combustion-infrared detection [H2O_DOC] (Shimadzu Corporation, 1997). A list of elements and their reporting limits for anions, alkalinity, dissolved organic carbon, and ferrous iron are in Appendix 4 table 1-2.

\section{Soils}

Leaching methods varied from weak de-ionized water to near-total 4-acid digestion techniques. Among others, iron and manganese complexes, adsorption, and organic complexes all can play simultaneous roles in fixing metals in soil profiles. The purpose of using these partial leach procedures was to try to detect and enhance geochemical contrasts that may have developed in the soil profiles over buried mineralization. A good review of the theory and application of partial and sequential extractions is presented in Chao (1984). With modern instrumentation such as the quadrupole ICP-MS and high-resolution ICP-MS, extremely low concentrations $(<1$ $\mu \mathrm{g} / \mathrm{L}$ ) of analytes may be detected. Details on the various leach methods used are described below, in approximate order of increasing digestion/extraction strength.

\section{Soil pH and Conductivity (SPH)}

This procedure was applied to an unsieved portion of the SMM soil material. An extract was prepared by combining soil with water in a 1:3 ratio and stirring for five minutes. The $\mathrm{pH}$ and specific conductance were then measured on the slurry [Soil_pH-Cond] (Natural Resources Conservation Service, 1996, p. 415-417).

\section{Field Leach Test (FLT)}

This test was performed on a minus- 80 mesh sieved portion of the SMM soil material. An aliquot of $50 \mathrm{~g}$ was combined in a plastic bottle with $1.0 \mathrm{~L}$ de-ionized laboratory water and shaken for five minutes. The sample was allowed to settle and then filtered with a $0.45-\mu \mathrm{m}$ syringe-mounted filter and acidified (Hageman and Briggs, 2000). The leach solutions were analyzed in USGS labs by ICP-MS [Soil_ICPMSFLT] (Lamothe and others, 2002). A list of elements and their respective reporting limits are in Appendix 4 tables 1-3a-1-3c.

\section{Soil Gas Hydrocarbons (SGH)}

This proprietary technique, done on upper B-horizon soils, was developed and performed by Actlabs. The procedure involves analysis of hydrocarbons $\mathrm{C} 5$ through $\mathrm{C} 17$ that are sorbed to soil particles. This procedure is analogous to a weak leach that releases these compounds from the soil particles, which were then analyzed by gas chromatography/mass spectrometry [Soil_GCMS-SGH] (Actlabs, 2010). A list of elements and their respective reporting limits are in Appendix 4 tables 1-3a-1-3c.

\section{BioLeach (SBL)}

This proprietary leach was developed and performed by Actlabs. The BioLeach dissolves remnant proteins that bacteria have left behind when they die. These proteins are believed to migrate directly above mineral deposits by a variety of processes and BioLeach is designed to digest this soil component and release associated trace elements into solution for analysis (Actlabs, 2008). This procedure was performed on the SSG soil subsample, and the leachate was analyzed by high-resolution ICP-MS [Soil_ICPMS-BL]. A list of elements and their respective reporting limits are in Appendix 4 tables $1-3 a-1-3 c$.

\section{Enzyme Leach (SEZ)}

This is a proprietary leach designed to release weakly bound elements from soil (amorphous manganese oxides), developed and performed by Skyline Labs on the SEZ soil subsample. The leachate analysis was by ICP-MS [Soil ICPMS-EELch] (Skyline Assayers and Laboratories, 2011). A list of elements and their respective reporting limits are in Appendix 4 tables 1-3a-1-3c.

\section{TerraSol Leach (STL)}

This proprietary leach, somewhat stronger than the Enzyme Leach, is designed to release weakly bound elements from soil (amorphous iron oxides; primarily limonite). The leach was developed and performed by Skyline Labs on the SEZ soil subsample. The leachate analysis was by ICP-MS [Soil_ICPMS-TS] (Skyline Assayers and Laboratories, 2011). A list of elements and their respective reporting limits are in Appendix 4 tables 1-3a-1-3c. 


\section{Mobile Metal lons Leach (SMM)}

This is a proprietary leach developed and performed by SGS Mineral Services and is designed to release weakly bound (mobile) metals from soil particles. It was applied to the SMM subsample. The leachate analysis was by ICP-MS [Soil_ICPMS-MMI] (SGS Mineral Services, 2011a). A list of elements and their respective reporting limits are in Appendix 4 tables 1-3a-1-3c.

\section{Cold Hydroxylamine Hydrochloride Leach (SCH)}

This non-proprietary leach is somewhat stronger than those previous, and is designed to release metals from manganese oxides (ALS Minerals, 2010), and to a lesser degree, amorphous iron hydroxides (Chao, 1984; ALS Minerals, 2010). This leach does not dissolve crystalline iron oxides. Manganese forms several oxidation states and exists in a variety of amorphous and crystalline forms. As a result, manganese oxide has an extraordinary high cation exchange capacity, accommodating many different trace elements on its surfaces (ALS Minerals, 2010). The leach is useful for liberating metal ions adsorbed onto manganese oxide coatings on mineral grains in the soil. A $1.0 \mathrm{~g}$ aliquot is mixed with $20 \mathrm{ml}$ of $0.1 \mathrm{M}$ hydroxylamine hydrochloride in $0.1 \mathrm{M} \mathrm{HNO}_{3}$. The solution is rolled for two hours at room temperature, centrifuged, and then decanted for analysis. The leach was performed by ALS Minerals on the $\mathrm{SCH}$ soil subsample. The analysis was by ICP-MS [Soil_ICPMS-CHHLch] (ALS Minerals, 2010). A list of elements and their respective reporting limits are in Appendix 4 tables 1-3a-1-3c.

\section{Ionic Leach (SIL)}

This non-proprietary leach is similar to the cold hydroxylamine leach in strength (depending on hydroxylamine concentration) but is designed to release metals from the amorphous iron oxide phase, without attacking crystalline iron oxide phases. Fifty-gram aliquots of the SIL soil subsamples are subjected to a sodium cyanide solution, buffered to $\mathrm{pH} 8.5$, which contains ammonium chloride, citric acid, and EDTA as chelating agents (ALS Minerals, 2008; ALS Minerals, 2010). The analysis was by ICP-MS [Soil_ICPMS-ILch]. A list of elements and their respective reporting limits are in Appendix 4 tables 1-3a-1-3c.

\section{Sodium Pyrophosphate Leach (SNP)}

This non-proprietary leach releases metals bound to organic, humic and fulvic compounds in soils by creating metal chelates (Chao, 1984), using a neutral ( $\mathrm{pH} 7$ ) solution of sodium pyrophosphate. The extraction does not attack sulfides and does not dissolve significant amounts of amorphous iron oxides (ALS Minerals, 2010). It was performed by ALS Minerals on the SNP soil subsample. A $1.0 \mathrm{~g}$ sample of milled organic material was mixed with $25 \mathrm{ml}$ of $\mathrm{pH} 7.0$ sodium pyrophosphate solution, rolled for 1 hour at room temperature. The solution was centrifuged and decanted for analysis by ICP-MS [Soil_ICPMS-NaP] (ALS Minerals, 2010). A list of elements and their respective reporting limits are in Appendix 4 tables $1-3 a-1-3 c$.

\section{Aqua Regia (SAR)}

This leach attacks the soil phases described above, as well as primary and secondary sulfides (Chao, 1984). ACME Analytical Laboratories performed the leach on the SAR soil subsample, and analysis was by ICP-MS [Soil_ICPMS-AR] (Acme Analytical Laboratories, 2010). A list of elements and their respective reporting limits are in Appendix 4 tables 1-3a-1-3c.

\section{Total Analysis (STO)}

Soil subsamples were subjected to a mixture of hydrochloric, nitric, perchloric, and hydrofluoric acid. This is a near-total digestion, but some refractory minerals are not completely dissolved. The solutions were analyzed by both ICP-AES and ICP-MS [Soil_ICPAES-MS42]. The subsamples were also subjected to a sodium peroxide sinter, which is essentially a "total" digestion. The resulting solutions were also analyzed by ICP-AES and ICP-MS [Soil_ICPAESMS55]. These digestions and analyses were performed on a contract lab basis for the USGS by SGS Mineral Services (SGS, 2011b). A list of elements and their respective reporting limits are in Appendix 4 tables 1-3a-1-3c.

Additional single element analyses were performed on the STO soil subsample by SGS Minerals Services. These were (1) arsenic and antimony by hydride generation-atomic absorption spectrometry following a sodium peroxide sinter; (2) selenium by hydride generation atomic absorption spectrometry following a mixed-acid digestion; (3) mercury by flow-injection cold-vapor atomic absorption following a mixed acid-digestion (done on 2007 soils only); (4) gold by atomic absorption spectrophotometry following a fire assay preconcentration; (5) $\mathrm{Cl}^{-}$and $\mathrm{F}^{-}$by ion-specific electrode, following fusion with alkali hydroxide and nitrate; and (6) analyses for total carbon (combustion/IR detection), carbonate carbon (calculated from coulometric titration for $\mathrm{CO}_{2}$ ), and organic carbon (calculated difference between total and carbonate carbon). These analyses are in table Soil_AddlChem. Reporting limits for single-element analyses of soil samples from SGS Mineral Services are in Appendix 4 table 1-3d.

\section{Stream Sediment}

The stream-sediment samples (suffix "STS") were digested and analyzed for total analysis in the same manner as was done for soil samples [StreamSed_ICPAES-MS42 and StreamSed_ICPAES-MS55]. They were also analyzed for six 
additional elements ( $\mathrm{Sb}, \mathrm{Se}, \mathrm{Au}, \mathrm{Hg}, \mathrm{Cl}^{-}, \mathrm{F}^{-}$), and for forms of carbon as described above for soils [StreamSed_AddlChem]. Reporting limits are in Appendix 4 table 1-3c.

\section{Pond Surface and Core Sediment Analyses}

The pond-sediment samples (suffix "PDS") and pond core samples (suffix "CR") were digested and analyzed in the same manner as was done on the soil samples [PondSed ICPAES-MS42 and PondSed_ICPAES-MS55] and [PondSedCore_ICPAES-MS42 and PondSedCore_ICPAES-MS55]. They were also analyzed for six additional elements $(\mathrm{Sb}, \mathrm{Se}$, $\mathrm{Au}, \mathrm{Hg}, \mathrm{Cl}^{-}, \mathrm{F}^{-}$), and forms of carbon as described above for soils [PondSed_AddlChem] and [PondSedCore_AddlChem]. Reporting limits are in Appendix 4 table 1-3c.

\section{Vegetation}

The vegetation samples, twigs and leaves from willow, alder, and birch, were rinsed and dried prior to analysis by both Acme Labs and Actlabs. Samples sent to Acme Labs were digested first with $\mathrm{HNO}_{3}$, then with aqua regia, and then analyzed by ICP-MS [Veg_ICPMS-AR]. Samples sent to Actlabs were digested with aqua regia and then analyzed by high-resolution ICP-MS [Veg_ICPMS-HR-AR]. The list of elements and their reporting limits are in Appendix 4 table 1-4.

\section{Rocks}

Limited rock samples (suffix "R"), collected in 20072009 and analyzed in 2009, were digested and analyzed for total analysis in the same manner as was done for soil samples [Rock_ICPAES-MS42 and Rock_ICPAES-MS55]. They were also analyzed for six additional elements ( $\mathrm{Sb}, \mathrm{Se}, \mathrm{Au}, \mathrm{Hg}$, $\mathrm{Cl}^{-}, \mathrm{F}^{-}$), and for forms of carbon as described above for soils [Rock_AddlChem]. Reporting limits are in Appendix 4 table $1-3 c$.

\section{Indicator Minerals in Till}

Glacial till samples were disaggregated and sieved to obtain the $<2 \mathrm{~mm}$ fraction courtesy of Overburden Drilling Management, Ltd. (ODM). About $7.5 \mathrm{~kg}$ of material was fed through a shaking table and gold grain counts were reported. After heavy liquid (S.G. 2.8-3.2 and >3.2) and ferromagnetic separation, the non-ferromagnetic heavy mineral concentrate (NFM-HMC) fraction was sieved at $>0.25 \mathrm{~mm}$ to obtain the $0.25-2 \mathrm{~mm}$ fraction. Prior to indicator mineral examination and selection, the NFM-HMCs were sieved to $0.25-0.50 \mathrm{~mm}$, $0.50-1.0 \mathrm{~mm}$, and $1.0-2.0 \mathrm{~mm}$. All fractions were examined under a microscope at ODM to determine the amount of PCIMs. Checks were performed on selected grains using scanning electron microscopy (SEM)-energy dispersive x-ray spectrometer (EDS) to confirm mineral identity. Overburden
Drilling Management, Ltd., analyzed the samples using the methods for porphyry copper indicator minerals described in Averill (2001).

\section{Geochemistry Quality Assurance and Quality Control}

\section{Sources of Geochemical Variation and Methods for Assuring Data Quality}

There are several sources and levels of variation in geochemical data - for instance, between-site variation, site variation, sample inhomogeneity, and analytical variation. Statistical analysis of variation (ANOVA) sampling design generally shows that the primary variation in geochemical data is that found between individual samples at different and widely spaced sites (between-site variation). This variation is due to differences in sample parent material, local geology, mineralization processes, and possible anthropogenic influences. This variation provides areal geochemical contrasts that help delineate geochemical anomalies in exploration programs. The goal of regional geochemical surveys is to discern and interpret "between-site variation" by reducing other sources of geochemical variation.

The next level of geochemical variation is known as "site variation." Soils, sediments, and rocks are usually heterogeneous at any location; a single grab sample from one spot at a sample site may have different element concentrations than another grab sample collected a few meters away. This variation can be reduced by compositing several subsamples within the immediate area of sample collection, resulting in a more representative sample of the entire site. Usually a certain fraction (commonly between 10 and 20 percent) of sites is sampled twice. These "site duplicates" are then used to assess the efficacy of the sampling design at reducing site variation. Differences between sampling methods, sampling equipment, and individual collectors can also introduce variation as well as contamination. This variation can be reduced by establishing rigorous sampling protocols, providing identical sets of sampling equipment, and conducting training programs.

Variation is also found within any single sample due to inherent heterogeneity. Sample heterogeneity can be reduced by establishing a consistent sample preparation protocol. A process of crushing, grinding, mixing, and splitting the sample typically creates a very fine homogeneous powder from the original heterogeneous material. Despite consistent preparation procedures, some sample inhomogeneity may not be totally eliminated. For example, samples with small grains of native gold are notoriously difficult to process. The malleable nature of native gold resists the efforts of crushing and grinding. In addition, inhomogeneous distribution of gold particles in the processed sample (due to settling or incomplete mixing) can cause variability in the analyses. This is known as the "nugget effect." If the analyst happens to get a "nugget" 
of gold in the material that is analyzed, the results will show a high concentration of gold. On the other hand, a second analysis of the same sample may miss the "nugget" and, despite the presence of gold in the sample, give low results for gold. Larger sample aliquots and attention to fine grinding help to reduce this error for gold and similar elements.

Laboratory analytical procedures also can be sources of variation in the geochemical data. These sources include differences in analysts, dissolution procedures, analytical instruments, instrument calibration errors, and instrument drift. The combined variation due to sample preparation, aliquot size, and analytical procedures (commonly called "analytical variation") can be measured by using standard reference materials, analytical duplicates, and blanks.

\section{Quality Assurance/Quality Control Methods}

A quality management system for a standard geochemical survey includes both quality assurance (QA) and quality control (QC) elements. The QA focus is mainly in the analytical laboratory environment. Under the QA umbrella, the components of standard operating procedures, instrument logs, training records, data acceptance/rejection criteria, and lab audits are covered. The QA element is not easily measured. However, the QC element provides measures of the accuracy and precision of geochemical data produced by an analytical method. The accuracy and precision are established through the analysis of standard reference materials (SRMs), analytical duplicates, and blanks.

The precision of an analytical method is measured by the percent relative standard deviation (percent RSD) of data for a number of runs of a particular sample or standard and is calculated by dividing the standard deviation (SD) by the mean and multiplying by 100 . The SD is defined as the square root of the quantity s sum of squares of deviations of individual results from the mean, divided by one less than the number of results in the set\} (Dux, 1986):

$$
\left.S D=\sqrt{\sum_{i=1}^{n}\left(X_{i}\right.}-\bar{X}\right)^{2} / n-1
$$

The precision of an analytical method can also be determined from the assessment of analytical duplicates: samples that were split before analysis and then analyzed as two separate samples. The percent RSD is again calculated by dividing the standard deviation (SD) by the mean and multiplying by 100. However, the standard deviation for duplicate measurements is defined as the square root of the quantity s sum of squares of the difference between the duplicate results (R), divided by two times the number of sets of duplicate samples\} (Dux, 1986).

$$
\text { SDdupe }=\sqrt{\sum R^{2}} / 2 k
$$

The accuracy of an analytical method is measured by the percent Recovery, which is calculated by dividing the mean concentration by the target value of the standard reference material used and multiplying by 100 . Target values for standard reference materials may consist of certified values or, when certified values are not available, informational values. The percent Recovery derived from informational values is not as reliable as the percent Recovery calculated from certified values. In general, most selective leach methods do not have certified standard reference material values. Unless otherwise stated, it is expected that most of the SRM target values provided by the individual laboratories for their leach methods are informational values.

Measurements of precision and accuracy are best when elemental concentrations fall within the middle of the determination range for a specified analytical method and element. As a general rule, analytical determinations become less accurate and precise as data values approach the lower or upper reporting limits. For this report, percent RSD and percent Recovery values are given more weight when they are calculated on mean values greater than five times the lower reporting limit.

Possible contamination during the analytical procedure is assessed through the use of "procedure blanks." Blanks are defined based on the sample medium and analytical method and are processed concurrently with samples to determine whether contamination has occurred during the sample dissolution stages or whether cross-sample contamination has occurred in the analytical instrument during a sample run. Commonly, blanks are a set of all the reagents used in the sample processing and analysis procedure.

\section{Quality Control Samples}

Each of the analytical laboratories commonly analyzes a small number of SRMs with every batch of samples. It is also a common practice for most laboratories to pick a small percentage of submitted samples in a batch and analyze them a second time as an analytical duplicate. When appropriate, blank samples are also inserted into the batch by the laboratory. In this study, the data for these quality control samples were requested from each laboratory so that the analytical variation in each data set could be assessed.

For most of the laboratories, the USGS submitted additional quality control samples within each batch of samples sent. These included sample splits for analytical duplicates and a suite of USGS-prepared standard reference materials (SARL, SAR-M, DGPM, and GSP-QC). Two Pebble project soil standards were also submitted for analysis. These two standards were created by compositing and homogenizing excess minus- 80 mesh material derived from processing all of the soil samples from the 2007 field season: a B-horizon mineral soil standard (PB-SMM) and an organic-rich A-horizon soil standard (PB-SNP). Project standards can be used to currently evaluate analytical precision in sample batches and to assess variability among samples collected and analyzed for the 
project in the future. The advantage of a project standard over well-established SRMs is that project materials have exactly the same sample matrix as the submitted samples and may reveal analytical problems unique to this project that would be missed when using SRMs prepared from other soils or other media. No target values were previously determined for the Pebble project soil standards; however, the mean values obtained during the 2007 analyses of these standards were used in subsequent years to evaluate variation over time.

\section{Evaluation of Data Sets by Analytical Laboratory and Year}

Analytical data sets were evaluated each year based on the analyzed quality control samples that were reported by the laboratory. For each data set, summary quality control statistics were calculated and compiled in a series of tables. Where appropriate, quality control charts for data precision (percent RSD) and data accuracy (percent Recovery) were also created.

Quality control charts based on percent RSD and percent Recovery statistics are a tool to help quickly focus on elements that may be a problem in a data set. However, because several factors can strongly influence these statistics, decisions concerning the validity or applicability of the data should not be made solely on the results of these charts. Some factors that are beyond the control of the laboratory include single data outliers, samples with anomalously high or low concentrations, and a lack of homogeneity in the chosen analytical duplicate samples or reference material (the "nugget effect"). Another factor that influences these statistics is the use of very small quality control data sets composed of only two or three analyses. Often just a review of the actual quality control data for an element identified from the quality control charts will show that the variation is still within an acceptable range for the purposes of the data. In rare cases, it was necessary to contact the responsible laboratory to resolve an issue with the data.

Each of the following sections summarizes the analytical results determined by evaluating the quality control tables of statistics and charts. For most methods, the precision charts include a line showing a conservative "Control Limit" of 15 percent RSD. The accuracy charts include lines at 85 percent Recovery and 115 percent Recovery. These lines are used to identify elements that might be problematic and to guide the following discussions.

It should be noted that the \pm 15 percent guidelines were developed to assess the performance of near- and totaldigestion techniques, like 4-acid, sinter, and fusion methods. The variability in instrumental performance when analyzing solutions with analytes at greater than 10 times instrumental detection limits, is usually at the 5 percent level. Thus, the variation seen in the following techniques is predominantly a result of sample or digestion/extraction variability.

Even near-total digestions such as the 4-acid techniques typically do not liberate the total mass of "refractory" elements such as $\mathrm{Sn}, \mathrm{Ti}, \mathrm{Cr}$, or rare earths. Percent recovery and precision values for these elements are often less than that for more easily solubilized elements. The variability in recovery and precision for partial extraction techniques for the above and other elements is usually much higher than for more complete digestions. The partial techniques typically release only small percentages (sometimes less than one percent) of the mass of a given sample, so the variability is higher. Percent relative standard deviation (RSD) values as high as 50 percent are not unusual, nor are they grounds for dismissal of a technique or an element.

It is important to keep in mind that the purpose of applying partial-leach techniques is to develop geochemical datagenerally grouped into classes - that describe geochemical contrasts. The class boundaries may cover several orders of magnitude concentration, and so individual element variation on the order of 50 percent will not significantly change the interpretations.

\section{USGS De-Ionized Water Leach of 2007 Soils}

The batch of soil samples analyzed by the USGS after a de-ionized water leach contained 10 quality control samples: 5 analytical duplicates, and 5 samples of the USGS standard reference material SAR-L.

Appendix 4 contains two tables of summary statistics for these quality control samples: analytical duplicates (table 2-1) and USGS SRM SAR-L (table 2-2). These results are also represented in two quality control charts: precision (percent RSD) of analytical duplicates (fig. 2-1) and precision of SRM SAR-L (fig. 2-2).

Most of the elements detected above the reporting limits for the method show no problems with analytical precision, with the exceptions of Ta and the rare earth elements Ce, Dy, $\mathrm{Er}, \mathrm{Eu}, \mathrm{Gd}, \mathrm{La}, \mathrm{Nd}, \mathrm{Pr}, \mathrm{Tb}$, and $\mathrm{Yb}$ (figs. 2-1 and 2-2). The precision values for the rare earth elements almost all range from 15 to 20 percent RSD. This suggests that the data for these elements are still good but slightly more "noisy" than desired. Tantalum data may be a problem for this method and as a result may not be useful for further interpretations. The quality control analyses for five samples of SRM SAR-L ranged from 0.8 to $4 \mathrm{ppb}$ Ta for a mean value of $2.4 \mathrm{ppb}$ Ta (table 2-2).

\section{Activation Laboratories, Ltd., Soil Gas Hydrocarbons of 2007 Soils}

As part of the SGH analysis, Activation Laboratories, Ltd. (Actlabs) inserted 12 quality control samples: 7 analytical duplicates and 5 reagent blanks. The USGS submitted 15 additional quality control samples: 5 analytical duplicates, 5 samples of the USGS standard reference material SAR-L, and 5 samples of the Pebble project soil standard PB-SMM. All 12 of the analytical duplicate pairs were assessed together for this data set. 
Appendix 4 contains three tables of summary statistics for quality control samples analyzed by the Actlabs soil gas hydrocarbon method: analytical duplicates (table 3-1), USGS SRM SAR-L (table 3-2), and Pebble project standard PBSMM (table 3-3). These results are also represented in three quality control charts: precision (percent RSD) of analytical duplicates (fig. 3-1a, b, and c), precision of SRM SAR-L (fig. 3-2a, b, and c), and precision of Pebble project standard PB-SMM (fig. 3-3a, b, and c).

Actlabs considers the identities of the analyzed hydrocarbon compounds to be proprietary; therefore codes are used to identify each analyte (tables 3-1, 3-2, and 3-3). The precision plots (figs. 3-1, 3-2, and 3-3) show that most compounds with values greater than 5 times the reporting limit have a percent RSD (Coefficient of Variation) between 10 percent and 20 percent, but also that a significant number have values even higher. For most analytical methods this is often an issue of concern. However, SGH is an ultra low-level semi-quantitative method from which one would expect a higher level of imprecision.

A few numbers that are imprecise is "absolutely insignificant" to the use of SGH as an exploration geochemical tool as no one individual compound is used to depict buried mineralization. It is a group of compounds defining a chemical class that produces SGH's characteristically clear and well-defined target anomalies. The use of multiple compounds to define a class, and be part of a bigger signature, is a key factor in the robustness of the SGH geochemistry. (Actlabs, written commun., 2007; emphasis in original).

In an evaluation of the SGH data provided to the USGS, Actlabs reports an average Coefficient of Variation for replicate results of 7.5 percent, "which represents an excellent level of analytical performance" (Dale Sutherland and Eric Hoffman, Actlabs, written commun., 2007).

\section{Activation Laboratories, Ltd., Bioleach of 2007 Soils}

The soil samples submitted to Actlabs for soil gas hydrocarbon determinations were also used for a bioleach analysis. Actlabs inserted seven quality control samples: six analytical duplicates and one reagent blank. The USGS submitted 15 additional quality control samples: 5 analytical duplicates, 5 samples of the USGS standard reference material SAR-L, and 5 samples of the Pebble project soil standard PB-SMM. All 11 of the analytical duplicate pairs were assessed together for this data set.

Appendix 4 contains four tables of summary statistics for quality control samples analyzed by the Actlabs bioleach method: analytical duplicates (table 4-1), USGS SRM SAR-L based on all five samples (table 4-2), USGS SRM SAR-L based on only four samples (table 4-3), and Pebble project standard PB-SMM (table 4-4). These results are also represented in four quality control charts: precision (percent RSD) of analytical duplicates (fig. 4-1), precision of SRM SAR-L based on all five samples (fig. 4-2), precision of SRM SAR-L based on only four samples (fig. 4-3), and precision of Pebble project standard PB-SMM (fig. 4-4).

The analyses of analytical duplicates show very good results for repeatability with most elements having percent RSD values below 10 percent and only $\mathrm{Li}$ (17 percent RSD) and Zn (16 percent RSD) above 15 percent (table 4-1, fig. 4-1). The precision plot for the Pebble project soil standard PB-SMM (table 4-4, fig. 4-4) shows more variability with most elements ranging between 7 and 20 percent RSD. Only Li stands out with a value of 64 percent RSD.

In contrast, the precision plot for SRM SAR-L (table 4-2, fig. 4-2) shows a lot of variability for almost a third of the elements analyzed. An examination of the data for the analyses of five SAR-L samples reveals that one sample has very different chemistry. One unconfirmed possibility is that this sample is not SAR-L and was mistakenly switched either in sample preparation, during sample submission, or at the laboratory. When all the data for this one sample are removed, the statistics (table 4-3) and quality control chart (fig. 4-3) become similar to those for the analytical duplicates and PB-SMM. Only Li remains above 15 percent RSD. For the 2007 field season samples, this suggests that $\mathrm{Li}$ was not well constrained by the Bioleach method and may not be useful for making valid interpretations of these data.

\section{Skyline Assayers and Laboratories Enzyme Leach of 2007 Soils}

Skyline Labs included 19 quality control samples in the batch of 2007 field season soil samples that were analyzed using the proprietary Enzyme Leach method: 10 analytical duplicates, 3 samples of the laboratory reference material QAlqt, 3 samples of the laboratory reference material QRd, and 3 blanks. Because project samples were sent to Skyline Labs without preparation (as requested) immediately upon return from the field, no USGS quality control samples were included.

Appendix 4 contains three tables of summary statistics for the quality control samples associated with the 2007 field season samples: Analytical duplicates (table 5-1), laboratory SRM QAlqt (table 5-2), and laboratory SRM QRd (table 5-3). These results are also represented in five quality control charts: precision (percent RSD) of analytical duplicates (fig. 5-1), precision of SRM QAlqt (fig. 5-2), accuracy (percent Recovery) of SRM QAlqt (fig. 5-3), precision of SRM QRd (fig. 5-4), and accuracy of SRM QRd (fig. 5-5). The results returned for analytical blanks are not listed in this report but all values were less than the reporting limits for the method.

Skyline Labs differentiates element analyses in their Enzyme Leach method as either quantitative or semi-quantitative. Even so, the analytical precision charts for standard reference materials QAlqt (fig. 5-2) and QRd (fig. 5-4) show 
excellent results for almost all elements. The only exceptions are $\mathrm{Te}$ and the semi-quantitative elements $\mathrm{Cl}$ and $\mathrm{S}$ in the QAlqt SRM (fig. 5-2). In 2009, Skyline Labs updated their target values for SRMs QAlqt (table 5-2) and QRd (table 5-3). Using these new values, the accuracy plots for QAlqt (fig. 5-3) and QRd (fig. 5-5) are much more in control than when the older target values were used (Fey and others, 2008). Meaning that the results fall within the set parameters, which in this case are \pm 15 percent Recovery. Even with the new target values, the results for many elements determined in SRM QAlqt are biased low (fig. 5-3).

The precision chart for analytical duplicates derived from the Pebble project soils (fig. 5-1) shows significantly more variation than either of the Skyline Laboratory SRMs, with most values ranging between 3 and 25 percent RSD. It appears that the Pebble project soils are less homogeneous than either of the Skyline Laboratory SRMs. Two elements show significant variation for the analytical duplicates: $\mathrm{Ni}$ at 45 percent $\mathrm{RSD}$ and $\mathrm{Pb}$ at 95 percent RSD (fig. 5-1, table 5-1). Most of this variation for both of these elements can be attributed to significant differences between analytical values within a single duplicate sample pair. Removing this one sample pair from the analysis reduces the precision statistic for Ni to 6 percent $\mathrm{RSD}$ and $\mathrm{Pb}$ to 27 percent RSD.

\section{Skyline Assayers and Laboratories Enzyme Leach of 2008 Soils}

Two batches of 2008 field season soil samples were sent to Skyline Labs. The first set of samples was collected in July of 2008 and the second set was collected in September 2008. Skyline Labs inserted twelve quality control samples into those two batches of soil samples: six samples of their laboratory reference material QAlqt and six samples of their laboratory reference material QRd. Four more quality control samples were submitted by the USGS: two samples of the Pebble project reference material $\mathrm{PB}-\mathrm{SMM}$ and two samples of the Pebble project reference material PB-SNP. In addition, Skyline Labs selected 14 of the submitted soil samples (the first, the last, and every tenth sample in each batch) to be analyzed as analytical duplicates.

For the 2008 field season, Appendix 4 contains five tables of summary statistics for the Skyline Labs quality control samples: analytical duplicates (table 5-4), laboratory SRM QAlqt (table 5-5), laboratory SRM QRd (table 5-6), Pebble project SRM PB-SMM (table 5-7), and Pebble project SRM PB-SNP (table 5-8). These results are also represented in seven quality control charts: precision (percent RSD) of analytical duplicates (fig. 5-6), precision of SRM QAlqt (fig. 5-7), accuracy (percent Recovery) of SRM QAlqt (fig. 5-8), precision of SRM QRd (fig. 5-9), accuracy of SRM QRd (fig. 5-10), precision of Pebble project SRM PB-SMM (fig. 5-11), and precision of Pebble project SRM PB-SNP (fig. 5-12).

The precision graphs for analytical SRMs QAlqt (fig. 5-7) and QRd (fig. 5-9) show excellent results with only a few elements exceeding 15 percent RSD and none above 25 percent RSD for either SRM. Based on the 2009 updated target values, accuracy plots for SRMs QAlqt (fig. 5-8) and QRd (fig. 5-10) show very few elements that fall outside the desired percent Recovery limits. However, both of these accuracy plots have many elements that are slightly biased toward the high side of 100 percent. This differs from the 2007 results for these same SRMs (figs. 5-3 and 5-4) where many elements show a bias in percent Recovery below 100 percent.

As was noted for the 2007 field season, there is significantly more variation in the precision of analytical duplicates derived from the Pebble project soils (fig. 5-6) than there is in the Skyline Laboratory SRMs. Most elements are below 25 percent RSD and the removal of just one duplicate sample pair reduces 15 of these elements below the 15 percent RSD threshold. Seven elements have percent RSD values above 15 percent that appear to be associated with variation in multiple duplicate sample pairs: $\mathrm{Au}, \mathrm{Cl}, \mathrm{Cu}, \mathrm{Pb}, \mathrm{Ta}, \mathrm{Ti}$, and $\mathrm{Zn}$. This suggests that the variation seen in the analytical duplicates (fig. 5-6) reflects inhomogeneity within the Pebble soils samples that may be due, in part, to the "nugget effect." The evaluation of a very limited number of the Pebble project SRMs PB-SMM (fig. 5-11) and PB-SNP (fig. 5-12) also suggests some problems with reproducibility due to sample inhomogeneity in the Pebble soils. Based on only two samples of each Pebble project SRM, Cl, Se, W, and Zn exceed 15 percent RSD for PB-SMM (fig. 5-11) and $\mathrm{Au}, \mathrm{Ga}, \mathrm{Pb}$, and $\mathrm{W}$ exceed 15 percent RSD for PB-SNP (fig. 5-12).

\section{Skyline Assayers and Laboratories Enzyme Leach of 2009 Soils}

Within the batch of 2009 field season soil samples that were analyzed using the proprietary Enzyme Leach method, Skyline Labs included nine laboratory reference quality control samples: three samples of QAlqt, three samples of QRd, and three samples of QMthd60. Four more quality control samples were submitted by the USGS: two samples of the Pebble project reference material PB-SMM and two samples of the Pebble project reference material PB-SNP. In addition, Skyline Labs selected four of the submitted soil samples (the first, the last, and every tenth sample in each batch) to be analyzed as analytical duplicates.

Appendix 4 contains five tables of summary statistics for the Skyline Labs quality control samples associated with the 2009 field season samples: Analytical duplicates (table 5-9), laboratory SRM QAlqt (table 5-10), laboratory SRM QRd (table 5-11), Pebble project SRM PB-SMM (table 5-12), and Pebble project SRM PB-SNP (table 5-13). These results are also represented in nine quality control charts: precision (percent RSD) of analytical duplicates (fig. 5-13), precision of SRM QAlqt (fig. 5-14), accuracy (percent Recovery) of SRM QAlqt (fig. 5-15), precision of SRM QRd (fig. 5-16), accuracy of SRM QRd (fig. 5-17), precision of Pebble project SRM PB-SMM (fig. 5-18), accuracy of Pebble project 
SRM PB-SMM (fig. 5-19), precision of Pebble project SRM PB-SNP (fig. 5-20), and accuracy of Pebble project SRM PB-SNP (fig. 5-21). Appendix 4 does not contain any results for laboratory SRM QMthd60 because the evaluation of these quality control samples did not add anything unexpected to the discussion that follows.

The precision graphs for analytical SRMs QAlqt (fig. 5-14) and QRd (fig. 5-16) show excellent results with only $\mathrm{Hg}$ in QAlqt exceeding 15 percent RSD. Accuracy plots for SRMs QAlqt (fig. 5-15) and QRd (fig. 5-17) also show very few elements that fall outside the desired percent Recovery limits. As was the case with the 2008 field season data, both of these accuracy plots have many elements that are slightly biased toward the high side of 100 percent. This is similar to the results noted for the 2008 analyses for these same SRMs. The 2007 field season results have many elements with a bias in recovery below 100 percent and may need to be interpreted separately from the 2008 and 2009 data.

The precision results for 2009 season analytical duplicates (fig. 5-13) are based on only 4 duplicate sample pairs; unlike the 2007 season with 10 pairs and the 2008 season with 14 pairs. This may explain why there is less variation than that shown in 2007 (fig. 5-1) and 2008 (fig. 5-6). Still, the values for $\mathrm{I}, \mathrm{Pb}$, and $\mathrm{W}$ exceed 15 percent RSD in the 2009 analytical duplicates (fig.5-13) and probably reflect the same issue with inhomogeneity and the "nugget effect" noted in the previous years. Likewise precision charts for the very limited number of the Pebble project SRMs, PB-SMM (fig. 5-18) and PB-SNP (fig. 5-20), analyzed in 2009 show very good results with only $\mathrm{Au}$ and $\mathrm{Pb}$ exceeding 15 percent RSD in the 2 samples of $\mathrm{PB}-$ SMM (fig. 5-18).

Using the mean values from the 2008 field season analysis of the two Pebble project SRMs as target values (tables 5-7 and 5-8), accuracy charts were prepared for the 2009 analyses of PB-SMM (fig. 5-19) and PB-SNP (fig. 5-21). These results are very semi-quantitative because the 2008 mean values are based on the analysis of only two samples for each Pebble project SRM and these are being compared to the mean values of only two samples each that were analyzed in 2009 . The scatter in these two accuracy plots (figs. 5-19 and 5-21) is thought to be reflective of the same homogeneity issues discussed above.

\section{Skyline Assayers and Laboratories TerraSol Leach of 2007 Soils}

The 2007 field season soil samples submitted to Skyline Labs for Enzyme Leach determinations were also used for a TerraSol leach analysis. Skyline Labs inserted 16 quality control samples into the analytical batch: 10 analytical duplicates, 3 samples of the laboratory reference material FA, and 3 blanks. Because project samples were sent to Skyline Labs without preparation (as requested) immediately upon return from the field, no USGS quality control samples were included.
Appendix 4 contains two tables of summary statistics for the Skyline Labs quality control samples associated with the 2007 field season samples: analytical duplicates (table 6-1) and laboratory SRM FA (table 6-2). These results are also represented in two quality control charts: Precision (percent RSD) of analytical duplicates (fig. 6-1) and precision of SRM FA (fig. 6-2). The results returned for analytical blanks are not listed in this report but all values were less than the reporting limits for the method.

Skyline Labs differentiates element analyses in their TerraSol leach method as either quantitative or semi-quantitative. The quality control charts for analytical duplicates (fig. 6-1) and Skyline Laboratory SRM FA (fig. 6-2) show that almost all of the elements analyzed have acceptable levels of precision. The only exceptions are the semi-quantitative analyses for $\mathrm{S}$ and $\mathrm{Hg}$. The high variation in $\mathrm{S}$ (86 percent RSD) shows up in the analysis of analytical duplicates (table 6-1, fig. 6-1), where only 2 of the 10 analytical duplicate pairs have detectable $\mathrm{S}$. The results from these 2 sample pairs are highly variable $(1,680 \mathrm{ppm}$ vs. $2,120 \mathrm{ppm} \mathrm{S}$; and $<10 \mathrm{ppm}$ vs. $808 \mathrm{ppm} \mathrm{S}$ ). Sulfur shows much better reproducibility in the Skyline Laboratory SRM FA (14 percent RSD; table 6-2, fig. 6-2).

The results from the semi-quantitative analysis of $\mathrm{Hg}$ show a large amount of variability in the analytical duplicates (113 percent RSD; table 6-1, fig. 6-1) and SRM FA (102 percent RSD; table 6-2, fig. 6-2). The actual analytical data also show poor reproducibility for $\mathrm{Hg}$ analyses in most of the quality control samples.

\section{Skyline Assayers and Laboratories TerraSol Leach of 2008 Soils}

For the 2 batches of soil samples submitted from the 2008 field season, Skyline Labs inserted 12 quality control samples into the analytical batches: 6 samples of their laboratory analytical reference material QAlqt and 6 samples of their laboratory analytical reference material QRd. Four quality control samples were submitted by the USGS: two samples of the Pebble project analytical reference material PB-SMM, and two samples of the Pebble project analytical reference material PB-SNP. Skyline Labs selected fourteen analytical duplicates from the batch of soil samples. The results for analytical blanks were not included in the Skyline Labs QC reports.

Appendix 4 contains five tables of summary statistics for the Skyline Labs quality control samples: analytical duplicate pairs (table 6-3), laboratory SRM QAlqt (table 6-4), laboratory SRM QRd (table 6-5), Pebble project SRM PB-SMM (table 6-6), and Pebble project SRM PB-SNP (table 6-7). These results are also represented in seven quality control charts: precision (percent RSD) of analytical duplicates (fig. 6-3), precision of SRM QAlqt (fig. 6-4), accuracy (percent Recovery) of SRM QAlqt (fig. 6-5), precision of SRM QRd (fig. 6-6), accuracy of SRM QRd (fig. 6-7), precision 
of Pebble project SRM PB-SMM (fig. 6-8), and precision of Pebble project SRM PB-SNP (fig. 6-9).

The quality control charts for TerraSol Leach of the Skyline Labs' QAlqt and QRd SRMs (figs. 6-4, 6-5, 6-6, and 6-7) and the Pebble project PB-SMM and PB-SNP SRMs (figs. 6-8 and 6-9) show well-constrained results for all elements except Hg. Unlike the results from the 2007 field season (fig. 6-1), the precision for analytical duplicates from 2008 (fig. 6-3) shows 16 elements above the 15 percent control limit. An examination of the analytical data showed that the removal of just one of the 14 analytical duplicate sample pairs reduced the variability of 11 elements $(\mathrm{Bi}, \mathrm{Cu}, \mathrm{Dy}, \mathrm{Er}, \mathrm{Ho}$, In, $\mathrm{Lu}, \mathrm{Tm}, \mathrm{Y}, \mathrm{Yb}$, and $\mathrm{U}$ ) to levels below the desired 15 percent control limit. It seems likely that this one duplicated sample is inhomogeneous for these elements. Although Fe, Mn, V, and $\mathrm{Zn}$ remained above the control limit after removing this single duplicated sample pair, the lack of issues for these elements in any of the other control samples suggests that they are not a systematic problem and may represent minor heterogeneity in sample material. However, like that seen in the other quality control results for the 2008 field season, $\mathrm{Hg}$ shows up again as a problem in the analytical duplicates data (table 6-3, fig. 6-4).

\section{Skyline Assayers and Laboratories TerraSol Leach of 2009 Soils}

For the 2009 field season soil samples, Skyline Labs inserted nine quality control samples of their laboratory analytical reference materials into the analytical batches: three samples of QAlqt, three samples of QRd, and three samples of QMthd60. Four quality control samples of Pebble project analytical reference material were also submitted by the USGS: two samples of PB-SMM, and two samples of PB-SNP. Four analytical duplicates were selected by Skyline Labs from the batch of soil samples.

Appendix 4 contains six tables of summary statistics for the Skyline Labs quality control samples associated with the 2009 field season soils: analytical duplicate pairs (table 6-8), laboratory SRM QAlqt (table 6-9), laboratory SRM QRd (table 6-10), laboratory SRM QMthd60 (table 6-11), Pebble project SRM PB-SMM (table 6-12), and Pebble project SRM PB-SNP (table 6-13). These results are also represented in 11 quality control charts: precision (percent RSD) of analytical duplicates (fig. 6-10), precision of SRM QAlqt (fig. 6-11), accuracy (percent Recovery) of SRM QAlqt (fig. 6-12), precision of SRM QRd (fig. 6-13), accuracy of SRM QRd (fig. 6-14), precision of SRM QMthd60 (fig. 6-15), accuracy of SRM QMthd60 (fig. 6-16), precision of Pebble project SRM PB-SMM (fig. 6-17), accuracy of Pebble project SRM PB-SMM (fig. 6-18), precision of Pebble project SRM PBSNP (fig. 6-19), and accuracy of Pebble project SRM PB-SNP (fig. 6-20).

Except for $\mathrm{Hg}$, the quality control charts show excellent results for analytical precision by the TerraSol Leach method (figs. 6-10, 6-11, 6-13, 6-15, 6-17, and 6-19). The analytical accuracy results for Skyline Labs' laboratory analytical reference materials (figs. 6-12, 6-14, and 6-16) were acceptable but do show more scatter than is desired. This is especially true for $\mathrm{Sr}$ and the semi-quantitative elements $\mathrm{Ca}, \mathrm{K}$, and $\mathrm{Na}$ and, to a lesser extent, for $\mathrm{Ba}, \mathrm{Mg}$, and $\mathrm{Mn}$ as well. Mercury again is problematic and this is illustrated best by the percent Recovery value of 535 percent obtained for analyses of the SRM QRd (table 6-10, fig. 6-14).

Accuracy (percent Recovery) charts were prepared for the two Pebble project reference materials PB-SMM (fig. 6-18) and PB-SNP (fig. 6-20). The target values for these charts are the mean values obtained for the TerraSol Leach analyses of these standards in 2008 (PB-SMM table 6-6; PB-SNP table 6-7). Because these target values are based on a very small number of analyses, the results are only semiquantitative but they do provide a way to evaluate analytical variability between field seasons. Considering the limitations of these comparisons, the mean values for the 2009 field season are very similar to the means of the 2008 field season with most falling between 85 and 115 percent Recovery. Among those that exceed these desired limits are the same elements that were noted for Skyline's laboratory analytical reference materials QAlqt, QRd, and QMthd60 (Ba, Ca, K, Mg, Mn, $\mathrm{Na}$, and $\mathrm{Sr}$ ). This pattern suggests that the 2009 field season analytical results for these elements may be biased high when compared with the results from the 2007 and 2008 seasons. The results for $\mathrm{Zn}$ in the two Pebble project reference materials PB-SMM (fig. 6-18) and PB-SNP (fig. 6-20) are also high when compared to the means obtained for these materials in 2008. The reason for that could not be determined.

\section{SGS Mineral Services Metal Mobile Ion Leach of 2007 Soils}

SGS Minerals inserted 11 quality control samples into the batch of 2007 field season soil samples analyzed by their proprietary MMI Leach: 7 analytical duplicates, 2 samples of the laboratory reference material MMISRM14, and 2 blanks. Because project samples were sent to SGS Minerals without preparation (as requested) immediately upon return from the field, no USGS quality control samples were included.

Appendix 4 contains two tables of summary statistics for the SGS Minerals quality control samples: Analytical duplicates (table 7-1) and laboratory SRM MMISRM14 (table 7-2). These results are also represented in three quality control charts: precision (percent RSD) of analytical duplicates (fig. 7-1), precision of SRM MMISRM14 (fig. 7-2), and accuracy (percent Recovery) of SRM MMISRM14 (fig. 7-3). The results returned for analytical blanks are not listed in this report but all values were less than the reporting limits for the method.

The precision plot based upon the results of two analyses of the MMISRM14 standard reference material (fig. 7-2) shows excellent control for the analytical variation with the single exception of $\mathrm{Pb}$ ( 39 percent RSD). One of the 2 
analyses of MMISRM14 returned a value for $\mathrm{Pb}$ that is nearly twice the target value of $120 \mathrm{ppb}$ (table 7-2). Because of the small sample set, it could not be determined whether $\mathrm{Pb}$ poses an analytical problem or whether the variation is due to sample inhomogeneity. The percent RSD chart for analytical duplicates selected from Pebble project soils (fig. 7-1) shows less precision for some elements than for laboratory SRM. This suggests that the Pebble project soils are less homogeneous then the laboratory standard reference material.

\section{ALS Minerals Cold Hydroxylamine Hydrochloride Leach of 2007 Soils}

Eleven quality control samples were inserted by ALS Minerals into the batch of 2007 field season soil samples analyzed by their cold hydroxylamine hydrochloride soil leach method: 5 analytical duplicates, 2 samples of the laboratory reference material LK3-ALG, 2 samples of the laboratory reference material LK4-ALG, and 2 blanks. Fifteen additional quality control samples were submitted by the USGS: 5 analytical duplicates, 5 samples of the USGS standard reference material SAR-L, and 5 samples of the Pebble project soil standard PB-SMM. All 10 of the analytical duplicate pairs were assessed together for this data set.

Appendix 4 contains five tables of summary statistics for quality control samples analyzed for the 2007 field season by the ALS Minerals cold hydroxylamine hydrochloride soil leach method: Analytical duplicates (table 8-1), laboratory SRM LK3-ALG (table 8-2), laboratory SRM LK4-ALG (table 8-3), USGS SRM SAR-L (table 8-4), and Pebble project standard PB-SMM (table 8-5). These results are also represented in seven quality control charts: precision (percent RSD) of analytical duplicates (fig. 8-1), precision of SRM LK3-ALG (fig. 8-2), accuracy (percent Recovery) of SRM LK3-ALG (fig. 8-3), precision of SRM LK4-ALG (fig. 8-4), accuracy of SRM LK4-ALG (fig. 8-5), precision of SRM SAR-L (fig. 8-6), and precision of Pebble project standard PB-SMM (fig. 8-7). The results returned for analytical blanks are not listed in this report but all values were less than the reporting limits for the method.

The quality control charts for the ALS Minerals cold hydroxylamine hydrochloride leach of soils (figs. 8-1, 8-2, 8-4, and 8-6) show excellent results for the repeatability of analyses. The only elements that exceed 15 percent RSD and are detected at greater than 5 times the reporting limit are $\mathrm{Ag}$ (17 percent RSD; fig. 8-1, table 8-1) in the analytical duplicates and $\mathrm{Cr}$ in the USGS SRM SAR-L (29 percent RSD; fig. 8-6, table 8-4). Because none of the other precision charts have problems for these elements, this variation is not considered to be a significant problem.

The accuracy chart for LK4-ALG (fig. 8-5) has 4 elements $(\mathrm{Cr}, \mathrm{Cs}, \mathrm{Ga}$, and $\mathrm{Tm})$ with mean values at least 5 times greater than their reporting limit, that also exceed the desired upper control limit of 115 percent Recovery. Analytical results for these elements may be biased high.

\section{ALS Minerals Cold Hydroxylamine Hydrochloride Leach of 2008 Soils}

Eight quality control samples were inserted by ALS Minerals into the batch of 2008 field season soil samples analyzed by their cold hydroxylamine hydrochloride soil leach method: one sample of laboratory reference material LK3-ALG, two samples of laboratory reference material LK4-ALG and five analytical duplicates chosen by ALS Minerals from submitted soil samples. Ten additional quality control samples were submitted by the USGS: 2 samples of USGS standard reference material SAR-L, and 8 samples of Pebble project standard PB-SMM.

Appendix 4 contains three tables of summary statistics for quality control samples analyzed by the ALS Minerals cold hydroxylamine hydrochloride soil leach method: analytical duplicates (table 8-6), laboratory SRM LK4-ALG (table 8-7), and Pebble SRM PB-SMM (table 8-8). These results are also represented in five quality control charts: precision (percent RSD) of analytical duplicates (fig. 8-8), precision of laboratory SRM LK4-ALG (fig. 8-9), accuracy (percent Recovery) of laboratory SRM LK4-ALG (fig. 8-10), precision of Pebble SRM PB-SMM (fig. 8-11), and accuracy of Pebble SRM PBSMM (fig. 8-12). The mean values from the 2007 analyses of Pebble project SRM PB-SMM (table 8-5) were used as target values for the 2008 analyses of PB-SMM. The results returned for laboratory SRMs LK3-ALG and USGS SRM SAR-L are not reported here due to the small number of samples analyzed.

The analytical precision charts for the SRM LK4-ALG (fig. 8-9) and SRM PB-SMM (fig. 8-11) show excellent results. The precision results for the 5 analytical duplicate pairs (fig. 8-8) show more than the desired variation for at least 10 elements with mean values greater than 5 times their respective reporting limits. Most of this variation is due to the results for just two of the five duplicate sample pairs and probably reflects some inhomogeneity of the sample material. The accuracy of analyses for Pebble project SRM PB-SMM (fig. $8-12$ ) is generally quite good compared to the mean concentrations of the 2007 analyses with only Ag, Cs, I, and U values falling outside of the desired recovery range. Similar to the results noted for the SRM LK4-ALG 2007 analyses (fig. 8-5), the accuracy chart for the 2008 analyses of LK4-ALG (fig. 8-10) has four elements ( $\mathrm{Cr}, \mathrm{Cs}, \mathrm{Lu}$, and $\mathrm{Tm})$ with mean values at least 5 times greater than their reporting limit, that also exceed the desired upper control limit of 115 percent Recovery. The mean values for $\mathrm{Ga}$ and $\mathrm{Lu}$ for both years (tables 8-3 and 8-7) are so close to the "five times the Reporting Limit" cutoff, that they both show up as valid values in one of the two charts (figs. 8-5 and 8-10) and "less than" values in the other of the two charts. 


\section{ALS Minerals Cold Hydroxylamine Hydrochloride Leach of 2009 Soils}

Only three quality control samples were inserted by ALS Minerals into the 2009 field season soil samples that were analyzed by the cold hydroxylamine hydrochloride soil leach method: one sample of laboratory reference material LK3ALG, one sample of laboratory reference material LK4-ALG, and one analytical duplicate sample chosen by ALS Minerals from submitted soil samples. Two samples of Pebble project standard PB-SMM were also submitted by the USGS.

For the 2009 field season, Appendix 4 contains three tables of summary statistics for quality control samples: analytical duplicates (table 8-9), laboratory SRMs LK3-ALG and LK4-ALG (table 8-10), and Pebble SRM PB-SMM (table $8-11)$. These results are also represented in four quality control charts: precision (percent RSD) of analytical duplicates (fig. 8-13), accuracy (percent Recovery) of laboratory SRM LK3ALG (fig. 8-14), accuracy of laboratory SRM LK4-ALG (fig. 8-15), and precision of Pebble SRM PB-SMM (fig. 8-16).

Because only one sample each of LK3-ALG and LK4ALG were analyzed for the 2009 field season soils, it is only possible to evaluate the accuracy (percent Recovery) for these ALS Minerals laboratory SRMs (figs. 8-14 and 8-15). The results were acceptable although a few elements may be biased high in SRM LK3-ALG (fig. 8-14). The analytical duplicates (fig. 8-13) also show very good precision results with all values below 15 percent RSD and only one value greater than 10 percent RSD. Like many analyses there are a number of elements with means "less than five times the reporting limit" that exceed the desired control limits This chart for a single duplicate sample pair (fig. 8-13) does not show the inhomogeneity for some Pebble soil samples that was noted in analytical duplicates from 2008 (fig.8-8). Likewise, the precision results for the two samples of Pebble project SRM PB-SMM (fig. 8-16) all fall below 15 percent RSD.

\section{ALS Minerals Ionic Leach of 2007 and 2008 Soils}

In 2008, the Ionic Leach method of ALS Minerals was added to the battery of analytical methods used on the Pebble soil samples. Splits of archived sample material from the 2007 field season were sent to ALS Minerals along with the batch of 2008 field season samples. Because all of these samples were analyzed at about the same time, the quality control samples from both seasons can be evaluated together.

ALS Minerals inserted seven samples of laboratory reference material ION-SRM18 into these batches of soil samples. In addition, the USGS submitted 18 more quality control samples: 4 samples of USGS standard reference material SAR-L and 14 samples of Pebble project standard PB-SMM. Thirteen analytical duplicates were selected by ALS Minerals for analysis from the submitted soil samples but only one had sufficient material to be analyzed a second time and so these results were not evaluated.
Appendix 4 contains three tables of summary statistics for quality control samples analyzed by the ALS Minerals Ionic Leach method: laboratory SRM ION-SRM18 (table 9-1), USGS SRM SAR-L (table 9-2), and Pebble project SRM PB-SMM (table 9-3). These results are also represented in four quality control charts: precision (percent RSD) of laboratory SRM ION-SRM18 (fig. 9-1), accuracy (percent Recovery) of laboratory SRM ION-SRM18 (fig. 9-2), precision of USGS SRM SAR-L (fig. 9-3), and precision of Pebble project SRM PB-SMM (fig. 9-4).

The laboratory SRM ION-SRM18 data table (table 9-1) and quality control charts (figs. 9-1 and 9-2) show excellent results for elements with values having a mean greater than five times the reporting limit. On the ION-SRM18 precision chart (fig. 9-1), only $\mathrm{Cr}$ exceeds the 15 percent RSD control limit at 21 percent. The associated accuracy chart (fig. 9-2) shows all elements within the 85-115 percent Recovery control limits except for Ti at 79 percent.

The summary statistics table (table 9-2) and precision chart (fig. 9-3) for USGS SRM SAR-L show that roughly half of the elements are above 15 percent RSD. Of these, the highest value is $\mathrm{Pd}$ at 81 percent. Similar results are seen for the Pebble SRM PB-SMM (table 9-3; fig. 9-4) where most element values with a mean greater than 5 times the reporting limit actually exceed 15 percent RSD, and all but 2 elements $(\mathrm{Rb}$ and $\mathrm{Tb})$ are above 10 percent RSD. The behavior of the Pebble SRM PB-SMM (fig. 9-4) results suggests that Pebble soil samples may not respond in a homogeneous manner to Ionic Leach analyses. This does not invalidate the use of Ionic Leach analyses because the expected elemental ranges in mineralized areas may cover several orders of magnitude concentration, and so individual element variation on the order of 50 percent RSD will not significantly change the interpretations.

\section{ALS Minerals Ionic Leach of 2009 Soils}

For the 2009 field season soil samples, ALS Minerals inserted three quality control samples of laboratory SRM ION-SRM18. They also chose two of the Pebble soils to reanalyze as analytical duplicates. Unfortunately, only one of these samples had sufficient material to run a second analysis. The USGS also submitted three quality control samples: one sample of USGS standard reference material SAR-L and two samples of the Pebble project standard PB-SMM.

Appendix 4 contains three tables of summary statistics for quality control samples analyzed in 2009 by the ALS Minerals Ionic Leach method: analytical duplicates (table 9-4), laboratory SRM ION-SRM18 (table 9-5), and Pebble project SRM PB-SMM (table 9-6). These results are also represented in four quality control charts: precision (percent RSD) of analytical duplicates (fig. 9-5), precision of laboratory SRM ION-SRM18 (fig. 9-6), accuracy (percent Recovery) of laboratory SRM ION-SRM18 (fig. 9-7), and precision of Pebble SRM PB-SMM (fig. 9-8). Accuracy charts, with target values based on the mean values obtained for analyses in the previous years, were not included for USGS SRM SAR-L and 
Pebble SRM PB-SMM because the high variability noted in the respective 2007-2008 charts (figs. 9-3 and 9-4) precluded the reliability of any chosen value.

The precision plot for SRM ION-SRM18 (fig. 9-6) shows a little more variability than expected for a conservative 15 percent RSD control limit. Although most elements fall below this line, there are 10 elements that plot between 15 and 30 percent RSD. Among the elements with means greater than 5 times the reporting limit, only Ti exceeds 30 percent RSD. Despite the variability noted in precision, an accuracy plot for SRM ION-SRM18 (fig. 9-7) gives excellent results with only Ti falling well outside of the desired range of percent Recovery.

Despite the fact that there is only a single pair of analytical duplicate sample analyses, a precision chart (fig. 9-5) was created to evaluate variability. It is unfortunate that only one of the samples chosen for duplicate analyses had sufficient material because a full evaluation of analytical duplicates would give a better picture on how much variability could be expected in Pebble soil samples analyzed by Ionic Leach. Based on this single pair, the precision plot (fig. 9-5) gives very good results with only five elements exceeding 15 percent RSD and all elements with "means greater than 5 times their reporting limit" are less than 30 percent RSD. The Pebble project SRM PB-SMM, created by homogenizing a large amount of excess Pebble soil sample material collected in 2007, was also expected to provide a means for evaluating the variability of Pebble soils analyzed by various analytical leach methods. However, the results for two PB-SMM samples submitted to ALS Minerals in 2009 (fig. 9-8) show so much variation that it is suspected at least one of these samples was somehow switched before analysis. An evaluation of the entire batch of 2009 results shows that there is no other sample analyzed in 2009 with chemistry that matches either of the two PB-SMM samples. Therefore if a misidentified sample was included as PB-SMM, that error occurred before the samples were submitted to ALS Minerals.

\section{ALS Minerals Sodium Pyrophosphate Leach of 2007 Soils}

ALS Minerals inserted 17 quality control samples into the 2007 field season soil samples analyzed by their sodium pyrophosphate leach method: 5 analytical duplicates, 4 samples of the laboratory reference material LK3-PYR, 4 samples of the laboratory reference material LK4-PYR, and 4 blanks. The USGS submitted 15 additional quality control samples: 5 analytical duplicates, 5 samples of the USGS standard reference material SAR-L, and 5 samples of the Pebble project A-horizon soil standard PB-SNP. All 10 of the analytical duplicate pairs were assessed together for this data set.

Appendix 4 contains five tables of summary statistics for quality control samples analyzed by the ALS Minerals sodium pyrophosphate leach method: Analytical duplicates (table 10-1), laboratory SRM LK3-PYR (table 10-2), laboratory SRM LK4-PYR (table 10-3), USGS SRM SAR-L (table 10-4), and Pebble project standard PB-SNP (table 10-5). These results are also represented in seven quality control charts: precision (percent RSD) of analytical duplicates (fig. 10-1), precision of SRM LK3-PYR (fig. 10-2), accuracy (percent Recovery) of SRM LK3-PYR (fig. 10-3), precision of SRM LK4-PYR (fig. 10-4), accuracy of SRM LK4-PYR (fig. 10-5), precision of SRM SAR-L (fig. 10-6), and precision of Pebble project standard PB-SNP (fig. 10-7).

The results returned for analytical blanks are not listed in this report but all values were no higher than two times the lower reporting limits for the method (that is, an element with a reporting limit of $0.05 \mathrm{ppm}$ may report values between $<0.05$ and $0.10 \mathrm{ppm}$ ). The one exception was $\mathrm{Br}$. With a reporting limit of $2 \mathrm{ppm}$ for $\mathrm{Br}$, the last two of the four blanks had values of 2, whereas the first two had values of 29 and $59 \mathrm{ppm} \mathrm{Br}$. A similar problem for $\mathrm{Br}$ was noted for the standard reference materials LK3-PYR (figs. 10-2 and 10-3) and LK4-PYR (figs. 10-4 and 10-5). In each case, two of the four analyses had very high $\mathrm{Br}$ values while the other two analyses had values near the target values. Although not confirmed, it appears that ALS Minerals may have noted the Br problem in their blanks and standard reference materials and corrected the problem for all of the submitted samples. No problems with $\mathrm{Br}$ are noted in the analytical duplicates of Pebble project soils (table 10-1, fig. 10-1), the USGS-submitted SRM SAR-L (table 10-4, fig. 10-6), or the Pebble project A-horizon soil standard PB-SNP (table 10-5, fig. 10-7).

Although most of the analyzed elements fall within the desired parameters for repeatability, three elements have problems in multiple data sets. Silver has high percent RSD values in the analytical duplicates (table 10-1, fig. 10-1), the laboratory SRM LK3-PYR (table 10-2, fig. 10-2), and the USGS SRM SAR-L (table 10-4, fig. 10-6). Bismuth has high percent RSD or percent Recovery values in the analytical duplicates (table 10-1, fig. 10-1), the laboratory SRM LK4PYR (table 10-3, figs. 10-3 and 10-4), the USGS-submitted SRM SAR-L (table 10-4, fig. 10-6), and the Pebble project soil standard PB-SNP (table 10-5, fig. 10-7). Similarly, Th has high percent RSD or percent Recovery values in the laboratory SRM LK3-PYR (table 10-2, fig. 10-3), the laboratory SRM LK4-PYR (table 10-3, figs. 10-3 and 10-4), the USGS-submitted SRM SAR-L (table 10-4, fig. 10-6), and the Pebble project soil standard PB-SNP (table 10-5, fig. 10-7). This suggests that the sodium pyrophosphate leach method has problems reproducing results for $\mathrm{Ag}, \mathrm{Bi}$, and $\mathrm{Th}$ in Pebble soil samples.

\section{Acme Analytical Laboratories, Ltd., Aqua Regia Leach of 2007 Soils}

Fifteen USGS quality control samples were included with the 2007 field season soil samples submitted to Acme Labs for aqua regia leach: 5 analytical duplicates, 5 samples of the USGS standard reference material SAR-L, and 5 samples of the Pebble project soil standard PB-SMM. Acme 
Labs inserted five more analytical duplicates, three samples of their laboratory standard reference material DS7, and three analytical blanks. All 10 of the analytical duplicate pairs were assessed together for this data set.

Appendix 4 contains four tables of summary statistics for quality control samples analyzed in 2007 by the Acme Labs aqua regia leach method: Analytical duplicates (table 11-1), laboratory SRM DS7 (table 11-2), USGS SRM SAR-L (table 11-3), and Pebble project standard PB-SMM (table 11-4). These results are also represented in five quality control charts: precision (percent RSD) of analytical duplicates (fig. 11-1), precision of SRM DS7 (fig. 11-2), accuracy (percent Recovery) of SRM DS7 (fig. 11-3), precision of SRM SAR-L (fig. 11-4), and precision of Pebble project standard PB-SMM (fig. 11-5). The results returned for analytical blanks are not listed in this report but all values were less than the reporting limits for the method.

Almost all of the 36 elements reported by the Acme Labs aqua regia leach data fall within the quality control limits of this assessment. Only B and S could not be assessed due to the proximity of values to the lower reporting limits of the method. Five other elements show variations that merit comment.

Potassium and sodium values for the laboratory SRM DS7 had percent Recovery values of 126 percent and 130 percent, respectively (table 11-2, fig. 11-3). However, neither of these elements shows problems with precision for any of the other quality control samples. This suggests that although $\mathrm{K}$ and $\mathrm{Na}$ may be biased a little high, interpretations based on their geographic distribution and relative concentrations should be permissible.

When looking at the results of analytical duplicates (table 11-1, fig. 11-1), Cu has a slightly high percent RSD value of 19 percent. Much of this variation is due to a single analytical duplicate pair with very high concentrations of copper $(1,750$ ppm versus $1,580 \mathrm{ppm}$ ). This suggests that $\mathrm{Cu}$ concentrations may be more variable at higher concentration in the samples, but should not present a problem for interpreting the data.

Problems with the precision of gold determinations are evident from the results of analytical duplicates (table 11-1, fig. 11-1), USGS SRM SAR-L (table 11-3, fig. 11-4), and Pebble project standard PB-SMM (table 11-4, fig. 11-5). It is known that the USGS SRM SAR-L has particulate gold grains that often return variable results from any analysis. This "nugget effect" problem is also suspected in soil samples collected in the Pebble project area. Therefore these gold data should be interpreted with care, not because of analytical variability in the Acme Labs aqua regia method, but because of a lack of homogeneity for gold in the soil samples.

The reproducibility of mercury is also variable in the analysis of analytical duplicates (table 11-1, fig. 11-1) and, to a lesser extent, in the USGS SRM SAR-L (table 11-3, fig. 11-4). The percent RSD for all 10 analytical pairs is 290 percent. Removing one duplicate pair with very different concentration values ( $3.49 \mathrm{ppm}$ versus $0.13 \mathrm{ppm} \mathrm{Hg}$ ) from the calculation reduces the percent RSD to 34 percent.

\section{Acme Analytical Laboratories, Ltd., Aqua Regia Leach of 2008 and 2009 Soils}

During the 2008 field season, none of the soils samples were submitted for an aqua regia leach analysis. In 2009, splits of archived 2008 field season soil samples were submitted along with the 2009 field season samples to Acme Labs for analysis by aqua regia leach. Within this batch of 2008 and 2009 samples, Acme Labs analyzed five samples of their laboratory reference material DS7 and five analytical duplicates. The USGS also submitted six samples of the Pebble project soil standard PB-SMM.

Appendix 4 contains three tables of summary statistics for quality control samples analyzed with the 2008 and 2009 soil samples: Analytical duplicates (table 11-5), laboratory SRM DS7 (table 11-6), and Pebble project standard PB-SMM (table 11-7). These results are also represented in five quality control charts: precision (percent RSD) of analytical duplicates (fig. 11-6), precision of SRM DS7 (fig. 11-7), accuracy (percent Recovery) of SRM DS7 (fig. 11-8), precision of Pebble project standard PB-SMM (fig. 11-9), and accuracy of Pebble project standard PB-SMM (fig. 11-10).

A cursory examination of any one of these data tables for 2008-2009 soils (table 11-5, for example), shows that Acme Labs changed their analytical procedures for aqua regia leach sometime after the analysis of the 2007 field season soils (See table 11-1 for an example). The new procedure or instrumentation reports analyses for 53 elements instead of 36 and has different reporting limits. A precision plot for the laboratory SRM DS7 (fig. 11-7) reports all elements below 15 percent RSD and only 4 elements (Au, Hf, Nb, and Pt) between 15 and 25 percent RSD. Similarly, the accuracy plot for DS7 (fig. 11-8) gives excellent results with only two elements $(\mathrm{Cr}$ and $\mathrm{Na}$ ) falling outside of the desired recovery range.

The precision chart for analytical duplicates (fig. 11-6) is also excellent with only $\mathrm{Au}$ and $\mathrm{Cd}$ exceeding the 15 percent RSD control limit. Likewise the precision results for the Pebble project standard PB-SMM (fig. 11-9) only has 6 elements ( $\mathrm{Au}, \mathrm{Be}, \mathrm{Cd}, \mathrm{Hg}, \mathrm{Se}$, and $\mathrm{W}$ ) that exceed 15 percent RSD. Based on mean values from the 2007 field season, an accuracy plot for PB-SMM (fig. 11-10) shows that every element is biased high. Rather than the expected range of $85-115$ percent Recovery, all but 3 elements (Au, Sc, and Ti) fall between 105-125 percent Recovery (table 11-7; fig. 11-10) for an average bias of 15 percent. This suggests that the results of the 2007 field season analyzed by a different procedure or instrumentation might benefit from being interpreted separately from the 2008-2009 field season data. However, it should be noted that the accuracy results for the laboratory SRM DS7 (fig. 11-8), using the exact same target values, do not show a similar bias between field seasons.

Another observation based on these results is that certain elements show up with higher variability in more than one quality control chart for the aqua regia method. Gold, an element well known for its "nugget effect" behavior, was repeatedly noted as exceeding the conservative control limits used in 
these evaluations. Other elements with similar results include $\mathrm{Cd}, \mathrm{Cr}, \mathrm{Hg}, \mathrm{Ti}$, and W. Higher variability for elements like these often creates a spiky pattern for anomalies along sample traverse lines.

\section{SGS Minerals Services (USGS Contract) ICPAES-MS42 Total Analysis of 2007 Soils}

Soil samples from the 2007 field season were submitted to SGS Minerals, under the USGS analytical chemistry contract, for analysis by the ICPAES-MS42 multielement package. Within each sub-batch of samples submitted, the USGS Quality Control Manager inserted selected standard reference materials. A total of seven SRMs were included in the 2007 field season soil samples submitted to SGS Minerals: three samples of the USGS standard reference material SAR-L and four samples of the USGS standard reference material SAR-M. As part of this project, the USGS also included five analytical duplicates and five samples of the Pebble project soil standard PB-SMM for quality control. SGS Minerals also inserted their own analytical duplicates, SRMs, and blanks into the batches of submitted samples but these quality control data were not retrieved for this assessment.

Appendix 4 contains four tables of summary statistics for the quality control samples from the 2007 field season: Analytical duplicates (table 12-1), USGS SRM SAR-L (table 12-2), USGS SRM SAR-M (table 12-3), and Pebble project standard PB-SMM (table 12-4). These results are also represented in six quality control charts: precision (percent RSD) of analytical duplicates (fig. 12-1), precision of USGS SRM SAR-L (fig. 12-2), accuracy (percent Recovery) of SRM SAR-L (fig. 12-3), precision of USGS SRM SAR-M (fig. 12-4), accuracy of SRM SAR-M (fig. 12-5), and precision of Pebble project standard PB-SMM (fig. 12-6).

The ICPAES-MS42 technique is a near-total digestion followed by analysis by ICP-AES and ICP-MS. The target control limits of 15 percent RSD and \pm 15 percent Recovery are more instructive here than for the previous partial-digestion techniques and are part of the normal quality control assessments of analyses done under the analytical chemistry contract with SGS Minerals. The quality control charts for the ICPAES-MS42 method show very good results for data accuracy and precision. Only a few elements slightly exceed 15 percent RSD on any of the precision charts: $\mathrm{Nb}$ in analytical duplicates (fig. 12-1), $\mathrm{Sn}$ in SAR-L (fig. 12-2), Be and Bi in SAR-M (fig. 12-4), and S in PB-SMM (fig. 12-6). The accuracy plot for SAR-L (fig. 12-3) has 3 elements (Be, $\mathrm{Cd}$, and $\mathrm{Sb}$ ) that exceed 115 percent Recovery and 4 elements (P, Sn, U, and Y) below 85 percent Recovery. Similarly, the accuracy plot for SAR-M (fig. 12-5) has 6 elements (Be, Bi, Mo, S, Sb, and Te) that exceed 115 percent Recovery and 5 elements ( $\mathrm{Sn}, \mathrm{Ti}, \mathrm{U}, \mathrm{W}$, and $\mathrm{Y}$ ) below 85 percent Recovery. The percent Recovery value for Sn in SAR-M (table 12-3) is only 31 percent.

\section{SGS Minerals Services (USGS Contract) ICPAES-MS42 Total Analysis of 2008 Soils, Sediments, and Pond-Sediment Cores}

Soil, stream sediment, pond sediment, and pond core sediment samples from the 2008 field season were submitted to SGS Minerals, using a current USGS analytical chemistry contract, for analysis by the 4-acid digestion ICPAES-MS42 multielement package. Within sub-batches of samples submitted, the USGS Quality Control Manager inserted 22 selected standard reference materials: 7 samples of the USGS standard reference material SAR-L, 8 samples of the USGS standard reference material SAR-M, 3 samples of the USGS standard reference material DGPM, and 4 samples of the USGS standard reference material GSP-QC. As part of this project, the USGS also submitted 20 samples of the Pebble project standard reference material PB-SMM. SGS Minerals selected 11 of the 2008 field season samples for a duplicate analysis. SGS Minerals also inserted their own reference materials and analytical blanks into the batches of submitted samples but these quality control data were not requested for this assessment.

Appendix 4 contains six tables of summary statistics for quality control samples from the 2008 field season: Analytical duplicates (table 12-5), USGS SRM SAR-L (table 12-6), USGS SRM SAR-M (table 12-7), USGS SRM DGPM (table 12-8), USGS SRM GSP-QC (table 12-9), and Pebble project standard PB-SMM (table 12-10). These results are also represented in 11 quality control charts: precision (percent RSD) of analytical duplicates (fig. 12-7), precision of USGS SRM SAR-L (fig. 12-8), accuracy (percent Recovery) of SRM SAR-L (fig. 12-9), precision of USGS SRM SAR-M (fig. 12-10), accuracy of SRM SAR-M (fig. 12-11), precision of USGS SRM DGPM (fig. 12-12), accuracy of SRM DGPM (fig. 12-13), precision of USGS SRM GSP-QC (fig. 12-14), accuracy of SRM GSP-QC (fig. 12-15), precision of Pebble project standard PB-SMM (fig. 12-16), and accuracy of Pebble project standard PB-SMM (fig. 12-17).

The quality control charts for the ICPAES-MS42 method show very good results for accuracy and precision of most elements. Only a few elements slightly exceed 15 percent RSD on any of the precision charts: $\mathrm{Be}, \mathrm{Sn}$, and Te in SAR-L (fig. 12-8); $\mathrm{Be}$ and $\mathrm{Nb}$ in $\mathrm{SAR}-\mathrm{M}$ (fig. 12-10); $\mathrm{Be}, \mathrm{Cr}, \mathrm{Cu}$, and $\mathrm{Pb}$ in DGPM (fig. 12-12); and $\mathrm{Be}, \mathrm{Bi}$, and $\mathrm{W}$ in PB-SMM (fig. 12-16). The accuracy plot for SAR-L (fig. 12-9) has 2 elements $(\mathrm{Be}$, and $\mathrm{Cd})$ that exceed 115 percent Recovery and 4 elements (P, Sn, U, and Y) below 85 percent Recovery. The accuracy plot for SAR-M (fig. 12-11) has 3 elements (Be, Sb, and $\mathrm{Te}$ ) that exceed 115 percent Recovery and 6 elements (P, $\mathrm{Sn}, \mathrm{Ti}, \mathrm{U}, \mathrm{W}$, and Y) below 85 percent Recovery. The percent Recovery value for Sn in SAR-M (table 12-7) is only 31 percent. The accuracy plot for DGPM (fig. 12-13) has 2 elements $(\mathrm{Be}$ and $\mathrm{Pb})$ that exceed 115 percent Recovery while the accuracy plot for GSP-QC (fig. 12-15) has 3 elements (As, Be, and 
Cr) that exceed 115 percent Recovery and only Ni below 85 percent Recovery. Many of these same elements were noted above in the evaluation of the 2007 field season precision and accuracy charts.

Mean values from the 2007 analyses of the reference material PB-SMM (table 12-4) were used as target values for the assessment of analytical accuracy for 2008 PB-SMM (fig. 12-17). Although these target values are not as robust as values for standard reference materials based on hundreds of analyses, this gives a rough measure of the variability of mean values from year to year. The results of this comparison (fig. 12-17) are excellent and provide confidence in the ICPAESMS42 method.

\section{SGS Minerals Services (USGS Contract) ICPAES-MS42 Total Analysis of 2009 Soils, Sediments, Pond-Sediment Cores, and Rocks}

For the 2009 field season, samples of soil, stream sediment, pond sediment, pond core-sediments and rocks were submitted to SGS Minerals for contract analysis by the 4-acid digestion ICPAES-MS42 multielement package. Along with these various batches of sample media, the USGS Quality Control Manager inserted two samples of USGS standard reference material SAR-L, two samples of USGS standard reference material SAR-M, five samples of the USGS standard reference material DGPM, and four samples of the USGS standard reference material GSP-QC. The USGS also submitted 10 samples of the Pebble project standard reference material PB-SMM. SGS Minerals selected five of the 2009 field season samples for a duplicate analysis. The data for laboratory quality control reference materials and analytical blanks was not requested for this assessment.

For the 2009 field season, Appendix 4 contains six tables of summary statistics for quality control samples: Analytical duplicates (table 12-11), USGS SRM SAR-L (table 12-12), USGS SRM SAR-M (table 12-13), USGS SRM DGPM (table 12-14), USGS SRM GSP-QC (table 12-15), and Pebble project standard PB-SMM (table 12-16). These results are also represented in 11 quality control charts: precision (percent RSD) of analytical duplicates (fig. 12-18), precision of USGS SRM SAR-L (fig. 12-19), accuracy (percent Recovery) of SRM SAR-L (fig. 12-20), precision of USGS SRM SAR-M (fig. 12-21), accuracy of SRM SAR-M (fig. 12-22), precision of USGS SRM DGPM (fig. 12-23), accuracy of SRM DGPM (fig. 12-24), precision of USGS SRM GSP-QC (fig. 12-25), accuracy of SRM GSP-QC (fig. 12-26), precision of Pebble project standard PB-SMM (fig. 12-27), and accuracy of Pebble project standard PB-SMM (fig. 12-28).

As in previous years, most elements reported by the ICPAES-MS42 method show very good results for accuracy and precision plots of quality control samples. Only a few elements slightly exceed 15 percent RSD on any of the precision charts: Sn and W in analytical duplicates (fig. 12-18), Te in SAR-L (fig. 12-19); and Sn and W in PB-SMM (fig. 12-27).
The accuracy plot for SAR-L (fig. 12-20) has 2 elements (Be, and $\mathrm{Te}$ ) that exceed 115 percent Recovery and three elements $(\mathrm{Cr}, \mathrm{Sn}$, and $\mathrm{U})$ below 85 percent Recovery. The accuracy plot for SAR-M (fig. 12-22) has 4 elements (Bi, $\mathrm{Nb}, \mathrm{Sb}$, and $\mathrm{Te}$ ) that exceed 115 percent Recovery and four elements $(\mathrm{Cr}, \mathrm{Sn}$, $\mathrm{U}$, and $\mathrm{W}$ ) below 85 percent Recovery. The percent Recovery value for $\mathrm{Sn}$ in SAR-M (table 12-13) is 59 percent. The accuracy plot for DGPM (fig. 12-24) has three elements (Be, Nb and $\mathrm{Ti}$ ) that exceed 115 percent Recovery and only $\mathrm{Cr}$ is below 85 percent Recovery. Finally, the accuracy plot for GSP-QC (fig. 12-26) only has $\mathrm{Nb}$ that exceeds 115 percent Recovery and 2 elements ( $\mathrm{Cr}$ and $\mathrm{Ni}$ ) below 85 percent Recovery. Many of these same elements were noted above in the evaluations of the 2007 and 2008 field season precision and accuracy charts.

The mean values from the 2007 analyses of the reference material PB-SMM (table 12-4) were used as target values for the assessment of analytical accuracy for 2009 PB-SMM (fig. 12-28). As in 2008, the results are excellent despite the limited number of analyses used to create the target values. The only elements that fall outside of the desired 85-115 percent Recovery range are $\mathrm{Nb}, \mathrm{Pb}, \mathrm{S}, \mathrm{Sn}, \mathrm{W}$, and $\mathrm{Zn}$.

In this evaluation of the three years of data returned by the ICPAES-MS42 method, a small number of elements have been repeatedly noted with higher variance both in percent RSD and percent Recovery. Some of this variance is inherent in the method of sample digestion. Although the mixed 4-acid digestion is considered to be a "total digestion," there is always a small amount of residue composed of refractory minerals that could not be totally dissolved into the analyzed solution. Elements commonly found in this refractory residue include $\mathrm{Cr}, \mathrm{Ni}, \mathrm{P}, \mathrm{Sn}, \mathrm{Ti}, \mathrm{U}$, and W. Thus it is typical for the ICPAES-MS42 method to return lower percent Recovery values for these elements.

The analytical results for Be tend to show more variability in several of the quality control materials. The concentrations display a narrow range of about 0.1 to $2 \mathrm{ppm}$ but the cause of the variance has not been determined.

\section{SGS Minerals Services (USGS Contract) ICPAES-MS55 Total Analysis of 2007 Soils}

The 2007 field season soil samples that were submitted to SGS Minerals for analysis by the ICPAES-MS42 multielement package were also analyzed by a sinter-decomposition ICPAES-MS55 multielement package. These samples included the seven selected reference materials inserted by the USGS Quality Control Manager - three samples of USGS SRM SAR-L and four samples of USGS SRM SAR-M-plus five analytical duplicates and five samples of the Pebble project soil standard PB-SMM for quality control. The laboratory analytical duplicates, SRMs, and blanks inserted by SGS Minerals into the batches of submitted samples were not retrieved for this assessment.

Appendix 4 contains four tables of summary statistics for the quality control samples from the 2007 field season: 
Analytical duplicates (table 13-1), USGS SRM SAR-L (table 13-2), USGS SRM SAR-M (table 13-3), and Pebble project standard PB-SMM (table 13-4). These results are also represented in six quality control charts: precision (percent RSD) of analytical duplicates (fig. 13-1), precision of USGS SRM SAR-L (fig. 13-2), accuracy (percent Recovery) of SRM SAR-L (fig. 13-3), precision of USGS SRM SAR-M (fig. 13-4), accuracy of SRM SAR-M (fig. 13-5), and precision of Pebble project standard PB-SMM (fig. 13-6).

The ICPAES-MS55 technique is a sodium peroxide sinter decomposition followed by analysis by ICP-AES and ICP-MS. The target control limits of 15 percent RSD and \pm 15 percent Recovery are more instructive here than for the previous partial-digestion techniques and are part of the normal quality control assessments of analyses done under the analytical chemistry contract with SGS Minerals. The precision results for 4 analytical duplicate sample pairs (fig. 13-1) are excellent with only 3 elements $(\mathrm{Cu}, \mathrm{La}$, and $\mathrm{Zn})$ exceeding the desired 15 percent RSD. Copper precision was determined to be 28 percent RSD (table 13-1). Almost all of this variation was due to the results from a single pair of samples (170 ppm vs. $219 \mathrm{ppm} \mathrm{Cu}$ ). Removing this duplicate pair reduces the variation to 7 percent $\mathrm{RSD}$. Because the variation of $\mathrm{Cu}$ is less than 10 percent RSD in all of the other quality control measurements for the ICPAES-MS55 method, it is suspected that the problem is with the homogeneity of this one sample rather than a failing of the analytical method. Lanthanum and zinc in analytical duplicates have values between 15 and 20 percent RSD (table 13-1, fig. 13-1). Although this may reflect a higher level of imprecision for these elements in the Pebble project soil samples, the same elements do not show high variability in the Pebble project soil standard PB-SMM (fig. 13-6). In fact, all of the elements reported by the ICPAES-MS55 method are below 15 percent RSD in SRM SAR-L (fig. 13-2) and in PB-SMM (fig. 13-6). The SRM SAR-M (fig. 13-4) has only 4 elements (Dy, Ho, P, and W) that exceed 15 percent RSD although all are below 25 percent RSD.

The accuracy plot for SAR-L (fig. 13-3) has four elements $(\mathrm{Cd}, \mathrm{Nb}, \mathrm{Ti}$, and $\mathrm{Y})$ that exceed 115 percent Recovery and five elements (Cr, Nd, P, Sm, and U) below 85 percent Recovery. Similarly, the accuracy plot for SAR-M (fig. 13-5) has five elements ( $\mathrm{Bi}, \mathrm{Mo}, \mathrm{Nb}, \mathrm{Sb}$, and $\mathrm{Y}$ ) that exceed 115 percent Recovery and two elements (Ho and $\mathrm{P}$ ) below 85 percent Recovery

\section{SGS Minerals Services (USGS Contract) ICPAES-MS55 Total Analysis of 2008 Soils, Sediments, and Pond-Sediment Cores}

Soil, stream sediment, pond sediment, and pond core sediment samples from the 2008 field season were submitted to SGS Minerals, using a current USGS analytical chemistry contract, for analysis by the sinter digestion ICPAES-MS55 multielement package. These samples included 22 selected reference materials inserted by the USGS Quality Control Manager: 7 samples of USGS SRM SAR-L, 8 samples of the USGS SRM SAR-M, 3 samples of the USGS SRM DGPM, and 4 samples of the USGS SRM GSP-QC. As part of this project, the USGS also submitted 20 samples of the Pebble project standard reference material PB-SMM. SGS Minerals selected 11 of the 2008 field season samples for a duplicate analysis. SGS Minerals also inserted their own reference materials and analytical blanks into the batches of submitted samples but these quality control data were not requested for this assessment.

Appendix 4 contains six tables of summary statistics for quality control samples from the 2008 field season: Analytical duplicates (table 13-5), USGS SRM SAR-L (table 13-6), USGS SRM SAR-M (table 13-7), USGS SRM DGPM (table 13-8), USGS SRM GSP-QC (table 13-9), and Pebble project standard PB-SMM (table 13-10). These results are also represented in 11 quality control charts: precision (percent RSD) of analytical duplicates (fig. 13-7), precision of USGS SRM SAR-L (fig. 13-8), accuracy (percent Recovery) of SRM SAR-L (fig. 13-9), precision of USGS SRM SAR-M (fig. 13-10), accuracy of SRM SAR-M (fig. 13-11), precision of USGS SRM DGPM (fig. 13-12), accuracy of SRM DGPM (fig. 13-13), precision of USGS SRM GSP-QC (fig. 13-14), accuracy of SRM GSP-QC (fig. 13-15), precision of Pebble project standard PB-SMM (fig. 13-16), and accuracy of Pebble project standard PB-SMM (fig. 13-17).

The precision charts for the 2008 analyses by the ICPAES-MS55 method show that almost all 55 elements give excellent results below 15 percent RSD. Those elements that exceed the desired control limit are $\mathrm{Ni}$ in the analytical duplicate samples (fig. 13-7), Ni in SRM SAR-L (fig. 13-8), Ca and $\mathrm{Ni}$ in SAR-M (fig. 13-10), Ca, Ce, Cr, Ni, and $\mathrm{Zn}$ in SRM DGPM (fig. 13-12), Ni in SRM GSP-QC (fig. 13-14), and Ni and $\mathrm{Sb}$ in the Pebble project standard PB-SMM (fig. 13-16). Except for Ni, the other elements listed are not of great concern because they were only noted in one or two charts.

The ubiquitous Ni problem is also noted in the accuracy charts where Ni greatly exceeds 115 percent recovery in SAR-L (fig. 13-9), SAR-M (fig. 13-11), DGPM (fig. 13-13), GSP-QC (fig. 13-15), and PB-SMM (fig. 13-17). The source of the non-reproducible and excess $\mathrm{Ni}$ in the quality control samples could not be determined. However, because it is found in every single quality control assessment, the use of the Ni data by ICPAES-MS55 for the 2008 field season soil, stream sediment, pond sediment, and pond core sediment samples is not recommended.

Using mean values from the 2007 analyses of the Pebble soil reference material PB-SMM (table 13-4) as target values, an accuracy plot was created for the 2008 analyses of PBSMM (fig. 13-17). Despite being based on a limited number of samples analyzed during a single season, the plot shows an excellent agreement of results between the two years. 


\section{SGS Minerals Services (USGS Contract) ICPAES-MS55 Total Analysis of 2009 Soils, Sediments, Pond-Sediment Cores, and Rocks}

All of the 2009 field season samples of soil, stream sediment, pond sediment, pond core-sediments and rocks were submitted to SGS Minerals for contract analysis by the ICPAES-MS55 multielement package. With these samples, the USGS Quality Control Manager inserted two samples of USGS standard reference material SAR-L, two samples of USGS standard reference material SAR-M, five samples of the USGS standard reference material DGPM, and four samples of the USGS standard reference material GSP-QC. In addition, the USGS submitted 10 samples of the Pebble project standard reference material PB-SMM. SGS Minerals selected eight of the 2009 field season samples for a duplicate analysis. The data for SGS Minerals quality control reference materials and analytical blanks were not requested for this assessment.

For the 2009 field season, Appendix 4 contains six tables of summary statistics for quality control samples: Analytical duplicates (table 13-11), USGS SRM SAR-L (table 13-12), USGS SRM SAR-M (table 13-13), USGS SRM DGPM (table 13-14), USGS SRM GSP-QC (table 13-15), and Pebble project standard PB-SMM (table 13-16). These results are also represented in 11 quality control charts: precision (percent RSD) of analytical duplicates (fig. 13-18), precision of USGS SRM SAR-L (fig. 13-19), accuracy (percent Recovery) of SRM SAR-L (fig. 13-20), precision of USGS SRM SAR-M (fig. 13-21), accuracy of SRM SAR-M (fig. 13-22), precision of USGS SRM DGPM (fig. 13-23), accuracy of SRM DGPM (fig. 13-24), precision of USGS SRM GSP-QC (fig. 13-25), accuracy of SRM GSP-QC (fig. 13-26), precision of Pebble project standard PB-SMM (fig. 13-27), and accuracy of Pebble project standard PB-SMM (fig. 13-28).

The precision chart for analytical duplicates (fig. 13-18) shows excellent results with all elements having a mean value greater than 5 times their reporting limit are at 15 percent RSD or below. In fact, very few elements exceed 15 percent RSD on any of the precision plots: Cs in SAR-L (fig. 13-19); Bi in SAR-M (fig. 13-21); $\mathrm{Zr}$ in DGPM (fig. 13-23); $\mathrm{Cs}, \mathrm{Cu}$, and $\mathrm{Lu}$ in GSP-QC (fig. 13-25); and Cr in PB-SMM (fig. 13-27).

Except for DGPM (fig. 13-24), each of the other accuracy charts for quality control samples (SAR-L, fig. 13-20; SARM, fig. 13-22; and GSP-QC, fig. 13-25) has a few elements outside of the desired range of percent Recovery. However, like the precision charts, none of these elements occurs more than one or two times in different charts and no systematic patterns were observed. Likewise the accuracy chart for PBSMM (fig. 13-28), which was based on 2007 means as target values, shows excellent agreement with values obtained in 2007 and 2008.

It is important to note that $\mathrm{Ni}$, which was problematic in the 2008 samples, does not exceed a single control limit on any of the 2007 or 2009 field season quality control charts.

\section{SGS Minerals Services (USGS Contract) Analysis of Various Single Elements in 2007 Soils}

In addition to the multielement ICPAES-MS42 and ICPAES-MS55 methods, the 2007 field season soil samples submitted to SGS Minerals under the USGS analytical chemistry contract were analyzed for a series of various single element methods. Arsenic, Sb, and Se were individually analyzed by hydride generation-atomic absorption spectrometry; $\mathrm{Hg}$ by flow-injection cold-vapor atomic absorption; Au by fire assay; and $\mathrm{Cl}^{-}$and $\mathrm{F}^{-}$by ion-specific electrode. In addition, forms of carbon were determined by (1) analyzing total carbon (Tot C) by combustion/infrared detection, (2) analyzing $\mathrm{CO}_{2}$ by coulometric titration, (3) calculating carbonate carbon (Carb C) by converting the measured percent $\mathrm{CO}_{2}$ to percent carbon, and (4) calculating organic carbon (Org C) by subtracting carbonate carbon from total carbon.

The soil samples were accompanied by selected standard reference materials inserted by the USGS Quality Control Manager: three samples of the USGS standard reference material SAR-L, and four samples of the USGS standard reference material SAR-M. The USGS also included five analytical duplicates and five samples of the Pebble project soil standard PB-SMM for quality control. For some quality control samples, there was insufficient material remaining after the ICPAES-MS42 and ICPAES-MS55 methods for additional analyses by each of these various single element methods, therefore the numbers of SRMs listed here are the maximum number that were available.

Appendix 4 contains four tables of summary statistics for the quality control samples from the 2007 field season: Analytical duplicates (table 14-1), USGS SRM SAR-L (table 14-2), USGS SRM SAR-M (table 14-3), and Pebble project standard PB-SMM (table 14-4). These results are also represented in six quality control charts: precision (percent RSD) of analytical duplicates (fig. 14-1), precision of USGS SRM SAR-L (fig. 14-2), accuracy (percent Recovery) of SRM SAR-L (fig. 14-3), precision of USGS SRM SAR-M (fig. 14-4), accuracy of SRM SAR-M (fig. 14-5), and precision of Pebble project standard PB-SMM (fig. 14-6).

As part of the USGS analytical chemistry contract with SGS Minerals, several of the single-element methods are judged based on a 20 percent RSD rather than the more conservative 15 percent RSD used for the multielement methods. This difference is shown on the appropriate quality control precision charts in Appendix 4. Most of the quality control statistics for these elements and methods were at or below 20 percent RSD. Gold is notorious for homogeneity problems in many sample materials. However, the data for Au determined by fire assay methods show only slightly elevated percent RSD values for the SRM SAR-L (fig. 14-4) and the Pebble project soil standard PB-SMM (fig. 14-6). In contrast, the variation for $\mathrm{Au}$ in analytical duplicate samples (table 14-1, fig. 14-1) was 179 percent RSD. An examination of the quality control data revealed a systematic difference between analytical duplicates: all of the samples analyzed in an early batch 
had values for gold that were below the reporting limit of $0.005 \mathrm{ppm}$, whereas all of the corresponding duplicate samples analyzed in a later batch had values that ranged from 0.014 to $0.126 \mathrm{ppm} \mathrm{Au}$. To resolve this problem, the laboratory redid the $\mathrm{Au}$ analyses. The reanalyzed $\mathrm{Au}$ values are addressed below concurrently with the 2008 field season data.

\section{SGS Minerals Services (USGS Contract) Analysis of Various Single Elements in 2008 Soils, Sediments, and Pond-Sediment Cores}

The soil, stream sediment, pond sediment, and pond core sediment samples from the 2008 field season that were submitted to SGS Minerals for multielement analyses were also analyzed for the same various single elements, except for As, that were determined for the 2007 field season samples. These batches of samples included 22 selected reference materials inserted by the USGS Quality Control Manager: 7 samples of USGS SRM SAR-L, 8 samples of the USGS SRM SAR-M, 3 samples of the USGS SRM DGPM, and 4 samples of the USGS SRM GSP-QC. The USGS also submitted 20 samples of the Pebble project standard reference material PB-SMM. SGS Minerals selected 11 of the 2008 field season samples for a duplicate analysis. For some quality control samples, there was insufficient material remaining after the ICPAES-MS42 and ICPAES-MS55 methods for additional analyses by each of these various single element methods, therefore the numbers of SRMs listed here are the maximum number that were available.

Appendix 4 contains six tables of summary statistics for quality control samples from the 2008 field season: Analytical duplicates (table 14-5), USGS SRM SAR-L (table 14-6), USGS SRM SAR-M (table 14-7), USGS SRM DGPM (table 14-8), USGS SRM GSP-QC (table 14-9), and Pebble project standard PB-SMM (table 14-10). These results are also represented in eleven quality control charts: precision (percent RSD) of analytical duplicates (fig. 14-7), precision of USGS SRM SAR-L (fig. 14-8), accuracy (percent Recovery) of SRM SAR-L (fig. 14-9), precision of USGS SRM SAR-M (fig. 14-10), accuracy of SRM SAR-M (fig. 14-11), precision of USGS SRM DGPM (fig. 14-12), accuracy of SRM DGPM (fig. 14-13), precision of USGS SRM GSP-QC (fig. 14-14), accuracy of SRM GSP-QC (fig. 14-15), precision of Pebble project standard PB-SMM (fig. 14-16), and accuracy of Pebble project standard PB-SMM (fig. 14-17).

The primary issue noted in the quality control charts is the reproducibility of $\mathrm{Au}$ analyses. The precision plots for analytical duplicates (fig. 14-7), SAR-L (fig. 14-8), SAR-M (fig. 14-10), and PB-SMM (fig. 14-16) all have percent RSD values above 20 percent. The percent RSD for Au in the analytical duplicate samples (table 14-5, fig 14-7) is 195 percent. The accuracy (percent Recovery) plot for SAR-L (fig. 14-9) also indicates issues with reproducing gold values.

Unlike the issue noted with the $2007 \mathrm{Au}$ analyses, there were no systematic problems with the 2008 field season (or the reanalyzed 2007 field season) Au determinations. The higher variability noted in these standards and duplicates appears to be due to the "nugget effect" where gold is not homogeneous within the material and the subsampled material used for analysis may or may not contain a "nugget." The USGS SRM SAR-L (fig. 14-8) is known to be inhomogeneous for gold. The results from the analytical duplicate samples (fig. 14-7) and the Pebble project soil standard PB-SMM (fig. 14-16) suggest that the soil and various sediment samples collected in the Pebble area also have the common problem of gold inhomogeneity.

To a lesser extent than gold, the results from the analytical duplicate samples (fig. 14-7) and the Pebble project soil standard PB-SMM (fig. 14-16) also suggest that there are some issues with reproducing $\mathrm{CO}_{2}$ values in Pebble soils. This is not a big issue because the amount of $\mathrm{CO}_{2}$ determined (and consequently the amount of carbonate carbon calculated) is only a very small fraction of the total carbon in the soils. The major form of carbon in the Pebble soils is identified as organic carbon.

\section{SGS Minerals Services (USGS Contract) Analysis of Various Single Elements in 2009 Soils, Sediments, Pond-Sediment Cores, and Rocks}

All of the 2009 field season samples of soil, stream sediment, pond sediment, pond core-sediments and rocks that were submitted to SGS Minerals for multielement analyses were also analyzed for the same various single elements, except for As, that were determined for the 2007 field season samples. With these samples, the USGS Quality Control Manager inserted two samples of USGS standard reference material SAR-L, two samples of USGS standard reference material SAR-M, five samples of the USGS standard reference material DGPM, and four samples of the USGS standard reference material GSP-QC. In addition, the USGS submitted 10 samples of the Pebble project standard reference material PB-SMM. SGS Minerals selected eight of the 2009 field season samples for a duplicate analysis. For some quality control samples, there was insufficient material remaining after the ICPAES-MS42 and ICPAES-MS55 methods for additional analyses by each of these various single element methods, therefore the numbers of SRMs listed here are the maximum number that were available. This problem of insufficient quality control material is most noticeable for the Au by fire assay method.

For the 2009 field season, Appendix 4 contains six tables of summary statistics for quality control samples: Analytical duplicates (table 14-11), USGS SRM SAR-L (table 14-12), USGS SRM SAR-M (table 14-13), USGS SRM DGPM (table 14-14), USGS SRM GSP-QC (table 14-15), and Pebble project standard PB-SMM (table 14-16). These results are also represented in 11 quality control charts: precision (percent RSD) of analytical duplicates (fig. 14-18), precision of USGS SRM SAR-L (fig. 14-19), accuracy (percent Recovery) of 
SRM SAR-L (fig. 14-20), precision of USGS SRM SAR-M (fig. 14-21), accuracy of SRM SAR-M (fig. 14-22), precision of USGS SRM DGPM (fig. 14-23), accuracy of SRM DGPM (fig. 14-24), precision of USGS SRM GSP-QC (fig. 14-25), accuracy of SRM GSP-QC (fig. 14-26), precision of Pebble project standard PB-SMM (fig. 14-27), and accuracy of Pebble project standard PB-SMM (fig. 14-28).

The precision plots for these quality control samples look excellent with no values exceeding the 20 percent RSD control limit for analytical duplicates (fig. 14-18), SAR-L (fig. 14-19), SAR-M (fig. 14-21), DGPM (fig. 14-23), or GSP-QC (fig. 14-25). Unfortunately, Au results cannot be evaluated for analytical duplicates (fig. 14-18), SAR-L (fig. 14-19), or SAR-M (fig. 14-21) due to a lack of analyses for these quality control samples. No problems are noted for the limited number of DGPM (fig. 14-23) and GSP-QC (fig. 14-25) reference samples analyzed. Gold also does not show up as an issue in the 2009 analyses of the Pebble project reference soil PB-SMM (fig. 14-27). As in the 2008 samples, PB-SMM (fig. 14-27) does show some reproducibility problems with measurements of $\mathrm{CO}_{2}$. However, as previously noted, the amount of $\mathrm{CO}_{2}$ determined (or recalculated percent carbonate carbon) is a very small fraction of the total carbon in the soils. The major form of carbon in the Pebble soils is identified as organic carbon.

\section{Activation Laboratories, Ltd., High-Resolution ICP-MS Analysis of 2007 Waters}

Samples of pond, seep, stream, and drill hole waters collected during the 2007 field season were submitted to Actlabs for analyses by their High-Resolution ICP-MS method. This is a very sensitive analytical method that reports results in the low parts-per-billion (ppb) and parts-per-trillion (ppt). Table 1-1a lists the reporting limits for this method in micrograms per Liter $(\mu \mathrm{g} / \mathrm{L}$; equivalent to $1 \mathrm{ppb}$ or $1,000 \mathrm{ppt})$. Actlabs inserted only two quality control samples into the batch: one sample of standard reference material SLRS-4 and one sample of standard reference material NIST-1640 (NIST, 2008). The USGS did not submit any additional quality control samples with this batch.

Appendix 4 contains one table of summary statistics for the quality control samples analyzed for the 2007 field season by the Actlabs High-Resolution ICP-MS method: SRM SLRS-4 and SRM NIST-1640 (table 15-1). These results are also represented in two quality control charts: accuracy (percent Recovery) of laboratory SRM SLRS-4 (fig. 15-1) and accuracy of laboratory SRM NIST-1640 (fig. 15-2).

There was not a sufficient number of quality control samples to measure analytical precision and so the results of the two analyses are portrayed only as accuracy charts. The plots for SLRS-4 (fig. 15-1) and NIST-1640 (fig. 15-2) both show very good percent Recovery results for those elements whose means are greater than five times their reporting limit and for which there is a recognized target value.

\section{Activation Laboratories, Ltd., High-Resolution ICP-MS Analysis of 2008 Waters}

Pond, seep, drill hole and stream water samples from the 2008 field season were submitted to Actlabs for analysis by their High-Resolution ICP-MS method. Three quality control samples of standard reference material NIST-1643e (NIST, 2009) were inserted by Actlabs into the batch. Sixteen additional quality control samples were submitted by the USGS: 8 samples of the USGS standard reference material T-159, and 8 samples of the USGS standard reference material T-177.

Appendix 4 contains three tables of summary statistics for quality control samples analyzed by the Actlabs HighResolution ICP-MS method: SRM NIST-1643e (table 15-2), USGS SRM T-159 (table 15-3), and USGS SRM T-177 (table 15-4). These results are also represented in six quality control charts: precision (percent RSD) of laboratory SRM NIST1643e (fig. 15-3), accuracy (percent Recovery) of laboratory SRM NIST-1643e (fig. 15-4), precision of USGS SRM T-159 (fig.15-5), accuracy of USGS SRM T-159 (fig. 15-6), precision of USGS SRM T-177 (fig.15-7), and accuracy of USGS SRM T-177 (fig. 15-8).

The plot of analytical precision for SRM NIST-1643e (fig. 15-3) shows that most elements whose means are more than 5 times their reporting limits fall within the 15 percent RSD control limit. Only Ce, Cs, Ga, Hf, and W exceed this limit and none by more than 30 percent RSD. The accuracy chart for NIST-1643e (fig. 15-4) shows all elements with a target value to be very close to 100 percent Recovery, and none exceeds the 85-115 percent control limits.

The results for USGS SRM T-159 (table 15-3) show considerably greater variation than for SRM NIST-1643e. The T-159 precision chart (fig. 15-5) shows that $\mathrm{Ce}, \mathrm{Eu}, \mathrm{Gd}$, Ge, Hf, La, Li, Lu, Mg, Na, Nb, Pr, Tb, Th, Y, and Zr plot above 15 percent RSD. Of these, Eu and Hf are the highest with values near 60 percent. On the accuracy plot for T-159 (fig. 15-6), As, Be, Cd, Na, and $\mathrm{Zn}$ fall outside of the desired 85-115 percent Recovery control limits, with As at over 140 percent. Most elements falling within the control limits are slightly biased high between 100-115 percent Recovery.

Results for USGS SRM T-177 (table 15-4) are similar to those of T-159. The precision chart for T-177 (fig. 15-7) plots $\mathrm{As}, \mathrm{Ce}, \mathrm{Eu}, \mathrm{Fe}, \mathrm{Ga}, \mathrm{Gd}, \mathrm{Ge}, \mathrm{Hf}, \mathrm{La}, \mathrm{Li}, \mathrm{Nb}, \mathrm{Pd}, \mathrm{Tb}$, Th, $\mathrm{Ti}$, and $\mathrm{Zr}$ above 15 percent RSD with values for Th and $\mathrm{W}$ near 90 percent RSD. The accuracy plot for T-177 (fig. 15-8) also shows a similar pattern to that for $\mathrm{T}-159$ with $\mathrm{As}, \mathrm{Be}, \mathrm{Cd}$, $\mathrm{Fe}, \mathrm{Li}$, and $\mathrm{Zn}$ exceeding the $85-115$ percent Recovery control limits.

\section{Activation Laboratories, Ltd., High-Resolution ICP-MS Analysis of 2009 Waters}

Pond, seep, and stream water samples collected in 2009 were submitted to Actlabs for analysis by their HighResolution ICP-MS method. Three quality control samples 
of the standard reference material NIST-1643e (NIST, 2009) were inserted by Actlabs into the sample batches. Four additional quality control samples were submitted by the USGS: two samples of the USGS standard reference water T-167, and two samples of the USGS standard reference water T-177.

Appendix 4 contains three tables of summary statistics for quality control samples analyzed by the Actlabs HighResolution ICP-MS method in 2009: SRM NIST-1643e (table 15-5), USGS SRM T-167 (table 15-6), and USGS SRM $\mathrm{T}-177$ (table 15-7). These results are also represented in six quality control charts: precision (percent RSD) of laboratory SRM NIST-1643e (fig. 15-9), accuracy (percent Recovery) of laboratory SRM NIST-1643e (fig. 15-10), precision of USGS SRM T-167 (fig.15-11), accuracy of USGS SRM T-167

(fig. 15-12), precision of USGS SRM T-177 (fig.15-13), and accuracy of USGS SRM T-177 (fig. 15-14).

As in 2008, the 2009 results for SRM NIST-1643e (table 15-5) are well constrained. The NIST-1643e precision chart (fig. 15-9) shows that almost all elements whose means are more than 5 times their reporting limits are within the desired 15 percent RSD control limit. Only Cs, Dy, Ga, In, W, and Yb are higher than 15 percent RSD. However, as a demonstration of the sensitivity of the new high-resolution mass spectroscopy technique, these elements' concentrations are extremely low; of these, tungsten had the highest mean concentration at only $0.028 \mathrm{ppb}$. None of these elements had a certified reference concentration value. The accuracy chart for NIST-1643e (fig. 15-10) shows that all those elements having target values and concentrations greater than five times the reporting limit (elements plotted with filled-in diamonds) plot close to 100 percent Recovery. Only selenium plots below 85 percent, and the mean for this element was less than five times the reporting limit.

The USGS standard reference material T-167 was inserted into the sample batches prior to submittal to Actlabs. The quality control statistics (table 15-6) and precision graph (fig. 15-11) for $\mathrm{T}-167$ show that $\mathrm{Ga}, \mathrm{Ge}, \mathrm{Te}, \mathrm{Th}$, and $\mathrm{W}$ have percent RSD values greater than 15 percent. The accuracy graph for T-167 (fig. 15-12) shows that $\mathrm{As}, \mathrm{B}, \mathrm{Be}, \mathrm{Ca}, \mathrm{Cd}, \mathrm{Cu}$, $\mathrm{K}, \mathrm{Mg}, \mathrm{V}$, and $\mathrm{Zn}$ exceeds 115 percent Recovery.

USGS SRM T-177 (table 15-7; figs. 15-13 and 15-14) shows similar results to those of $\mathrm{T}-167$. The analytical precision chart for USGS SRM T-177 (fig. 15-13) only plots Ag, $\mathrm{Ga}, \mathrm{Ge}, \mathrm{Se}$, and Te above 15 percent. Silver and selenium, however, are present at concentrations lower than five times their reporting limits where a higher amount of variability is expected. The T-177 accuracy graph (fig. 15-14) also shows a similar pattern to that for $\mathrm{T}-167$ with $\mathrm{As}, \mathrm{B}, \mathrm{Be}, \mathrm{Ca}, \mathrm{Cd}, \mathrm{Cu}$, $\mathrm{K}, \mathrm{Mg}, \mathrm{V}$, Se and $\mathrm{Zn}$ exceeding 115 percent Recovery. The T-177 standard exhibits better precision (lower percent RSD values) for the 2009 analyses than it does for those samples analyzed in 2008 (fig. 15-7).

\section{Activation Laboratories, Ltd., High-Resolution ICP-MS Analysis of 2010 Waters}

Pond, seep, and stream water samples collected in 2010 were submitted to Actlabs for analysis by their HighResolution ICP-MS method. Three quality control samples of standard reference material NIST-1643e (NIST, 2009) were inserted by Actlabs into the batch. Four additional quality control samples were submitted by the USGS: two samples of the USGS standard reference water T-167, and two samples of the USGS standard reference water T-177. Between 2009 and 2010, Actlabs modified this method so that only 60 elements (rather than 63) are reported. Corresponding reporting limits were also changed.

For the 2010 field season samples, Appendix 4 contains three tables of summary statistics for quality control samples analyzed by the Actlabs High-Resolution ICP-MS method in 2010: SRM NIST-1643e (table 15-8), USGS SRM T-167 (table 15-9), and USGS SRM T-177 (table 15-10). These results are also represented in six quality control charts: precision (percent RSD) of laboratory SRM NIST-1643e (fig. 15-15), accuracy (percent Recovery) of laboratory SRM NIST-1643e (fig. 15-16), precision of USGS SRM T-167 (fig.15-17), accuracy of USGS SRM T-167 (fig. 15-18), precision of USGS SRM T-177 (fig.15-19), and accuracy of USGS SRM T-177 (fig. 15-20).

The summary statistics (table 15-8) and graphs (figs. 15-15 and 15-16) for the SRM NIST-1643e results reported by Actlabs again show well-constrained results, although these are based on only three analyses. The analytical precision plot for NIST-1643e (fig. 15-15) shows that no elements whose means are more than 5 times their reporting limits are above 15 percent RSD. The accuracy plot for NIST1643e (fig. 15-16) shows that all those elements having target values and concentrations greater than 5 times the reporting limit (elements represented with filled-in diamonds) plot close to 100 percent Recovery.

The precision results for USGS SRM T-167 (fig.15-17) show $\mathrm{Ge}$ and $\mathrm{Nb}$ as the only elements with values greater than 15 percent RSD. However, the accuracy chart for T-167 (fig. 15-18) plots Al, B, Be, Ca, Cd, Co, Cr, Fe, K, Li, Mg, $\mathrm{Mn}, \mathrm{Na}, \mathrm{Se}, \mathrm{V}$, and $\mathrm{Zn}$ above the 115 percent Recovery control limits.

Similar behavior is noted with USGS SRM T-177. A precision chart for T-177 (fig. 15-19) only shows 3 elements (Ge, $\mathrm{Lu}$, and Te) with values above 15 percent RSD. Although based on only 2 analyzed samples of T-177, Te had a very high value of 111 percent RSD (table 15-10). The accuracy graph for T-177 (fig. 15-20) shows a similar pattern to that for USGS SRM T-167 with 11 elements (As, B, Be, Ca, Cd, Cu, $\mathrm{K}, \mathrm{Mg}, \mathrm{V}, \mathrm{Se}$ and $\mathrm{Zn}$ ) exceeding the 115 percent Recovery.

Summarizing the results, the precision values (percent RSD) for the Actlabs High-Resolution ICP-MS method appear to have improved each year from 2008 to 2010. This is especially the case for SRM NIST-1643e (figs. 15-3, 15-9, and 15-15) but is also noticeable for USGS SRM T-167 
(figs. 15-11 and 15-17) and USGS SRM T-177 (figs. 15-7. 15-13, and 15-19). However, the story from accuracy values (percent Recovery) is not as clear. The High-Resolution ICPMS method does an excellent job returning accurate numbers for the laboratory preferred SRM NIST-1643e, again with accuracy appearing to improve each year from 2008 to 2010 (figs. 15-4, 15-10, and 15-16). But this trend is not seen in the USGS standard reference materials T-167 (figs. 15-12 and 15-18) and T-177 (figs. 15-8, 15-14, and 15-20). For both of these standards, a large number of elements give values that greatly exceed 115 percent Recovery.

Some concern about the number of elements reporting outside of the accuracy control limits centered on the age of the standards $\mathrm{T}-167$ and $\mathrm{T}-177$. The production date of SRM $\mathrm{T}-167$ is 2001 , and that of SRM T-177 is 2004, while the production date for SRM NIST-1643e is 2009. However, experience with the T-167 and T-177 SRMs indicates that these standards are stable. Independent analyses of SRM T-177 at USGS laboratories in Denver showed recovery numbers much closer to 100 percent, averaging 103 percent Recovery for all elements that have a target value (Monique Adams, USGS, unpub. data, 2010).

It is not clear whether the accuracy difference seen here is due to a possible difference in the calibration between USGS and Activation Laboratories ICP-MS instrumentation or whether the problem is with the older USGS standard reference materials. Perhaps the increased sensitivity of the HighResolution ICP-MS may necessitate the development of new SRMs, or the re-certification of existing ones.

\section{Acme Analytical Laboratories, Ltd., Analysis of 2007 Vegetation}

Acme Labs inserted seven quality control samples into the batch of analyzed vegetation samples from the 2007 field season: two analytical duplicates, three samples of the laboratory reference material V6, and two samples of the laboratory reference material V14. No additional quality control samples were submitted by the USGS.

Appendix 4 contains three tables of summary statistics for quality control samples analyzed with the vegetation samples by Acme Labs: Analytical duplicates (table 16-1), laboratory SRM V6 (table 16-2), and laboratory SRM V14 (table 16-3). These results are also represented in five quality control charts: precision (percent RSD) of analytical duplicates (fig. 16-1), precision of SRM V6 (fig. 16-2), accuracy (percent Recovery) of SRM V6 (fig. 16-3), precision of SRM V14 (fig. 16-4), and accuracy of SRM V14 (fig. 16-5).

Mercury ( 25 percent) is the only element detected at levels greater than 5 times the reporting limit and above 15 percent RSD in the analytical duplicates (fig. 16-1). Mercury does not seem to be problematic in either of the two standard reference materials (figs. 16-2 and 16-4). This suggests that $\mathrm{Hg}$ may be inhomogeneous in the Pebble vegetation samples. In the standard reference materials, V6 has percent RSD values between 20 and 30 percent for $\mathrm{Cu}$, Hf, and $\mathrm{S}$ (table 16-2, fig. 16-2), whereas V14 has higher values (25-35 percent RSD) for Au, Mo, Li, and S (table 16-3, fig. 16-4). Except for $\mathrm{S}$, none of these elements show problems in both SRMs. This suggests that the variation seen for these elements is probably inherent in the chosen reference materials and not the analytical method. The variation in sulfur analyses may suggest either sample inhomogeneity or higher analytical variability. It is important to note that all of these evaluations are based on very small data sets that have only two or three quality control analyses each. A small variation between just two analyses may appear to be magnified in the quality control charts.

\section{Activation Laboratories, Ltd., Analysis of 2007 Vegetation}

Within the batch of vegetation samples from the 2007 field season, Actlabs inserted seven quality control samples: five analytical duplicates and two samples of the standard reference material NIST-1575a (NIST, 2002). No additional quality control samples were submitted by the USGS.

Appendix 4 contains two tables of summary statistics for quality control samples analyzed by Actlabs: analytical duplicates (table 17-1) and certified SRM NIST-1575a (table 17-2). These results are also represented in three quality control charts: precision (percent RSD) of analytical duplicates (fig. 17-1), precision of SRM NIST-1575a (fig. 17-2), and accuracy (percent Recovery) of SRM NIST-1575a (fig. 17-3).

The charts of analytical precision (figs. 17-1 and 17-2) show that most of the elements detected at values greater than 5 times the reporting limit fall below 20 percent RSD. The exceptions are $\mathrm{Be}, \mathrm{Pb}, \mathrm{Sb}$, and $\mathrm{Ti}$ in analytical duplicates (fig. 17-1), and As, Na, and Ti in SRM NIST-1575a (fig. 17-2). Only Ti appears high in both charts and may be a little noisy for this method, although probably not high enough to be of significant concern for the project. With the exception of As, the other elements with higher variation each appear to be due to a single value in the quality control data that slightly skews the percent RSD statistic. Arsenic, which could not be evaluated in the analytical duplicates due to the proximity to the reporting limit, appears to be a problem in SRM NIST1575a. Actlabs notes that their quality control database suggests that As in not homogeneous in the NIST-1575a standard reference material (Actlabs, written commun., 2007). Gold data also have high percent RSD values but could not be properly evaluated because most of the values are near the lower reporting limit for the method. 


\section{Summary and Conclusions of the Quality Control Evaluation for the Various Geochemical Data Sets}

Quality control evaluations tend to focus on those elements or methods that have problems. This evaluation is no exception. However, it is important to note that this evaluation revealed no precision or accuracy problems for the majority of analytical data from the various laboratories and analytical methods. Therefore, most of these data should be useful for evaluating real variation between sample sites and for assessing geochemical signatures of concealed mineralization in the Pebble project area. As is always the case, some care should be taken when interpreting geochemical data based on elements that are frequently reported at concentrations near their lower reporting limits.

\section{De-lonized Water Leach (USGS)}

The de-ionized water leach method was only used by the USGS on the 2007 field season soil samples. All of the elements returned acceptable precision values except for tantalum and the rare earth elements Ce, Dy, Er, Eu, Gd, La, Nd, Pr, Tb, and $\mathrm{Yb}$. The precision for the set of rare earth elements was a little noisier than desired but should still provide interpretable results. Based on the limited number of analyzed quality control samples, Ta may present a problem for this method during the 2007 field season and may not be useful for further interpretation.

\section{Soil Gas Hydrocarbons (Activation Laboratories, Ltd.)}

Actlabs analyzed the 2007 field season soils for soil gas hydrocarbons (SGH). Although this quality control evaluation showed higher than desired variation, SGH is an ultra lowlevel semi-quantitative method from which one would expect a higher level of imprecision. Rather than focusing on single hydrocarbon compounds (identified only by code because Actlabs considers the actual analyzed hydrocarbon compounds to be proprietary), the strength of the method is in the use of multiple compounds to define a class that will delineate geographic targets. For these data, Actlabs reports an average Coefficient of Variation for replicate results of 7.5 percent, "which represents an excellent level of analytical performance" (Dale Sutherland and Eric Hoffman, Actlabs, written commun., 2007).

\section{Bioleach (Activation Laboratories, Ltd.)}

The soil samples submitted to Actlabs in 2007 for soil gas hydrocarbon determinations were also used for a bioleach analysis. No problems were noted in the evaluation of quality control samples except for Li. Lithium results consistently gave higher than desired imprecision in each of the SRMs analyzed. This suggests that for the 2007 field season samples, $\mathrm{Li}$ was not well constrained by the Bioleach method and may not be useful for making valid interpretations of these data.

\section{Enzyme Leach (Skyline Assayers and Laboratories)}

Skyline Labs analyzed Pebble area soil samples from the 2007, 2008, and 2009 field seasons by their Enzyme Leach method. Analyses of their laboratory standard reference materials returned very good results for the reproducibility (precision) of element concentrations. Accuracy (percent Recovery) plots of their SRMs, using updated target values from 2009, showed that the data from the 2007 field season were biased low with most elements having percent Recovery values below 100 percent. Conversely, the accuracy plots for these same SRMs showed that the 2008 and 2009 field season data sets were biased high, with most elements having percent Recovery values above 100 percent. This change in bias suggests that the 2007 results may need to be interpreted separately from the 2008 and 2009 data.

The analysis of duplicate samples and, to a lesser extent, the analysis of Pebble project soil standards show that the Pebble soils are not as homogeneous as the SRMs when analyzed by the Enzyme Leach method. Several elements, including $\mathrm{Au}, \mathrm{Cu}, \mathrm{Ni}, \mathrm{Pb}, \mathrm{W}$, and $\mathrm{Zn}$, exhibited "nugget effect" behavior in the Pebble soils. Thus a second analysis of the same soil sample may not detect the same high concentrations of those elements seen in the first analysis. The result of this behavior is that elements found to be anomalously high in one sample may be low in an adjacent sample simply because a "nugget" was not included in the analysis of that second site. A concentration plot along a sampled traverse for an element exhibiting the "nugget effect" may appear inconsistent over an area with anomalously high values.

\section{TerraSol Leach (Skyline Assayers and Laboratories)}

A split of each soil sample from the 2007, 2008, and 2009 field seasons sent to Skyline Labs for Enzyme Leach determinations was also analyzed by their TerraSol Leach method. The evaluation of quality control samples for all three field seasons identified problems with the analytical results for $\mathrm{Hg}$. In both the SRMs and analytical duplicate samples, $\mathrm{Hg}$ values were neither reproducible nor accurate. It is recommended that the TerraSol mercury data not be used except, perhaps, to note its presence. Some minor problems with the reproducibility of S values were noted in the 2007 field season results. Because most $\mathrm{S}$ values are near or below the reporting limits and the issue noted in 2007 was not seen in the results from the following two years, the sulfur data should be acceptable if used with the same caution applied to other elements that are frequently detected near their reporting limits. 
It was also noted that some major and minor rock-forming elements ( $\mathrm{Ba}, \mathrm{Ca}, \mathrm{K}, \mathrm{Mg}, \mathrm{Mn}, \mathrm{Na}$, and $\mathrm{Sr}$ ) were slightly biased high in accuracy (percent Recovery) plots for the 2009 season. The 2009 results for these elements may need to be considered separately from the 2007 and 2008 data when interpreting the TerraSol Leach data.

\section{Metal Mobile Ion Leach (SGS Mineral Services)}

SGS Minerals analyzed the 2007 field season soil samples with their Metal Mobile Ion (MMI) Leach. The evaluation of the SRMs analyzed concurrently with the Pebble soils noted problems with the $\mathrm{Pb}$ determinations. Due to higher variability, the MMI $\mathrm{Pb}$ results should be used with caution. It was also noted from the determinations of analytical duplicates that the Pebble soils are less homogeneous with respect to the MMI Leach than the standard reference materials.

\section{Cold Hydroxylamine Hydrochloride Leach (ALS Minerals)}

Soil samples from the 2007, 2008, and 2009 field seasons were analyzed by ALS Minerals using a cold hydroxylamine hydrochloride leach. Precision charts for all laboratory SRMs are excellent with almost every element that has a mean value greater than five times their reporting limit, falling within the desired range of precision (percent RSD). Accuracy statistics for one standard (LK4-ALG) consistently report results for $\mathrm{Cr}, \mathrm{Cs}, \mathrm{Ga}, \mathrm{Lu}$, and Tm slightly above 115 percent Recovery. Because this pattern is not repeated for other SRMs, the issue appears to be only with the LK4-ALG standard and not with the method. An evaluation of the analytical duplicates (especially those from the 2008 field season) suggests that the Pebble soils are less homogeneous with respect to the cold hydroxylamine hydrochloride leach than the standard reference materials.

\section{Ionic Leach (ALS Minerals)}

The ALS Minerals Ionic Leach method was added in 2008. Splits of archive 2007 field season soils were analyzed along with the 2008 field season soils. The 2009 field season soils were analyzed the following year. The evaluation of the standard reference material analyzed concurrently with the samples indicates that the Ionic Leach method may have more variability than the conservative 15 percent RSD control limit used for total digestion analyses. For the 2009 data-precision values for all of the elements analyzed for the laboratory standard ION-SRM18 ranged as high as 30 percent RSD (except for Ti at 62 percent RSD). Precision values for USGS SRM SAR-L and Pebble project soil standard PB-SMM commonly reached as high as 50 percent RSD. This does not invalidate the use of Ionic Leach analyses because the expected elemental ranges in mineralized areas may cover several orders of magnitude concentration, and so individual element variation on the order of 50 percent RSD will not significantly change the interpretations. Like the issues of inhomogeneity that were previously discussed for the Enzyme Leach method, the Ionic Leach method may show some high variation in element concentrations plotted along a sampled traverse line.

\section{Sodium Pyrophosphate Leach (ALS Minerals)}

ALS Minerals analyzed soil samples using a sodium pyrophosphate leach only for the 2007 field season. An evaluation of associated quality control samples found that all of the analyzed elements show good precision and accuracy except for $\mathrm{Br}, \mathrm{Ag}, \mathrm{Bi}$, and $\mathrm{Th}$. Elevated spikes of $\mathrm{Br}$ were found in analytical blanks and at least one SRM. It is possible that $\mathrm{Br}$ may have similar problems in the Pebble soil data. The other three elements ( $\mathrm{Ag}, \mathrm{Bi}$, and $\mathrm{Th})$ had consistent problems with reproducibility in nearly all of the quality control samples. This suggests that $\mathrm{Ag}, \mathrm{Bi}, \mathrm{Th}$, and possibly $\mathrm{Br}$, in the sodium pyrophosphate leach data, may give odd results if used to interpret the Pebble soil data.

\section{Aqua Regia Leach (Acme Analytical Laboratories, Ltd.)}

The 2007 field season soil samples were sent to Acme Labs for analyses following an aqua regia leach. In 2009, soil samples from both the 2008 and 2009 field seasons were again submitted to Acme Labs. The results returned for 2008 and 2009 samples had a different suite of analyzed elements and different corresponding reporting limits suggesting a change in methodology or instrumentation after 2007. This change and the results returned from some of the inserted quality control samples suggest that the 2007 results should be treated separately from the 2008-2009 results for data interpretation.

Gold data, as evaluated in several quality control charts, commonly exhibited a "nugget effect" behavior. Other elements in the aqua regia leach data with similar behavior include $\mathrm{Cd}, \mathrm{Cr}, \mathrm{Hg}, \mathrm{Ti}$, and $\mathrm{W}$. Higher variability for elements like these often creates a spiky pattern for anomalies along sample traverse lines.

\section{ICPAES-MS42 Total Analysis (USGS Contract with SGS Mineral Services)}

Various combinations of soil, stream sediment, pond sediment, pond core sediment, and rock samples were submitted to SGS Minerals for analysis by the four-acid digestion ICPAESMS42 total analysis multielement package. An evaluation of quality control samples found that almost all elements analyzed had very good precision and accuracy. However, a small number of elements ( $\mathrm{Cr}, \mathrm{Ni}, \mathrm{P}, \mathrm{Sn}, \mathrm{Ti}, \mathrm{U}$, and $\mathrm{W}$ ) repeatedly had higher variance in percent RSD (precision) and low values for percent Recovery. Some of this variance is inherent in the method of sample digestion. Although the mixed 
4-acid digestion is considered to be a "total digestion," there is always a small amount of residue composed of refractory minerals that could not be totally dissolved into the analyzed solution. The elements listed above are commonly found in this undigested residue. Because this behavior is understood, the interpretation of these elements as analyzed by ICPAESMS42 does not present a problem. However, it should be noted that the ICPAES-MS42 results for these refractory elements should not strictly be considered "total" values.

The results for beryllium by ICPAES-MS42 were found to have problems with precision and accuracy that could not be explained by known digestion problems.

\section{ICPAES-MS55 Total Analysis (USGS Contract with SGS Mineral Services)}

The solid samples submitted for the 2007-2009 field seasons to SGS Minerals for the ICPAES-MS42 package were also analyzed by the sinter digestion ICPAES-MS55 multielement package. Although an evaluation of the quality control samples commonly found one or two elements per chart that did not fall exactly within the desired control limits, only $\mathrm{Ni}$ showed consistent behavior indicative of a problem. For the 2008 field season data, $\mathrm{Ni}$ was found to be out of control in every single quality control assessment. Therefore, the use of the Ni data by ICPAES-MS55 for the 2008 field season soil, stream sediment, pond sediment, and pond core sediment samples is not recommended. The Ni data for 2007 and 2009 field seasons do not exhibit any problems.

\section{Analysis of Various Single Elements (USGS Contract with SGS Mineral Services)}

In addition to ICPAES-MS42 and ICPAES-MS55, the 2007, 2008, and 2009 field season solid samples sent to SGS Minerals were also analyzed for a set of selected single elements by element specific methods (As, $\mathrm{Sb}, \mathrm{Se}, \mathrm{Hg}, \mathrm{Au}, \mathrm{Cl}^{-}$, $\mathrm{F}^{-}$, and forms of carbon). By contractual agreement, most of these methods are evaluated based on a precision of 20 percent RSD rather than the more conservative 15 percent RSD used for total analysis multielement methods. The evaluation of quality control samples identified a systematic problem with $\mathrm{Au}$ analyses from the 2007 field season. This problem was resolved when SGS Minerals reran the gold analyses for that year.

Even after the identified problem was resolved, precision values of $\mathrm{Au}$ analyses continued to remain high. This higher variability in some quality control samples appears to be due to the "nugget effect" where gold is not homogeneous within the material and the subsampled material used for analysis may or may not contain a "nugget." The results from the analytical duplicate samples and the Pebble project soil standard PB-SMM suggests that the soil and various sediment samples collected in the Pebble area also have the common problem of gold inhomogeneity.

The results from the analytical duplicate samples and the Pebble project soil standard PB-SMM also suggest that there are some issues with reproducing $\mathrm{CO}_{2}$ values in Pebble soils. This is not a big issue because the amount of $\mathrm{CO}_{2}$ determined (and consequently the amount of carbonate carbon calculated) is only a very small fraction of the total carbon in the soils. The major form of carbon in the Pebble soils is identified as organic carbon.

\section{High-Resolution ICP-MS Analysis (Activation Laboratories, Ltd.)}

Pond, seep, drill hole and stream water samples from the 2007, 2008, 2009, and 2010 field seasons were submitted to Actlabs for analysis by their High-Resolution ICP-MS method. Precision and accuracy values for the High-Resolution ICP-MS method appear to have improved each year from 2007 to 2010. This is especially the case for the SRM NIST1643 e used by Actlabs. However, despite improving precision values, accuracy results for USGS standard reference materials $\mathrm{T}-167$ and $\mathrm{T}-177$ consistently plotted a large number of elements with values that greatly exceed 115 percent Recovery. Independent analyses of T-177 at USGS laboratories in Denver showed accuracy numbers much closer to 100 percent Recovery. It is not clear whether these accuracy differences are due to a possible difference in the calibration between USGS and Activation Laboratories ICP-MS instrumentation or whether the problem is with the older USGS standard reference materials. Perhaps the increased sensitivity of the High-Resolution ICP-MS method may necessitate the development of new SRMs, or the re-certification of existing ones.

\section{Vegetation Analyses (Acme Analytical Laboratories, Ltd.)}

Vegetation samples collected during the 2007 field season were sent to Acme Labs for analysis. The only issues noted in the evaluation of quality control samples were with $\mathrm{Hg}$ and $\mathrm{S}$. Both of these elements may have small problems in reproducibility due to inhomogeneity within the sampled material from the Pebble area.

\section{Vegetation Analyses (Activation Laboratories, Ltd.)}

Vegetation samples collected during the 2007 field season were also sent to Actlabs for analysis. Precision measurements in quality control samples for all elements with mean values greater than 5 times their reporting limit were less than 30 percent RSD. The only exception was As in a standard known to have problems with the reproducibility of arsenic. 


\section{Geochemical Relational Database}

Because of the scope and complexity of the geochemical data collected as part of the Pebble deposit study, a relational database structure was designed for data storage. The Pebble deposit relational database was constructed for use as a data synthesis and analysis tool and as an archive of data collected during the study. It includes data from samples collected by USGS geoscientists within and adjacent to the Pebble deposit during the summers of 2007-2010. Data from 2007 and 2008 field seasons were previously released in Fey and others $(2008,2009)$. The database structure is similar to that used for 2008 Pebble sample results that were published by Fey and others (2009) and contains field measurements and laboratory analyses of samples collected at point locations. Quality assurance/quality control descriptions and interpretations are included in this report (see Geochemistry Data Quality Assurance and Quality Control section), but are not present in the database, or in the accompanying tables that have been derived from the database.

\section{Contents of Database}

The Pebble deposit database (PebbleGeochem.mdb) contains nine relational datasets. These datasets comprise all of the data derived from samples collected as part of the Pebble deposit study. Eight of these datasets, representing various types of data, were organized into 34 analytical data tables (fig. 2). A table of field name definitions was also created (FieldNameDictionary).

Data were collected at 426 sites (plus 20 duplicates) in the vicinity of the Pebble deposit (pl. 2). The database includes 178,899 results for 1,305 water subsamples, 1,796 soil subsamples, 80 pond-sediment grab samples, 123 pond-sediment core samples, 20 stream-sediment samples, 142 vegetation samples, and 11 rock samples. These entries contain quantitative, qualitative, and descriptive measurements. Data type discrimination is provided through the use of 410 unique parameters, or measurement types. The database also includes indicator mineralogy data for heavy mineral concentrate fractions of 71 till-sediment samples, as well as data for 349 gold grains separated from heavy mineral concentrate fractions (table 5).

\section{Database Structure}

Data are grouped into 9 primary logical units (tables), 34 secondary derivative tables, and relationships are defined to link the tables. This structure provides efficient storage of information, and provides for built-in data verification checks. For example, all valid results must have corresponding site, sample, and parameter information. The relational database structure is useful for efficient retrieval of subsets of data to meet user requirements.
The nine principal tables in the database are the FieldSite, Sample, QuantResult, QualResult, Parameter, IndicatorMineralogy, AnalyticMethod, AnalyticMethodBiblio and LabName tables (fig. 2). The FieldSite table contains information about each of the 446 sample sites in the database. FieldSiteNumber is the key field that uniquely identifies each site, which may be further described with data entered in the SiteLocationInfo, SiteDesc, and SiteComment fields. FieldSiteNumber is also the linking field between site and sample in a one-to-many relationship. The FieldSite table also includes Global Positioning System (GPS) geographic coordinate information in decimal degrees and in degrees/minutes/seconds (FieldLatitude_DD, FieldLongitude_DD, FieldLatitude_DMS and FieldLongitude_DMS), geologic and mineral deposit information, and information regarding weather conditions at the time of sampling. The relationship between the FieldSite table and other tables in the database is shown in figure 2.

The Sample table contains information about the sample material collected at each site. Each analyzed sample has a unique SampleID, as well as a SampleNumber that was provided by the sample collector. SampleID is the key field that links the sample to its chemical and physical data found in the QuantResult and QualResult tables. SampleID also links the sample to data found in the 34 derivative tables. The time and date of sample collection are noted in the SampleTime and SampleDate fields. The field SampleMediaGross defines the sample material type, while SampleMediaDetail, SampleSource, and SampleDesc provide more detailed information about the sample. Media type should be carefully noted when assessing data so that data from different sample types are not mistakenly equated. For example, the database contains analyses for copper found in 11 different subsamples that were derived from one soil sample site. The data in SampleMediaDetail show the different types of sample treatment used in preparation for different analytical methods that detect differing concentrations of copper. Information regarding the collection and preparation of the sample may be found in the optional fields CollectionMethod, FieldSamplePrep, LabSamplePrep, and SieveSize. The LAB_ID and JOB_ID information created by the various analytical laboratories, though not required, is found in the Sample table. Relationships between the Sample table and other tables in the database are shown in figure 2.

The QuantResult table contains laboratory and field measurements, expressed as numeric values, whereas the QualResult table (fig. 2) contains qualitative measurements that are expressed as text values. For the most part, the two tables function in the same way. Most of the project geochemical data are found in the QuantResult table. The measured characteristic is identified using a ParameterCode that can be used as a column name in a data report or spreadsheet. The ParameterCode links both result tables to the Parameter lookup table, which is further detailed later in this section. Measured characteristics such as units and techniques are identified using a Parameter entry, which is a concatenation of data from the fields ParameterCode and 


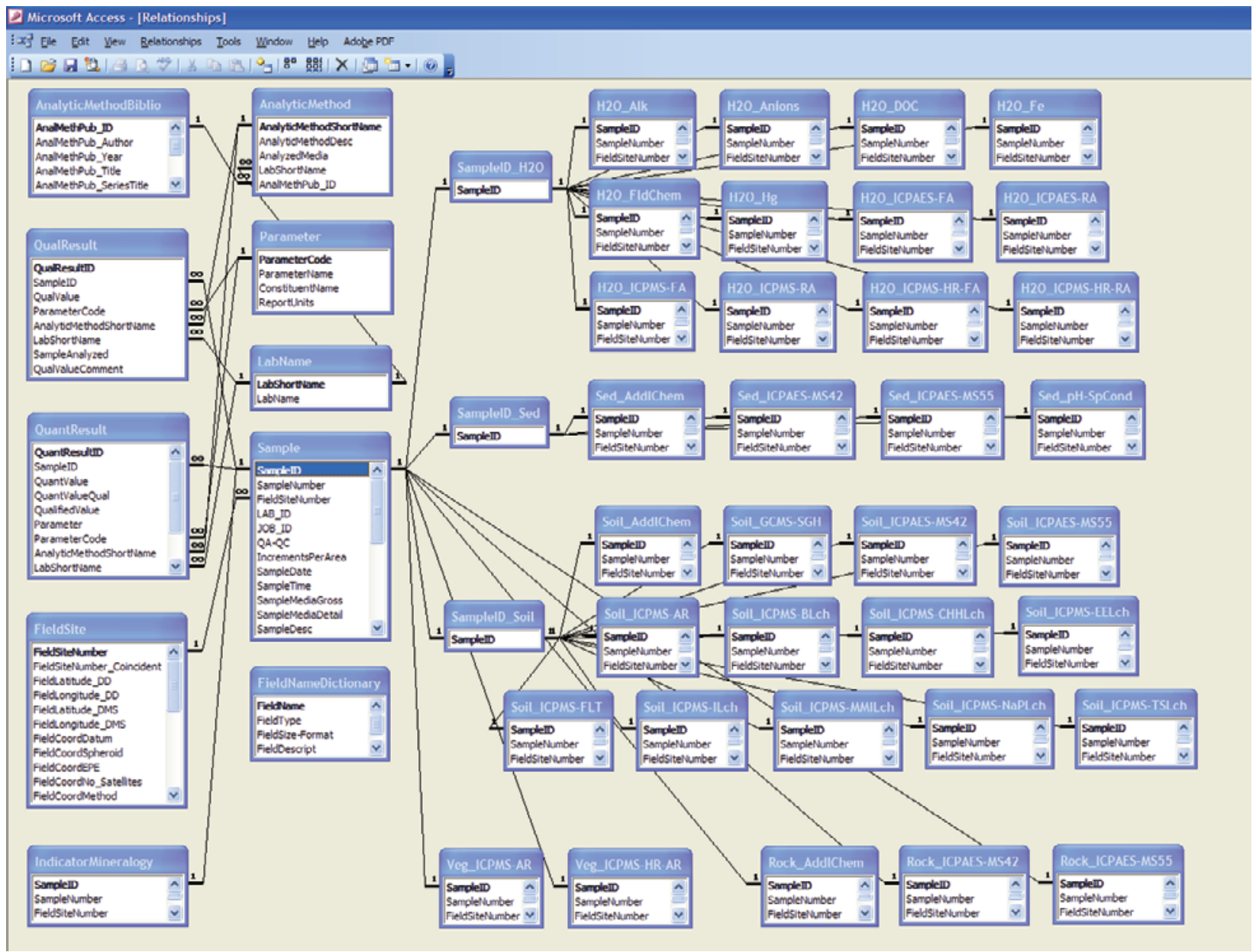

Figure 2. Tables in the relational database and the relationships between tables. The symbols "1" and " $\infty$ " at the ends of the relationship line indicate a one-to-many relationship; for example, a single site may have many samples.

AnalyticMethodShortName. There are 1,106 unique analytic parameters in the Pebble deposit database. For example, the parameter "Sb_ppb_MS-IL" represents the concentration of antimony, expressed in parts per billion, as detected by inductively coupled plasma-mass spectroscopy after ionic leach. Parameter is a succinct 35-character-length field that can be used as a column name in a data report or spreadsheet. Parameter entries are used as the field and column names of the derivative tables and are described in the FieldNameDictionary table. Measurements in QuantResult consist of a numeric QuantValue and an optional QuantValueQual, which is used to describe results such as nondetectable or estimates based on limits of instrumental detection. For example, nondetectable values are represented using a "less than" value, such as $<2$. Similarly a " $>$ " symbol indicates that a value is greater than the upper analytical determination limit (one instance in the database). QualifiedValue - entries used to populate the derivative tables - were generated by combining the data in QuantValue with its complement in QuantValueQual, according to the following convention: QuantValueQual entries that are accompanied by "<"entries in QuantValueQual are represented in QualifiedValue as negative numbers (for example, “-2"). QualifiedValue and Parameter fields greatly facilitate the use of cross-tab queries in the database. Information regarding the method of analysis or measurement used to obtain data is found in the AnalyticMethodShortName field; an abbreviated label linked to the AnalyticMethod lookup table, and provides additional information on field and laboratory techniques used for sample analysis. References for these analytic methods are contained in the AnalyticMethodBiblio lookup table, which is linked to AnalyticMethod by the common field AnalMethPub_ID. LabShortName is an abbreviated label field linked to the LabName lookup table and provides information regarding the laboratory or work group responsible for the analysis. Any further remarks regarding the value or the analytic process are found in the QuantValueComment field. Relationships between the QuantResult and 
QualResult tables and other tables in the database are shown in figure 2.

The Parameter table is a lookup table that contains a complete description of each characteristic measured. Whereas the QuantResult table contains a short description of the characteristic measured (ParameterCode), due to the highly specific nature of laboratory measurements, a lengthier description is needed. For example, the ParameterCode " $\mathrm{Cu} \_\mu \mathrm{g} / \mathrm{L}$ " is shorthand for "Copper, laboratory, micrograms per liter."

Relationships between these tables are depicted as lines in figure 2. The FieldSite table is linked to the Sample table by including a common field (FieldSiteNumber) in both tables. Therefore, a sample cannot exist without having a site in the FieldSite table. The symbols "1" and " $\infty$ " at the ends of the relationship line indicate a one-to-many relationship; for example, a single site may have many samples. Similarly, a sample may have many results, and a parameter may also have many results. Data may be extracted from the Pebble deposit relational database to meet specific user needs by constructing user-defined queries.

To facilitate ease of use, each of the 34 derivative tables represents a unique dataset containing analytical data gathered from a specific sample media by way of a certain analytic method (media/method specific datasets). For example, the table H2O_ICPMS-HR-FA contains chemical concentrations in filtered, acidified water obtained by high-resolution inductively coupled plasma-mass spectrometry (ICP-MS). Tables containing data for water, sediment, and soil media are grouped by sample media and linked to the Sample table by way of the sample media junction tables SampleID_H2O, SampleID_Sed, and SampleID_Soil (fig. 2). The sediment tables contain data for stream, pond bottom, and pond core sediments. The data for these three sediment types can be separated and retrieved by querying the field SampleSource in these four sediment data tables. To further aid the user, these tables were used to create spreadsheets of all the information in the database. The table FieldNameDictionary contains the field name, definition, and general data type of the 1,194 fields that are used in the tables of the Pebble deposit relational database, as well as the table or tables in which these fields appear. This is of particular importance as it contains the field names of the 31 cross-tab chemical data tables. These tables have also been exported as Excel spreadsheets (Microsoft, 2011) and as tab-delimited text files for use by the non-database user and are attached to this report in the folders "PebbleGeochem_xls" and "PebbleGeochem_txt." A summary of the Excel file names and a brief description of contents are in table 6.

Relational databases can be implemented using a variety of proprietary or non-proprietary software packages. The Pebble deposit relational database is attached to this report in a proprietary (Microsoft Office Access 2003, Microsoft, 2011) and non-proprietary (ASCII tab-delimited) format. The spreadsheets are accessible in the same manner in Microsoft Office Excel 2003 format (Microsoft, 2011).

\section{Geographic Information System (GIS)}

This report contains data that spans multiple geoscientific disciplines. Much of the data presented in this report has been integrated into a Geographic Information System (GIS) database. The GIS database also contains spatial data sets previously released by the USGS that may facilitate data interpretation. Admittedly, this is not a complete set of USGS spatial data for southwest Alaska. The user is encouraged to pursue more USGS spatial data, such as those referenced in the "Previous Work" section, as well as integrate their own data. The purpose of the GIS database is to provide a collection of geoscientific data sets to support the assessment of concealed mineral resources in southwest Alaska.

The GIS data consists of both raster and vector data types. The raster data are in binary ESRI GRID, ERDAS IMAGINE (.img), and Tagged Image File Format (.TIF) that can be used in many common GIS software packages (ESRI, 2011; ERDAS, 2011). The vector data consists of points, lines, and polygons and are mostly presented in ESRI shapefile format. The geochemical datasets collected from 2007-2010 are presented as an ESRI File Geodatabase. The reason for using the File Geodatabase format is to preserve attribute headings, which are limited to 10 characters in shapefiles, so that the column headers better describe the underlying data. The data within the File Geodatabase are derived from the Geochemical Relational Database (see previous section). The vector data also contain tabular information describing features within the data sets. All GIS data have been projected into the UTM Zone $5 \mathrm{~N}$, WGS84 projection.

The GIS data have been divided into 10 directories (Appendix 5). The ARDF, BaseLayers, DEM, Geology, Hydrology, Landsat, and RadiometricAges directories contain data that have been previously released by the USGS. The Contours directory contains contour lines that were provided by the Pebble Limited Partnership. The Geochemistry and Geophysics directories contain the newly acquired data presented in this report. The Geochemistry directory also contains legacy USGS geochemical data from the National Uranium Resource Evaluation Program (NURE). The Photos directory contains photographs of soil sample sites visited during the study, as well as response functions for each MT site. The photographs can be hyperlinked in the GIS to their appropriate sample site location. The 'hyperlink' tool in ArcGIS 9.X (ESRI, 2011) is used for this function.

The GIS database contains ESRI map documents that facilitate the display of the GIS database. A map exchange document (.mxd) is provided (USGS_SouthwestAK.mxd). This document is an ESRI ArcGIS 9.X project file that displays the underlying GIS data using ArcGIS 9.X software. The map exchange document contains relative paths to increase its portability. A published map document (.pmf) is also provided (USGS_SouthwestAK.pmf). This document contains identical data as those found on the map exchange document (.mxd). The published map document (.pmf) may be viewed using 
ArcReader 9.X. ArcReader is freely available from the ESRI website (http://www.esri.com/).

The map documents display map representations of the GIS database. The representations used here are not the only way in which the data may be displayed. The representations chosen are simply to help illustrate the distribution of the data values. For example, the geochemical data has been statistically grouped into percentiles to help illustrate the distribution of the chemical concentrations. All data representations should be further explored by the user.

\section{Acknowledgments}

We are grateful to the Pebble Limited Partnership (PLP, a partnership between Northern Dynasty Mineral, NDM; and Anglo American) for allowing access onto the Pebble property, for logistical support while in the field, providing proprietary color orthophotography, and for general encouragement in pursuing this research effort. In particular, we thank Mark Rebagliati (Geological Consulting), Lena Brommeland (NDM), Jim Lang (Lang Geoscience, Inc.), Robin Smith (PLP), and Gernot Wober (PLP) for facilitating logistics and providing geologic insight. For field assistance, we thank Crystal Chung, Cassady Harraden, Lindsey Kleppin, Brian McNulty, Miguel Ricardo, and Nicola Struyk (all from PLP); Megan Cardenas (University of Alaska); Déne Tarkyth (Anglo American); and Chad Ailes and Katie Jeffcoat (USGS). We are also thankful to the following commercial analytical laboratories and associated individuals for contributing analytical support: John Gravel, Acme Analytical Laboratories, Ltd. (www. acmelab.com), Eric Hoffman, Activation Laboratories, Ltd. (www.actlabs.com), S. Mary Doherty and Brenda Caughlin, ALS Minerals (www.alsglobal.com), Pierrete Prince, SGS Minerals Services (www.sgs.com), and J. Robert Clark, Skyline Assayers and Laboratories (www.skylinelab.com). We also thank the following USGS analysts: Monique Adams, Michael Anthony, Todor Todorov, Zoe Ann Brown, and Phil Hageman. Richard O'Leary provided great assistance with data management. We thank Mike Webring, USGS, for thoughtful discussions regarding collection and processing challenges and for help with preparing equipment for the field. Jean Morrison, Bob Horton, Rich O'Leary, and Paul Denning provided helpful internal reviews. Any use of trade names is for descriptive purposes only and does not imply endorsement by the U.S. Government.

\section{References Cited}

Acme Analytical Laboratories, 2010, AcmeLabs 2009-2010

Services and Fees: Vancouver, B.C., Canada, Acme Analytical Laboratories, Ltd., 42 p., accessed January 26, 2011, at http://acmelab.com/pdfs/Acme_Price_Brochure.pdf.
Actlabs, 2008, 2008 international schedule of services and fees: Actlabs Group of Companies, 28 p., accessed January 26, 2011, at http://www.actlabsint.com/pricelist/ serviceguide08_international.pdf.

Actlabs, 2010, Soil gas hydrocarbons: Activation Laboratories, Ltd., accessed January 26, 2011, at http://www.actlabs.com/ page.aspx $?$ menu $=74 \&$ app $=244 \&$ cat $1=591 \& t p=2 \& l k=n o$.

ALS Minerals, 2008, pH controlled ionic leach with ICPMS finish, code ME-MS23: ALS Minerals, Short Method Descriptions, accessed at http://www.alsglobal.com/ minerals/downloads/short-method-descriptions.aspx.

ALS Minerals, 2010, Selective leach geochemistry: ALS Minerals, Mineral Division, accessed January 26, 2011, at http://alsglobal.com/minerals/services.aspx.

Averill, S.A., 2001, The application of heavy indicator mineralogy in mineral exploration with emphasis on base metal indicators in glaciated metamorphic and plutonic terrains, in McClenaghan, M.B., and others, eds., Drift Exploration in Glaciated Terrain: Geological Society of London, Special Publication 185, p. 69-81.

Averill, S.A., 2007, Recent advances in base metal indicator mineralogy-An update from Overburden Drilling Management Limited: Explore, Newsletter of the Association of Applied Geochemists, 134, p. 2-6.

Baranov, V., and Naudy, Henri, 1964, Numerical calculation of the formula of reduction to the magnetic pole: Geophysics, v. 29, p. $67-79$.

Bedrosian, P.A., Shah, A.K., Anderson, E.D., and Kelley, K.D., 2010, Geophysical investigations into the tectonic and magmatic evolution of the Kahiltna terrane, SW Alaska: Geological Society of America Abstracts with Programs, v. 42 , no. 5 , p. 676 .

Blakely, R.J., 1996, Potential theory in gravity and magnetic applications: Cambridge, U.K., Cambridge University Press, $461 \mathrm{p}$.

Briggs, P.H., 2002, The determination of twenty-seven elements in aqueous samples by inductively coupled plasmaatomic emission spectrometry, in Taggart, J.E., Jr., ed., Analytical methods for chemical analysis of geologic and other materials, U.S. Geological Survey: U.S. Geological Survey Open-File Report 02-223, chapter F, 11 p.

Cagniard, Louis, 1953, Basic theory of the magneto-telluric method of geophysical prospecting: Geophysics 18, p. 605-635.

Castermant, J., Mendonça, C.A., Revil, A., Trolard, F., Bourrié, G., and Linde, N., 2008, Redox potential distribution inferred from self-potential measurements associated with the corrosion of a burden metallic body: Geophysical Prospecting, 56(2), p. 269-282. 
Chao, T.T., 1984, Use of partial dissolution techniques in geochemical exploration: Journal of Geochemical Exploration, v. 20 , no. 2 , p. 101-135.

Connard, G.G., Saltus, R.W., Hill, P.L., Carlson, Louis, and Milicevic, B., 1999, Alaska digital aeromagnetic database description (on-line edition): U.S. Geological Survey OpenFile Report 99-0503, available at http://pubs.usgs.gov/ of/1999/ofr-99-0503/DBDESC.HTM.

Dux, J.P., 1986, Handbook of quality assurance for the analytical chemistry laboratory: New York, Van Nostrand Reinhold Company, Inc., 123 p.

Egbert, G.D., 1997, Robust multiple-station magnetotelluric data processing: Geophys. J. Int., v. 130, p. 475-496.

Egbert, G.D., and Booker, J.R., 1986, Robust estimation of geomagnetic transfer functions: Geophysical Journal of the Royal Astronomical Society, v. 87, p. 173-194.

Electromagnetic Instruments, Inc. (EMI), 2010, EMI Technology Center, Richmond, California, accessed at http://www. slb.com/about/rd/technology/emi.aspx.

ERDAS, 2011, ERDAS IMAGINE software: ERDAS, Inc., Lakewood, Colorado, available at http://www.erdas.com.

ESRI, 2011, ArcGIS-ArcInfo computer software: Environmental Systems Research Institute, Inc., Redlands, California, available at http://www.esri.com/software/arcexplorer/.

Fey, D.L., Granitto, Matthew, Giles, S.A., Smith, S.M., Eppinger, R.G., and Kelley, K.D., 2008, Geochemical data for samples collected in 2007 near the concealed Pebble porphyry Cu-Au-Mo deposit, southwest Alaska: U.S. Geological Survey Open-File Report 2008-1132, $154 \mathrm{p}$.

Fey, D.L., Granitto, Matthew, Giles, S.A., Smith, S.M., Eppinger, R.G., and Kelley, K.D., 2009, Geochemical data for samples collected in 2008 near the concealed Pebble porphyry Cu-Au-Mo deposit, Southwest Alaska: U.S. Geological Survey Open-File Report 2009-1239.

Fournier, Claude, 1989, Spontaneous potentials and resistivity surveys applied to hydrogeology in a volcanic area-Case history of the Chaine-Des-Puys (Puy-De-Dome, France): Geophysical Prospecting, v. 37, no. 6, p. 647-668.

Gamble, T.D., Goubau, W.M., and Clarke, J., 1979, Magnetotellurics with a remote reference: Geophysics, 44, no. 1, p. 53-68.

Geosoft, 2010, Geosoft Oasis montaj software: Geosoft, Inc., Toronto, Canada, available at http://www.geosoft.com.
Gesch, D.B., Evans, Gayla, Mauck, James, Hutchinson, John, and Carswell, W.J., Jr., 2009, The National MapElevation: U.S. Geological Survey Fact Sheet 2009-3053, $4 \mathrm{p}$.

Hageman, P.L., and Briggs, P.H., 2000, A simple field leach test for rapid screenings and qualitative characterization of mine waste dump material on abandoned mine lands, in ICARD 2000, Proceedings of the Fifth International Conference on Acid Rock Drainage, Denver, Colo., May 21-24: Society for Mining, Metallurgy, and Exploration, Inc., p. 1463-1475.

Hamilton, S.M., 2000, Spontaneous potentials and electrochemical cells, in Hale, M., ed., Handbook of Exploration Geochemistry, volume 7, Geochemical remote sensing of the sub-surface: Amsterdam, Elsevier Science B.V., p. 81-119.

Ishido, Tsuneo, and Mizutani, Hitoshi, 1981, Experimental and theoretical basis of electrokinetic phenomena in rock-water systems and its applications to geophysics: Journal of Geophysical Research, v. 86, no. B3, p. 1763-1775.

Kellogg, O.D., 1953, Foundations of potential theory: New York, Dover Publications.

Lamothe, P.J., Meier, A.L., and Wilson, S.A., 2002, The determination of forty-four elements in aqueous samples by inductively coupled plasma-mass spectrometry, in Taggart, J.E., Jr., ed., Analytical methods for chemical analysis of geologic and other materials, U.S. Geological Survey: U.S. Geological Survey Open-File Report 02-223, chapter H, $13 \mathrm{p}$.

Luyendyk, A.P.J., 1997, Processing of airborne magnetic data: AGSO Journal of Australian Geology and Geophysics, v. 17 , no. 2 , p. $31-38$.

Microsoft, 2011, Microsoft Office software: Microsoft Corp., Redmond, Washington, available at http://www.microsoft. com.

Minsley, B.J., Coles, D.A., Vichabian, Yervant, and Morgan, F.D., 2008, Minimization of self-potential survey mis-ties acquired with multiple reference locations: Geophysics, v. 73, no. 2, p. F71-F81.

Minsley, B.J., Ball, L.B., Burton, B.L., Caine, J.S., CurryElrod, Erika, and Manning, A.H., 2010, Geophysical characterization of subsurface properties relevant to the hydrology of the Standard Mine in Elk Basin, Colorado: U.S. Geological Survey Open-File Report 2009-1284, 46 p.

Morgan, F.D., Williams, E.R., and Madden, T.R., 1989, Streaming potential properties of Westerly granite with applications: Journal of Geophysical Research-Solid Earth, v. 94, no. B9, p. 12449-12461. 
Nabighian, M.N., 1972, The analytic signal of two-dimensional magnetic bodies with polygonal cross-section-Its properties and use for automated anomaly interpretation: Geophysics, v. 37, no. 3, p. 507-517.

National Institute of Standards and Technology, 2002, Standard Reference Material 1575a - Trace elements in pine needles (Pinus taeda): National Institute of Standards and Technology Certificate of Analysis, Issue date 17 September 2002, 5 p., accessed March 24, 2011, at https://www-s.nist. gov/srmors/certificates/1575a.pdf.

National Institute of Standards and Technology, 2008, Standard Reference Material 1640 - Trace elements in natural water: National Institute of Standards and Technology Certificate of Analysis, Issue date 06 February 2008, 5 p., accessed March 24, 2011, at https://www-s.nist.gov/srmors/ certificates/1640.pdf.

National Institute of Standards and Technology, 2009, Standard Reference Material 1643e - Trace elements in natural water: National Institute of Standards and Technology Certificate of Analysis, Issue date 26 March 2009, 5 p., accessed March 24, 2011, at https://www-s.nist.gov/srmors/ certificates/1643e.pdf.

Natural Resources Conservation Service, 1996, Soil survey laboratory methods manual: U.S. Department of Agriculture, Natural Resources Conservations Service, National Soil Survey Center, Soil Survey Investigations Report No. 42, Version 3.0, 675 p., available at $f t p: / / f t p-f c$. sc.egov.usda.gov/NSSC/Lab_Methods_Manual/ssir42.pdf.

Naudet, V., Revil, A., Bottero, J.-Y., and Bégassat, P., 2003, Relationship between self-potential (SP) signals and redox conditions in contaminated groundwater: Geophysical Research Letters, v. 30, no. 21, p. 2091.

Nettleton, L.L., 1971, Elementary gravity and magnetics for geologists and seismologists: Tulsa, Okla., Society of Exploration Geophysicists Monograph Series, no. 1, 121 p.

Parkinson, W.D., 1959, Directions of rapid geomagnetic fluctuations: Geophysical Journal of the Royal Astronomical Society, v. 2, p. 1-14.

Petiau, Gilbert, 2000, Second generation of lead-lead chloride electrodes for geophysical applications: Pure \& Applied Geophysics, v. 157 , p. 357-382.

Revil, A., Naudet, V., and Meunier, J.D., 2004, The hydroelectric problem of porous rocks: Inversion of the position of the water table from self-potential data: Geophysical Journal International, v. 159, no. 2, p. 435-444.
Revil, A., Pezard, P.A., and Glover, P.W.J., 1999, Streaming potential in porous media 1 . Theory of the zeta potential: Journal of Geophysical Research-Solid Earth, v. 104, no. B9, p. 20021-20031.

Saltus, R.W., Brown, P.J., II, Morin, R.L., and Hill, P.L., 2008, 2006 compilation of Alaska gravity data and historical reports: U.S. Geological Survey Data Series 264, CD-ROM.

Sato, Motoaki, and Mooney, H.M., 1960, The electrochemical mechanism of sulfide self-potentials: Geophysics, v. 25, no. 1 , p. 226-249.

Schmucker, Ulrich, 1970, Anomalies of geomagnetic variations in the southwestern United States: Bulletin of the Scripps Institution of Oceanography, Univ. Calif. Press, v. 13,160 p.

Scintrex, 2009, CG-5 Scintrex Autograv System Operation Manuel: Scintrex Limited, Concord, Ontario, Canada. available at $h t t p: / /$ scintrexltd.com/.

SGS Mineral Services, 2011a, MMI overview: SGS Mineral Services, accessed January 26, 2011, at http://www.geochem.sgs.com/mmi-overview.htm.

SGS Mineral Services, 2011b, Geochemistry analysis guide: SGS Mineral Services, 59 p., accessed at January 26, 2011, at http://www.geochem.sgs.com/documents/sgsmin-geochem-guide-2011-booklet-v2-en-11.pdf.

Shah, A.K., Bedrosian, P.A., Anderson, E.D., Brown, Philip, Kelley, K.D., and Lang, J.R., 2010, Gravity, magnetotelluric, and magnetic field data distinguish magmatic features in the Iliamna-Lake Clark region near the Pebble porphyry deposit: Geological Society of America Abstracts with Programs, v. 42, no. 5, p. 676.

Shimadzu Corporation, 1997, Model TOC 5000 An instrument manual: Shimadzu Corporation, Kyoto, Japan, 155 p.

Sill, W.R., 1983, Self-potential modeling from primary flows: Geophysics, v. 48, no. 1, p. 76-86.

Simley, J.D., and Carswell, W.J., Jr., 2009, The National Map-Hydrography: U.S. Geological Survey Fact Sheet 2009-3054, 4 p.

Sivenas, Prokopis, and Beales, F.W., 1982a, Natural geobatteries associated with sulfide ore deposits, 1 . Theoreticalstudies: Journal of Geochemical Exploration, v. 17, no. 2, p. 123-143.

Sivenas, Prokopis, and Beales, F.W., 1982b, Natural geobatteries associated with sulfide ore deposits, II. Field studies at the Viburnum Trend, southeast Missouri, U.S.A.: Journal of Geochemical Exploration, v. 17, no. 2, p. 145-160. 
Skyline Assayers and Laboratories, 2011, 2011 schedule of services and fees: Skyline Assayers and Laboratories, Tucson, Arizona, 12 p., accessed January 26, 2011, at http:// www.skylinelab.com/docs/Skyline_Labs-2011_Schedule_of_ Services_and_Fees-20101119-EN-WEB.pdf.

Smith, D.A., and Roman, D.R., 2001, GEOID99 and G99SSS-1-arc-minute geoid models for the United States: Journal of Geodesy, v. 75, p. 469-490.

Smith, S.M., 1997, National Geochemical Database-Reformatted data from the National Uranium Resource Evaluation (NURE) Hydrogeochemical and Stream Sediment Reconnaissance (HSSR) Program: U.S. Geological Survey Open-File Report 97-492, available at http://pubs.usgs.gov/ of/1997/ofr-97-0492/.

Telford, W.M., Geldart, L.P., and Sheriff, R.E., 1990, Applied Geophysics, 2nd ed.: New York, Cambridge University Press.

Theodorakos, P.M., 2002, Determination of total alkalinity using a preset endpoint $(\mathrm{pH} 4.5)$ autotitration system, in Taggart, J.E., Jr., ed., Analytical methods for chemical analysis of geologic and other materials, U.S. Geological Survey: U.S. Geological Survey Open-File Report 02-223, chap. E, 3 p. (Also available at $h t t p: / / p u b s . u s g s . g o v / o f / 2002 /$ ofr-02-0223.)

Theodorakos, P.M., d'Angelo, W.M., and Ficklin, W.H., 2002, Fluoride, chloride, nitrate, and sulfate in aqueous solution utilizing AutoSupression chemically suppressed ion chromatography, in Taggart, J.E., Jr., ed., Analytical methods for chemical analysis of geologic and other materials, U.S. Geological Survey: U.S. Geological Survey Open-File Report 02-223, chap. V, 7 p. (Also available at http://pubs. usgs.gov/of/2002/ofr-02-0223.)

Tikhonov, A.N., 1950, On determining electrical characteristics of the deep layers of the Earth's crust: Doklady Akademy Nauk SSSR, v. 73, p. 295-297.

To, T.B., Nordstrom, D.K., Cunningham, K.M., Ball, J.W., and McCleskey, R.B., 1999, New method for the direct determination of dissolved Fe (III) concentration in acid mine waters: Environmental Science and Technology, v. 33, no. 5, p. $807-813$.

Urquhart, Ted, 1988, Decorrugation of enhanced magnetic field maps: Society of Exploration Geophysicists FiftyEighth Annual Meeting, GM1-Gravity and Magnetics Session, Expanded Abstracts 7, Anaheim, California, p. 371-372. (Available at http://library.seg.org/dbt/dbt.jsp?KE $Y=S E G E A B \&$ Volume $=7 \&$ Issue $=1 \&$ Sect $=14$.)

U.S. Geological Survey, 1999, Radiometric ages of rocks from Alaska: U.S. Geological Survey database, accessed May 25, 2010, at http://tin.er.usgs.gov/akages.
U.S. Geological Survey, 2002, Aeromagnetic surveys in the Anchorage, Iliamna, and Tyonek Quadrangles, Alaska-A website for the distribution of data: U.S. Geological Survey Open-File Report 02-0267. (Also available at $h t t p: / / p u b s$. usgs.gov/of/2002/ofr-02-0267/.)

U.S. Geological Survey, 2006a, Aeromagnetic survey of Taylor Mountains area in southwest Alaska-A website for the distribution of data: U.S. Geological Survey Data Series 224.

U.S. Geological Survey, 2006b, Aeromagnetic survey of Dillingham area in southwest Alaska-A website for the preliminary distribution of data: U.S. Geological Survey Open-File Report 06-1136. (Also available at http://pubs. usgs.gov/of/2006/1136/.)

U.S. Geological Survey, 2008, The Alaska resource data file (ARDF): U.S. Geological Survey database, accessed May 25, 2010, at http://ardf.wr.usgs.gov/.

U.S. Geological Survey, 2010, Landsat: A global land-imaging project: U.S. Geological Survey Fact Sheet 2010-3026.

Vozoff, Keeva, 1991, The magnetotelluric method, in Nabighian, M.N., ed., Electromagnetic methods in applied geophysics: Tulsa, Oklahoma, Society of Exploration Geophysicists, v. 2, 641-711.

Webring, M.W., 1981, MINC—A gridding program based on minimum curvature: U.S. Geological Survey Open-File Report 81-1224, 41 p.

Wight, D.E., 1987, MT/EMAP Data Interchange Standard, Revision 1.0: Society of Exploration Geophysicists Techni-

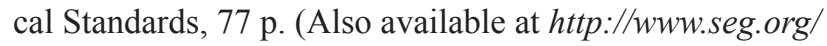
resources/publications/misc/technical-standards.)

Wilson, F.H., Blodgett, R.B., Blome, C.D., Mahadjer, S, Preller, C.C., Klimasauskas, E.P., Gamble, B.M., and Coonrad, W.L., 2006, Reconnaissance bedrock geologic map for the northern Alaska Peninsula area, southwest Alaska: U.S. Geological Survey Open-File Report 06-1303. (Also available at $h t t p: / / p u b s . u s g s . g o v / o f / 2006 / 1303 /$. 
Table 1. Compilation of specifications for five regional aeromagnetic surveys flown between 1977 and 2005, southwest Alaska.

[m, meters; km, kilometers]

\begin{tabular}{lccccc}
\hline \multicolumn{1}{c}{ Survey } & Year & $\begin{array}{c}\text { Nominal terrane } \\
\text { clearance }(\mathbf{m})\end{array}$ & $\begin{array}{c}\text { Flight line } \\
\text { separation }(\mathbf{m})\end{array}$ & IGRF year & $\begin{array}{c}\text { Area covered } \\
\left.\mathbf{( k m}^{2}\right)\end{array}$ \\
\hline Dillingham & 2005 & 305 & 1,600 & 2000 & 20,716 \\
Iliamna & 2000 & 305 & 1,600 & 1995 & 16,207 \\
Lake Clark & 1977 & 305 & 1,600 & 1980 & 21,130 \\
Rio & 2000 & 305 & 1,600 & 1995 & 9,553 \\
Taylor Mountains & 2004 & 305 & 1,600 & 2000 & 18,870 \\
\hline \multicolumn{1}{l}{ International Geomagnetic Reference Field }
\end{tabular}

Table 2. Previous gravity station locations and values used for gravity ties in the Iliamna/Lake Clark area, southwest Alaska.

[mGal, milligals; WGS84, World Geodetic System of 1984]

\begin{tabular}{lccc}
\hline \multicolumn{1}{c}{ Name } & $\begin{array}{c}\text { Measured gravity } \\
\text { (mGal) }\end{array}$ & Lat (WGS84) & Long (WGS84) \\
\hline ILIA & 981888.5 & $59^{\circ} 45.189^{\prime} \mathrm{N}$ & $154^{\circ} 54.642^{\prime} \mathrm{W}$ \\
ILIA & 981888.44 & $59^{\circ} 45.189^{\prime} \mathrm{N}$ & $154^{\circ} 54.642^{\prime} \mathrm{W}$ \\
ILIA & 981888.44 & $59^{\circ} 45.189^{\prime} \mathrm{N}$ & $154^{\circ} 54.642^{\prime} \mathrm{W}$ \\
ILIA & 981888.38 & $59^{\circ} 45.189^{\prime} \mathrm{N}$ & $154^{\circ} 54.642^{\prime} \mathrm{W}$ \\
ILIA & 981888.43 & $59^{\circ} 45.189^{\prime} \mathrm{N}$ & $154^{\circ} 54.642^{\prime} \mathrm{W}$ \\
ILIA & 981888.38 & $59^{\circ} 45.189^{\prime} \mathrm{N}$ & $154^{\circ} 54.642^{\prime} \mathrm{W}$ \\
ILIA & 981888.42 & $59^{\circ} 45.189^{\prime} \mathrm{N}$ & $154^{\circ} 54.642^{\prime} \mathrm{W}$ \\
ILIA Average: 981888.43 & & \\
ZB 9 & 981888.45 & $59^{\circ} 45.209^{\prime} \mathrm{N}$ & $154^{\circ} 54.632^{\prime} \mathrm{W}$ \\
KM72 & 981888.43 & $59^{\circ} 45.209^{\prime} \mathrm{N}$ & $154^{\circ} 54.632^{\prime} \mathrm{W}$ \\
ZB9/KM72 Average: 981888.44 & & \\
LJ49 & 981906.87 & $60^{\circ} 05.139^{\prime} \mathrm{N}$ & $155^{\circ} 30.554^{\prime} \mathrm{W}$ \\
DM45 & 981917.34 & $60^{\circ} 14.528^{\prime} \mathrm{N}$ & $156^{\circ} 19.165^{\prime} \mathrm{W}$ \\
\hline
\end{tabular}

Table 3. Comparison of new adjusted data to previous gravity station values used for gravity ties in the lliamna/Lake Clark area, southwest Alaska.

[WGS84, World Geodetic System of 1984; mGal, milligals]

\begin{tabular}{lccclc}
\hline $\begin{array}{c}\text { New } \\
\text { station }\end{array}$ & $\begin{array}{c}\text { Latitude } \\
\text { (WGS84) }\end{array}$ & $\begin{array}{c}\text { Longitude } \\
\text { (WGS84) }\end{array}$ & $\begin{array}{c}\text { Estimated } \\
\text { gravity } \\
\text { (mGal) }\end{array}$ & $\begin{array}{c}\text { Previous } \\
\text { station }\end{array}$ & $\begin{array}{c}\text { Station } \\
\text { gravity } \\
\text { (mGal) }\end{array}$ \\
\hline ILIA & $59^{\circ} 45.188^{\prime} \mathrm{N}$ & $154^{\circ} 54.644^{\prime} \mathrm{W}$ & 981888.43 & ILIA & 981888.43 \\
ILIB & $59^{\circ} 45.206^{\prime} \mathrm{N}$ & $154^{\circ} 54.638^{\prime} \mathrm{W}$ & 981888.44 & ZB9/KM72 & 981888.44 \\
TIE1 & $60^{\circ} 05.123^{\prime} \mathrm{N}$ & $155^{\circ} 30.579^{\prime} \mathrm{W}$ & 981906.80 & LJ49 & 981906.87 \\
TIE2 & $60^{\circ} 14.493^{\prime} \mathrm{N}$ & $156^{\circ} 18.914^{\prime} \mathrm{W}$ & 981918.43 & $\mathrm{DM} 45$ & 981917.34 \\
\hline
\end{tabular}


Table 4. Number of geochemical sample media collected from 2007 to 2010 in the Pebble porphyry deposit study area, southwest Alaska.

\begin{tabular}{|c|c|c|c|c|}
\hline \multirow{2}{*}{ Media } & \multicolumn{4}{|c|}{ Year } \\
\hline & \multirow{2}{*}{$\begin{array}{c}\mathbf{2 0 0 7} \\
11\end{array}$} & 2008 & \multirow{2}{*}{$\frac{\mathbf{2 0 0 9}}{22}$} & \multirow{2}{*}{$\begin{array}{c}\mathbf{2 0 1 0} \\
22\end{array}$} \\
\hline Tills (TIL) & & 16 & & \\
\hline Stream Sediments (STS) & 8 & 12 & 0 & 0 \\
\hline Pond Sediments (PDS) & 0 & 57 & 19 & 0 \\
\hline Pond Core Sediments (subsample intervals) (CR) & 0 & $2 *$ & $5 * *$ & 0 \\
\hline Rocks (R) & 2 & 5 & 4 & 0 \\
\hline \multicolumn{5}{|l|}{ Vegetation } \\
\hline Willow (VWI) & 21 & 0 & 0 & 0 \\
\hline Bog Birch (VBB) & 13 & 0 & 0 & 0 \\
\hline Alder $(V A L)$ & 12 & 0 & 0 & 0 \\
\hline \multicolumn{5}{|l|}{ Soil } \\
\hline Enzyme Leach (SEZ) & 85 & 102 & 23 & 0 \\
\hline TerraSol Leach (STL) & 85 & 102 & 23 & 0 \\
\hline Mobile Metal Ion Leach (SMM) & 77 & 0 & 0 & 0 \\
\hline Cold Hydroxylamine Leach (SCH) & 77 & 79 & 23 & 0 \\
\hline Ionic Leach (SIL) & 72 & 66 & 23 & 0 \\
\hline Aqua Regia (SAR) & 77 & 69 & 23 & 0 \\
\hline Total Analysis (STO) & 77 & 79 & 23 & 0 \\
\hline Soil $p H$ and Conductivity(SPH) & 77 & 79 & 23 & 0 \\
\hline De-ionized Water Leach (LFA) & 77 & 0 & 0 & 0 \\
\hline Sodium Pyrophosphate Leach (SNP) & 86 & 0 & 0 & 0 \\
\hline Soil Gas Hydrocarbons (SGH) & 86 & 0 & 0 & 0 \\
\hline Bio Leach $(S B L)$ & 86 & 0 & 0 & 0 \\
\hline \multicolumn{5}{|l|}{ Waters } \\
\hline Filtered acidified (FA) & 42 & 77 & 21 & 27 \\
\hline Unfiltered acidified ( $R A)$ & 41 & 77 & 21 & 27 \\
\hline$H R-I C P M S-F A$ & 42 & 77 & 21 & 27 \\
\hline$H R-I C P M S-R A$ & 0 & 77 & 21 & 27 \\
\hline ICPMS-FA & 42 & 0 & 0 & 0 \\
\hline$I C P M S-R A$ & 41 & 0 & 0 & 0 \\
\hline ICPAES-FA & 42 & 0 & 0 & 0 \\
\hline ICPAES-RA & 41 & 0 & 0 & 0 \\
\hline Anions (FU) & 42 & 77 & 21 & 27 \\
\hline$F e(I I)(F E)$ & 42 & 77 & 21 & 27 \\
\hline Alkalinity $(A L K)$ & 39 & 58 & 21 & 25 \\
\hline$H g(H G)$ & 39 & 0 & 0 & 0 \\
\hline Field Test (null) & 43 & 83 & 21 & 27 \\
\hline$D O C(D O C)$ & 41 & 77 & 21 & 27 \\
\hline
\end{tabular}

* Subsampled at $2 \mathrm{~cm}$ interval

**Subsampled at $2.5 \mathrm{~cm}$ interval 
Table 5. Samples and subsamples in the Pebble deposit database.

\begin{tabular}{|c|c|c|}
\hline Sample & Subsample & Count \\
\hline mineral & gold grains & 349 \\
\hline rock & acid, sinter or fusion digestion of rock & 11 \\
\hline sediment & acid, sinter or fusion digestion of pond sediment & 80 \\
\hline sediment & acid, sinter or fusion digestion of pond sediment core & 123 \\
\hline sediment & acid, sinter or fusion digestion of stream sediment & 21 \\
\hline sediment & stream sediment, heavy mineral concentrate & 20 \\
\hline sediment & till, heavy mineral concentrate & 71 \\
\hline soil & acid, sinter or fusion digestion of soil & 189 \\
\hline soil & aqua regia leachate of soil & 180 \\
\hline soil & aqueous extract for soil gas hydrocarbons & 91 \\
\hline soil & BioLeach leachate of soil & 91 \\
\hline soil & cold hydroxylamine hydrochloride leachate of soil & 189 \\
\hline soil & de-ionized water Field Leach Test leachate of soil & 82 \\
\hline soil & enhanced Enzyme Leachate of soil & 221 \\
\hline soil & ionic leachate of soil & 170 \\
\hline soil & mobile metal ion leachate of soil & 82 \\
\hline soil & $\mathrm{pH}$ and specific conductance of soil & 165 \\
\hline soil & sodium pyrophosphate leachate of soil & 91 \\
\hline soil & split for mobile metal ion leachate of soil & 24 \\
\hline soil & TerraSol leachate of soil & 221 \\
\hline vegetation & aqua regia leachate of alder leaves and twigs & 13 \\
\hline vegetation & aqua regia leachate of bog birch leaves and twigs & 9 \\
\hline vegetation & aqua regia leachate of dwarf bog birch leaves and twigs & 4 \\
\hline vegetation & aqua regia leachate of dwarf willow leaves and twigs & 1 \\
\hline vegetation & aqua regia leachate of willow leaves and twigs & 21 \\
\hline vegetation & high resolution aqua regia leachate of alder leaves & 13 \\
\hline vegetation & high resolution aqua regia leachate of alder twigs & 13 \\
\hline vegetation & high resolution aqua regia leachate of bog birch leaves & 13 \\
\hline vegetation & high resolution aqua regia leachate of bog birch twigs & 13 \\
\hline vegetation & high resolution aqua regia leachate of willow leaves & 21 \\
\hline vegetation & high resolution aqua regia leachate of willow twigs & 21 \\
\hline water & field test sample & 153 \\
\hline water & filtered and acidified & 647 \\
\hline water & filtered and unacidified & 177 \\
\hline water & unfiltered and acidified & 176 \\
\hline water & unfiltered and unacidified & 152 \\
\hline
\end{tabular}


Table 6. List of Pebble deposit spreadsheets generated from the geochemical relational database.

\begin{tabular}{|c|c|}
\hline Spreadsheet name & Spreadsheet description \\
\hline AnalyticMethod.xls & Analytical method criteria \\
\hline AnalyticMethodBiblio.xls & Analytical method references \\
\hline FieldNameDictionary.xls & Field name dictionary \\
\hline FieldSite.xls & Field site criteria \\
\hline LabName.xls & Laboratory name \\
\hline Sample.xls & Sample criteria \\
\hline IndicatorMineralogy.xls & Indicator mineralogy of till and stream sediment concentrates \\
\hline H2O_Alk.xls & Alkalinity of filtered, unacidified water \\
\hline H2O_Anions.xls & Anions in filtered, unacidified water \\
\hline H2O_DOC.xls & Dissolved organic carbon in filtered, acidified water \\
\hline H2O_Fe.xls & Ferrous, ferric and total iron in filtered, acidified water \\
\hline $\mathrm{H} 2 \mathrm{O} \_$FldChem.xls & Field chemistry parameters of water \\
\hline H2O_Hg.xls & Mercury in filtered, acidified water \\
\hline H2O_ICPAES-FA.xls & Cations in filtered, acidified water by ICP-AES \\
\hline H2O_ICPAES-RA.xls & Cations in unfiltered, acidified water by ICP-AES \\
\hline H2O_ICPMS-FA.xls & Cations in filtered, acidified water by ICP-MS \\
\hline H2O_ICPMS-RA.xls & Cations in unfiltered, acidified water by ICP-MS \\
\hline H2O_ICPMS-HR-FA.xls & Cations in filtered, acidified water by high-resolution ICP-MS \\
\hline H2O_ICPMS-HR-RA.xls & Cations in unfiltered, acidified water by high-resolution ICP-MS \\
\hline Rock_AddlChem.xls & Constituents in rock by AA, ISE, titration, combustion and fire assay \\
\hline Rock_ICPAES-MS42.xls & Cations in rock by ICP-AES and ICP-MS after 4-acid digestion \\
\hline Rock_ICPAES-MS55.xls & Cations in rock by ICP-AES and ICP-MS after sinter digestion \\
\hline Sed_AddlChem.xls & Constituents in sediment by AA, ISE, titration, combustion and fire assay \\
\hline Sed_ICPAES-MS42.xls & Cations in sediment by ICP-AES and ICP-MS after 4-acid digestion \\
\hline Sed_ICPAES-MS55.xls & Cations in sediment by ICP-AES and ICP-MS after sinter digestion \\
\hline Soil_AddlChem.xls & Constituents in soil by AA, ISE, titration, combustion and fire assay \\
\hline Soil_ICPAES-MS42.xls & Cations in soil by ICP-AES and ICP-MS after 4-acid digestion \\
\hline Soil_ICPAES-MS55.xls & Cations in soil by ICP-AES and ICP-MS after sinter digestion \\
\hline Soil_ICPMS-AR.xls & Constituents in soil by ICP-MS after aqua regia leach \\
\hline Soil_ICPMS-BLch.xls & Constituents in soil by ICP-MS after BioLeach leach \\
\hline Soil_ICPMS-CHHLch.xls & Constituents in soil by ICP-MS after cold hydroxylamine hydrochloride leach \\
\hline Soil_ICPMS-EELch.xls & Constituents in soil by ICP-MS after enhanced Enzyme Leach \\
\hline Soil_ICPMS-FLT.xls & Constituents in soil by ICP-MS after de-ionized water leach \\
\hline Soil_ICPMS-ILch.xls & Constituents in soil by ICP-MS after ionic leach \\
\hline Soil_ICPMS-MMILch.xls & Constituents in soil by ICP-MS after mobile metal ion leach \\
\hline Soil_ICPMS-NaPLch.xls & Constituents in soil by ICP-MS after sodium pyrophosphate leach \\
\hline Soil_ICPMS-TSLch.xls & Constituents in soil by ICP-MS after TerraSol leach \\
\hline Soil_pH-Cond.xls & $\mathrm{pH}$ and specific conductance of soil/de-ionized $\mathrm{H}_{2} \mathrm{O}$ paste \\
\hline Veg_ICPMS-AR.xls & Constituents in vegetation by ICP-MS after aqua regia leach \\
\hline Veg_ICPMS-HR-AR.xls & Constituents in vegetation by high-resolution ICP-MS after aqua regia leach \\
\hline
\end{tabular}


Publishing support provided by:

Denver Publishing Service Center

For more information concerning this publication, contact:

Center Director, USGS Crustal Geophysics and Geochemistry Science Center Box 25046, Mail Stop 964

Denver, CO 80225

(303) 236-1312

Or visit the Crustal Geophysics and Geochemistry Science Center Web site at: http://crustal.usgs.gov/ 